\title{
West Foster Creek 2007 Follow-up Habitat Evaluation Procedures Report
}

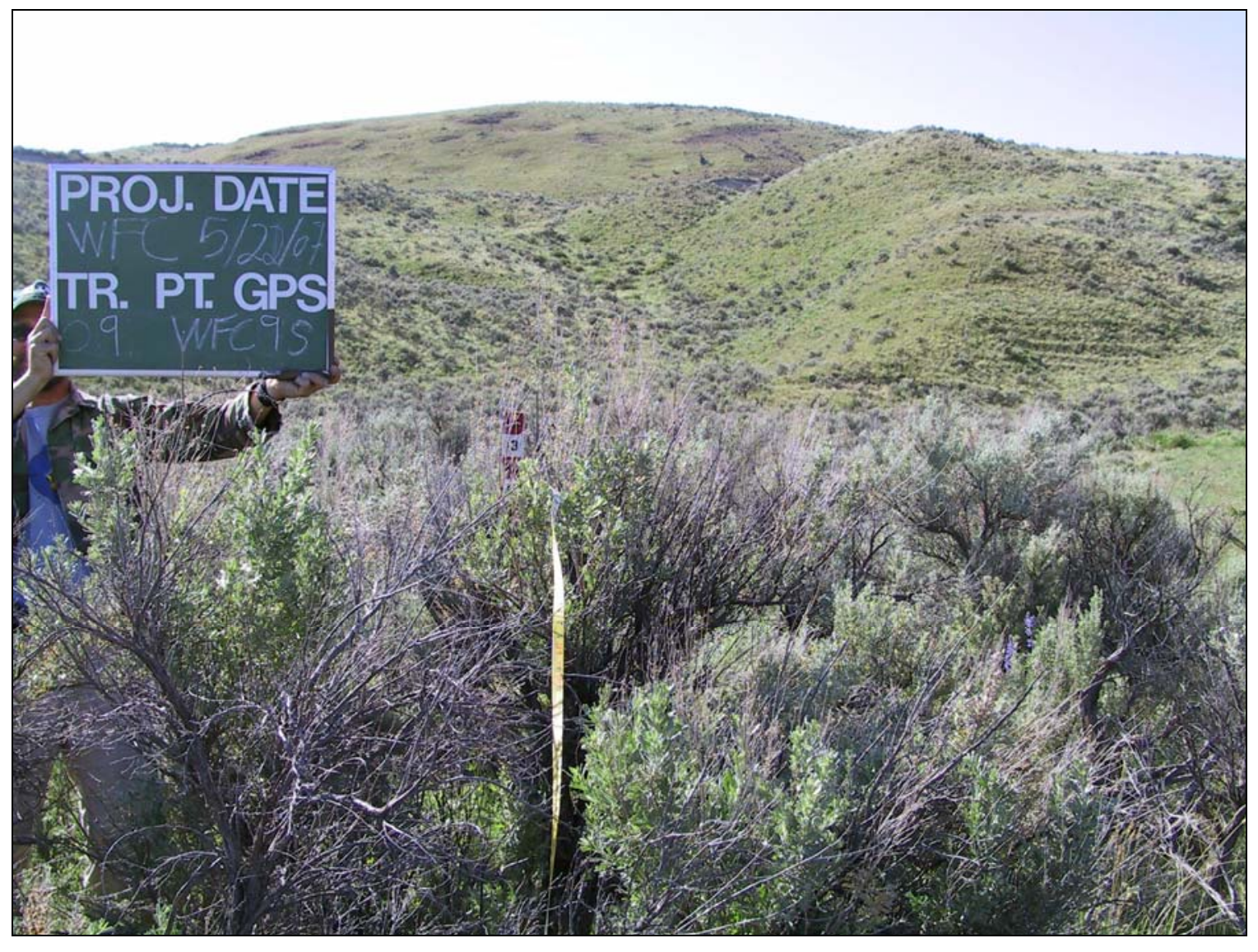

\section{Compiled By}

Paul R Ashley

Regional HEP Team Coordinator

\section{For}

Joe DeHerrera

Bonneville Power Administration

And

Nathan Pamplin

Washington Department of Fish and Wildlife

February 2008 


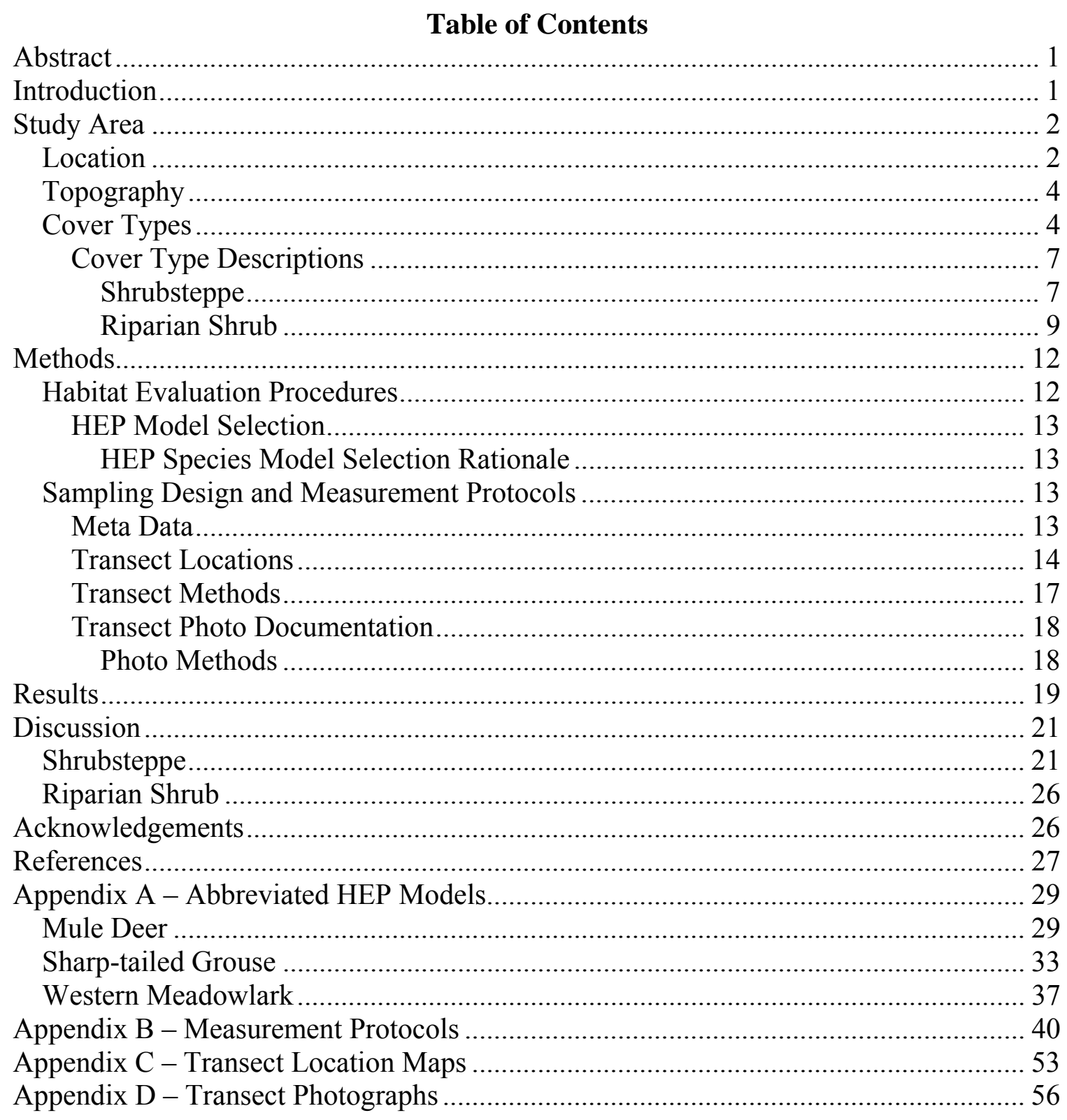


West Foster Creek (Smith) 2007 Follow-up HEP Report

\section{List of Tables}

Table 1. Habitat suitability index verbal equivalency table.

Table 2. Cover types and associated HEP species models for the West Foster Creek follow-up HEP survey....

Table 3. HEP model species selection rationale table.

Table 4. West Foster Creek 2007 follow-up HEP transect UTM coordinates, azimuths, and lengths.

Table 5. West Foster Creek 2007 follow-up HEP results summary............................... 20

Table 6. Follow-up and baseline HEP results comparison/summary. ............................ 21

Table 7. Comparison of 1999 HEP baseline and 2007 follow-up HEP transect results for shrub cover at West Foster Creek. 
West Foster Creek (Smith) 2007 Follow-up HEP Report

\section{Table of Figures}

Figure 1. West Foster Creek (Smith) location map (J. Talmadge, pers. comm.). ............. 2

Figure 2. West Foster Creek 1999 baseline HEP map.................................................. 3

Figure 3. West Foster Creek map with 2001 acquisitions. ............................................ 3

Figure 4. West foster Creek cover types based on 2000 GAP vegetation class data......... 5

Figure 5. ReGAP land cover classification map (J. Talmadge WDFW GIS Section)........ 6

Figure 6. Shrubland component example at West Foster Creek (2007).......................... 7

Figure 7. Native grassland example at West Foster Creek (2007). ................................. 8

Figure 8. An example of a "planted" grassland at West Foster Creek (2007).................. 9

Figure 9. Native riparian habitat along West Foster Creek (2007)................................ 10

Figure 10. Planted riparian habitat along West Foster Creek (2007). ........................... 11

Figure 11. Fenced riparian shrub enhancement along West Foster Creek (2007)........... 11

Figure 12. West Foster Creek follow-up transect location summary map. ...................... 16

Figure 13. Expanded map showing locations of the 2007 follow-up HEP transects ${ }^{7}$..... 17

Figure 14. HEP data collection and processing flow chart........................................... 18

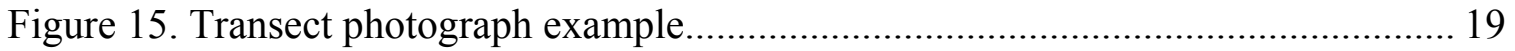

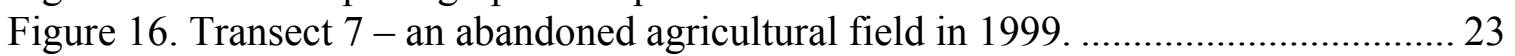

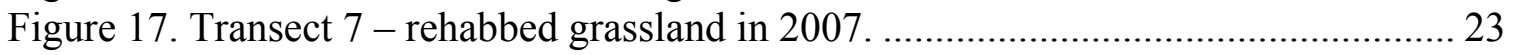

Figure 18. Transect 8 - shrubsteppe cover type in 1999 ............................................... 24

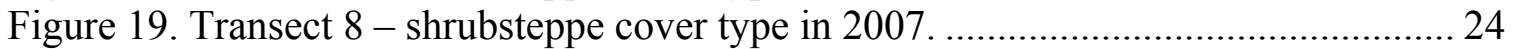

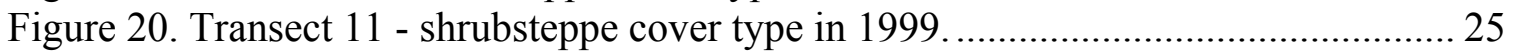

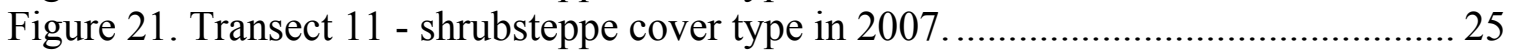

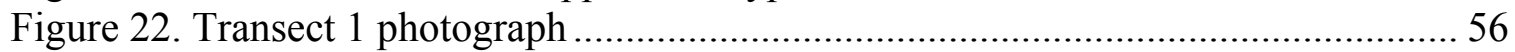

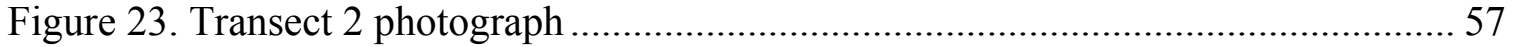

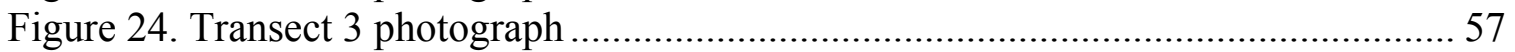

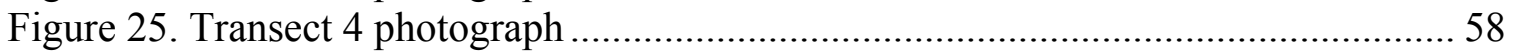

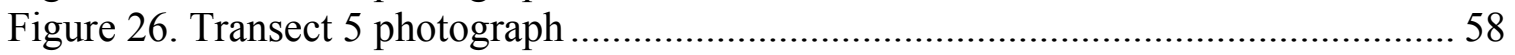

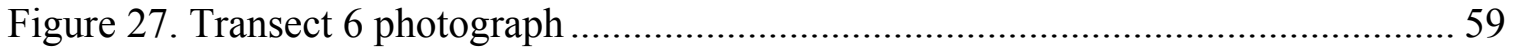

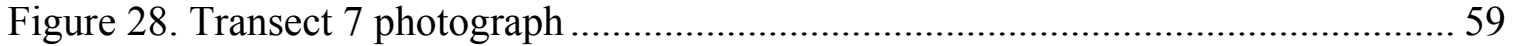

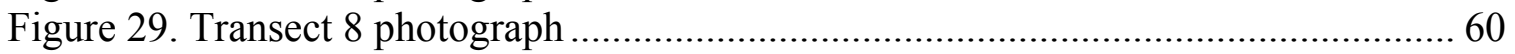

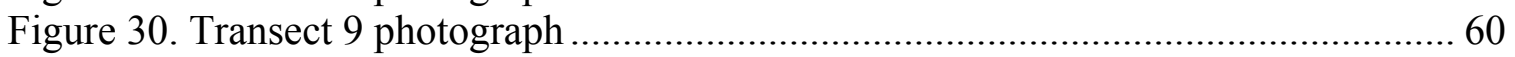

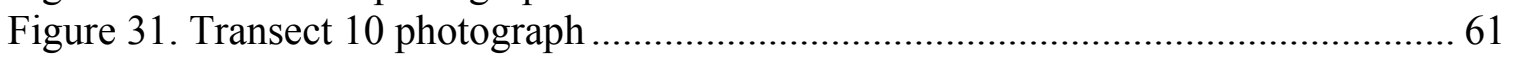

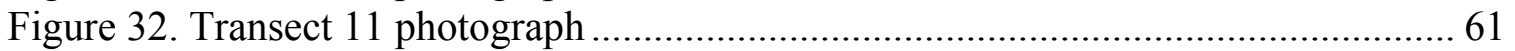

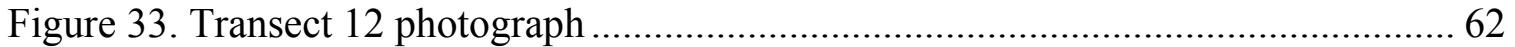

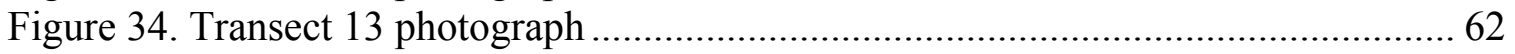




\section{Abstract}

A follow-up habitat evaluation procedures (HEP) analysis was conducted on the West Foster Creek (Smith acquisition) wildlife mitigation site in May 2007 to determine the number of additional habitat units to credit Bonneville Power Administration (BPA) for providing funds to enhance and maintain the project site as partial mitigation for habitat losses associated with construction of Grand Coulee Dam. The West Foster Creek 2007 follow-up HEP survey generated 2,981.96 habitat units (HU) or 1.51 HUs per acre for a 34\% increase (+751.34 HUs) above baseline HU credit (the 1999 baseline HEP survey generated 2,230.62 habitat units or 1.13 HUs per acre).

The 2007 follow-up HEP analysis yielded 1,380.26 sharp-tailed grouse (Tympanuchus phasianellus) habitat units, 879.40 mule deer (Odocoileus hemionus) HUs, and 722.29 western meadowlark (Sturnella neglecta) habitat units. Mule deer and sharp-tailed grouse habitat units increased by $346.42 \mathrm{HUs}$ and 470.62 HUs respectively over baseline (1999) survey results due largely to cessation of livestock grazing and subsequent passive restoration. In contrast, the western meadowlark generated slightly fewer habitat units in 2007 (-67.31) than in 1999, because of increased shrub cover, which lowers habitat suitability for that species.

\section{Introduction}

Bonneville Power Administration purchased the 1,974 acre West Foster Creek (Smith parcel) site September 15, 1998 for \$651,200 (D. Budd, pers. comm.) with Memorandum of Agreement (MOA) funds (BPA/WDFW 1996). With BPA's concurrence, Washington Department of Fish and Wildlife (WDFW) conducted the real estate transaction directly with the landowner. Therefore, transfer of the property title from BPA to WDFW was unnecessary (D. Budd, pers. comm.). This acquisition was partial fulfillment of BPA's mitigation obligation for construction of Grand Coulee Dam (Howerton et. al. 1986).

WDFW selected and subsequently acquired the West Foster Creek parcel to protect shrubsteppe habitat for obligate wildlife species (M. Schroeder, pers. comm.). Furthermore, M. Hallet (pers. comm.) suggested that public recreation was also an important factor in acquiring this site.

M. Schroeder (pers. comm.) stated that sharp-tailed grouse, sage grouse (Centrocercus urophasianus) and mule deer were high priority wildlife species in this area and that acquiring and permanently protecting this site could significantly benefit these species. In addition to the high priority target species, western meadowlarks and numerous of other wildlife species have and will continue to profit from protection and enhancement measures on this parcel.

A baseline Habitat Evaluation Procedures (HEP) (USFWS 1980) analysis was conducted by WDFW staff on the West Foster Creek property in September 1999 (P. Ashley, pers. comm.). Follow-up HEP evaluations were conducted by the Columbia Basin Fish and Wildlife Authority's (CBFWA) Regional HEP Team (RHT) in May 2007 ${ }^{1}$. Details and results of the 2007

\footnotetext{
${ }^{1}$ Paul Ashley organized and participated in both the original baseline HEP surveys and the 2007 follow-up HEP surveys.
} 
follow-up HEP analysis are included in this report along with a brief comparison of 1999 baseline and 2007 follow-up HEP survey results.

\section{Study Area}

\section{Location}

West Foster Creek is located in northern Douglas County approximately three miles south of Bridgeport, Washington and Chief Joseph Dam (Figure 1). The project boundary map used by WDFW's HEP Team in 1999 is illustrated in Figure 2 (WDFW 2001).

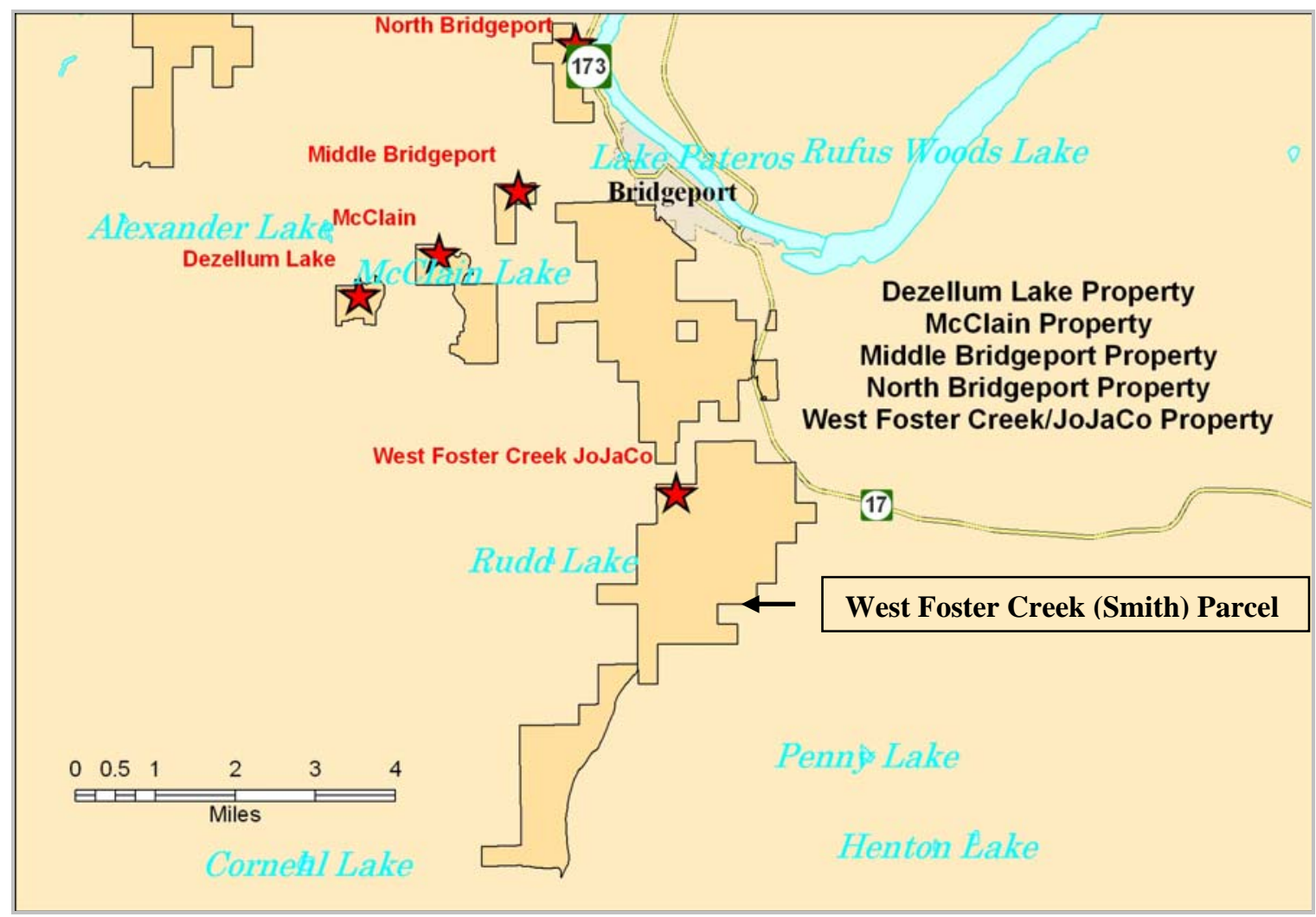

Figure 1. West Foster Creek (Smith) location map (J. Talmadge, pers. comm.).

Two parcels, one in the northeast corner and one in the southwest corner, were added in 2001 (Figure 3) - note: map scales are slightly different. The areas added in 2001 were evaluated during the 2007 follow-up HEP analysis. The added acreage and associated habitat unit computations, however, were not included in the follow-up HEP results as part of West Foster Creek, but were included with other adjacent new lands acquired since 1999. This was done to ensure consistency between the 1999 baseline and 2007 follow-up HEP analyses. 
West Foster Creek (Smith) 2007 Follow-up HEP Report

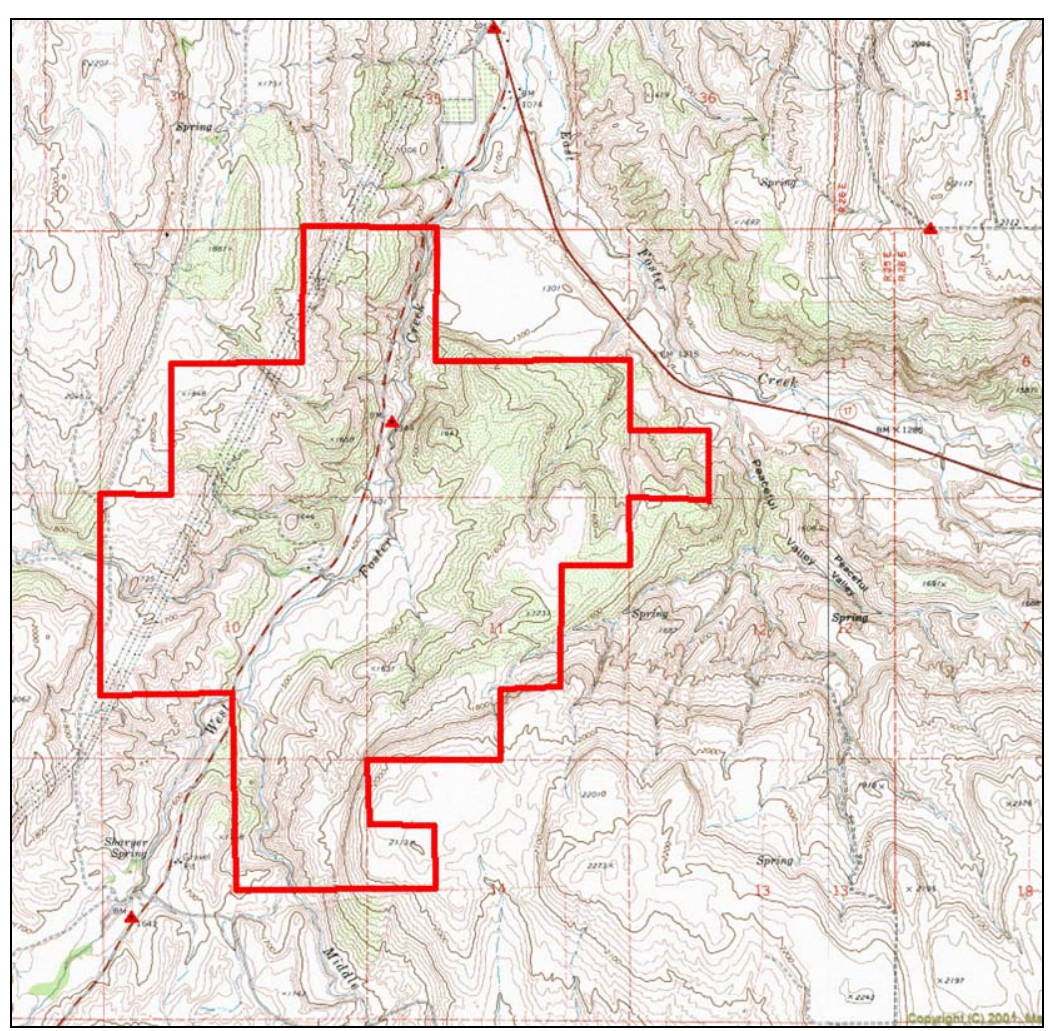

Figure 2. West Foster Creek 1999 baseline HEP map.

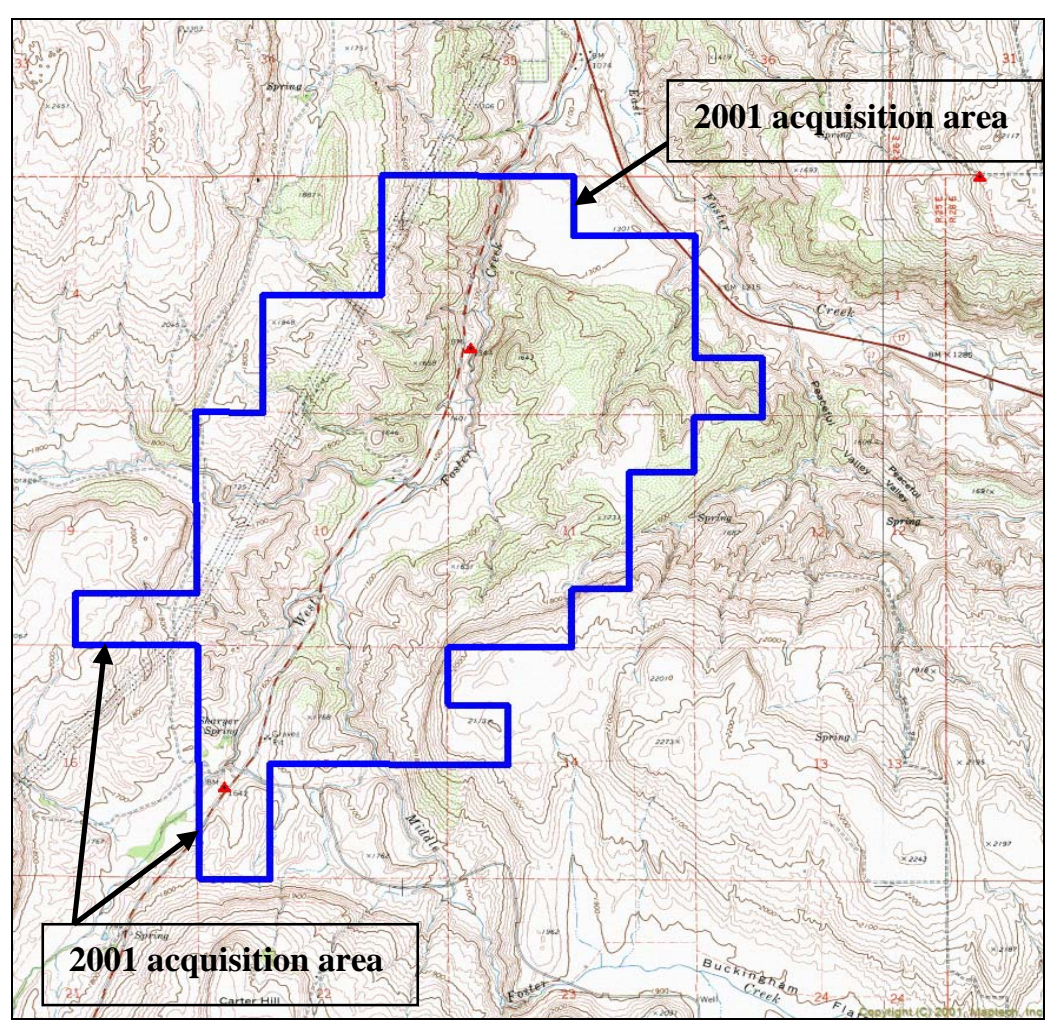

Figure 3. West Foster Creek map with 2001 acquisitions. 


\section{Topography}

Topography ranges from flat abandoned agriculture fields and incised stream channels along Bridgeport Hill Road to steep rolling hills with basalt outcrops. Aspect on the west side of Bridgeport Hill Road is generally east-southeast (ESE) while aspect on the east side of the road progresses from flat to a west (W) or northwest (NW) aspect. Elevation ranges from just under 1,400 feet to slightly more than 2,100 feet (MapTech ${ }^{\circledR}$ mapping software).

\section{Cover Types}

All cover types were combined and listed as shrubsteppe for the 1999 baseline surveys because accurate site specific cover type maps were not available or, in some instances, cover types were less than the minimum threshold area $^{2}$ required for a cover type to be considered independent for HEP evaluation purposes. In 2000, however, WDFW GIS support staff identified cover types (WDFW 2001) based on GAP vegetation class data (Figure 4).

GAP vegetation classes included grassland, disturbed shrubland, shrubland, riparian vegetation, cliff/talus, CRP grassland, and abandoned orchard ${ }^{3}$ (WDFW 2001). Since early GAP information was based on aerial/satellite imagery, subject to interpretation, and was not "ground truthed," WDFW's HEP Team, and subsequently the Regional HEP Team, believed that subdividing upland cover types would only complicate the HEP process with little impact on the outcome.

Gap vegetation class data was updated in 2006 (Ohmann et al. 2006) and is now known as ReGAP land classification data (Figure 5) (J. Talmadge, pers. comm.). Although the updated ReGAP information appears to be more accurate than earlier GAP data, the Regional HEP Team elected to combine upland cover types to ensure consistency with the 1999 baseline HEP analysis ${ }^{4}$. Unlike the baseline HEP, however, the RHT recognized riparian shrub as a separate cover type during the 2007 follow-up analysis. The Regional HEP Team evaluated 1,958 acres of shrubsteppe and 16 acres of riparian shrub for a total of 1,974 acres during the 2007 follow-up HEP analysis.

On a related note, The RHT recommends that WDFW evaluate the efficacy of using ReGAP land classification data for addressing cover type questions. For land/wildlife management purposes, ReGAP land classification data may be more useful to managers in some instances if land classifications e.g., shrubland and disturbed shrubland, were combined into a single land class, or had a temporal component. From a temporal perspective, "when does a "disturbed shrubland" site appear and function as a "shrubland" site? Does wildlife perceive a difference or use the area differently once plant communities, structure, and key ecological correlates become similar to "native" shrublands? Finally, what is the relationship between "land classifications"," cover types", and "habitat types”? Are the three terms synonymous from WDFW's perspective?

\footnotetext{
${ }^{2}$ Less than $1 \%$ of the project area acreage.

${ }^{3}$ GAP cover type data accuracy is limited. The abandoned orchard was removed for disease/pest control purposes.

${ }^{4}$ ReGAP data was not available to the RHT prior to the 2007 HEP surveys. Had ReGAP information been available to the RHT prior to the follow-up surveys, the RHT would have still elected to follow 1999 baseline procedures.
} 
West Foster Creek (Smith) 2007 Follow-up HEP Report

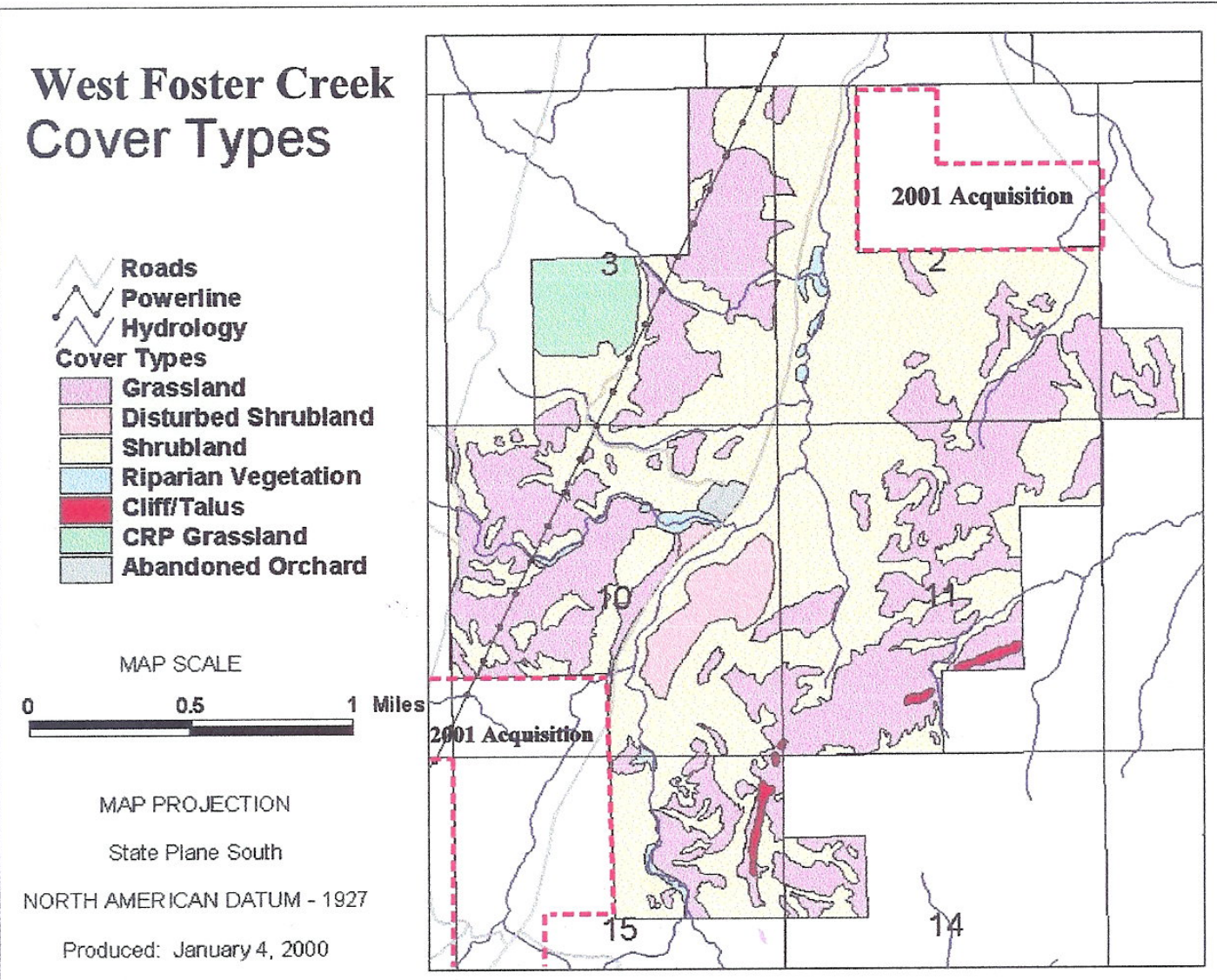

Figure 4. West foster Creek cover types based on 2000 GAP vegetation class data. 
West Foster Creek (Smith) 2007 Follow-up HEP Report

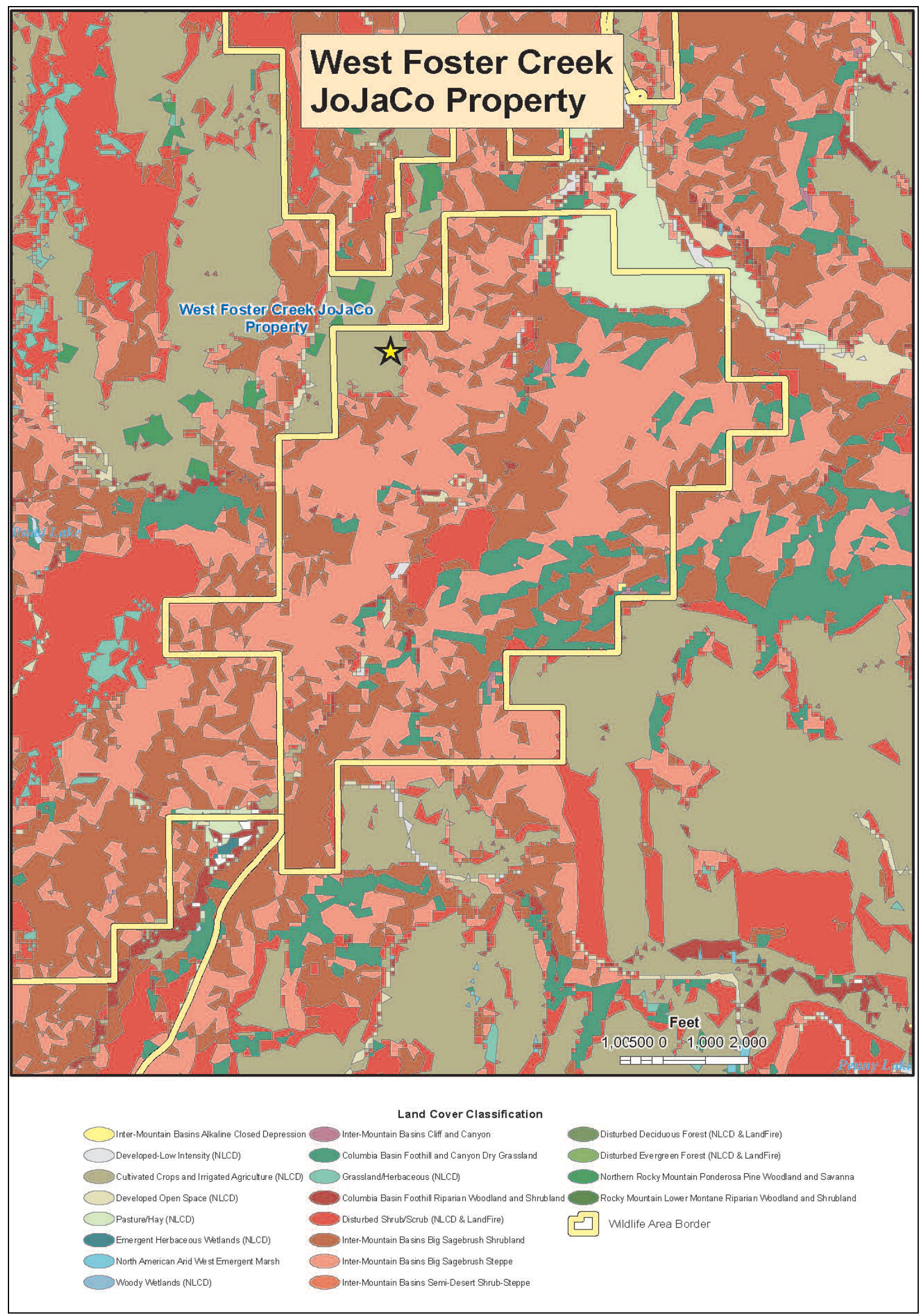

Figure 5. ReGAP land cover classification map (J. Talmadge WDFW GIS Section) 


\section{Cover Type Descriptions}

Shrubsteppe, the dominant cover type, included both shrub and grass (steppe) components. The shrubland component comprised approximately $75 \%$ of the entire area while interspersed grasslands comprised an estimated $20 \%$ of the parcel. Riparian shrub and other cover types, combined, occupied the remaining $5 \%$ of the project site.

\section{Shrubsteppe}

The shrubland component included xeric uplands with $\geq 5 \%$ shrub cover and $\leq 5 \%$ tree canopy dominated by native shrubsteppe vegetation and/or invasive species. In contrast, grassland was defined as "steppe" vegetation dominated by native and/or non-native grass and forbs species with less than $5 \%$ shrub or tree cover. The grassland component included undisturbed native grasslands, CRP fields, Soil Bank lands, pastures, and abandoned agriculture fields.

Shrub species recorded on the 2007 HEP transects included big sagebrush (Artemisia tridentata), three-tip sagebrush (A. tripartita), gray rabbitbrush (Chrysothamnus nauseosa), green rabbitbrush (C. viscidiflorus), and bitterbrush (Purshia tridentata). Gray horsebrush (Tetradymia canescens), detected during the 1999 baseline HEP surveys, was not observed on transects in 2007. An example of the shrubsteppe cover type is depicted in Figure 6.

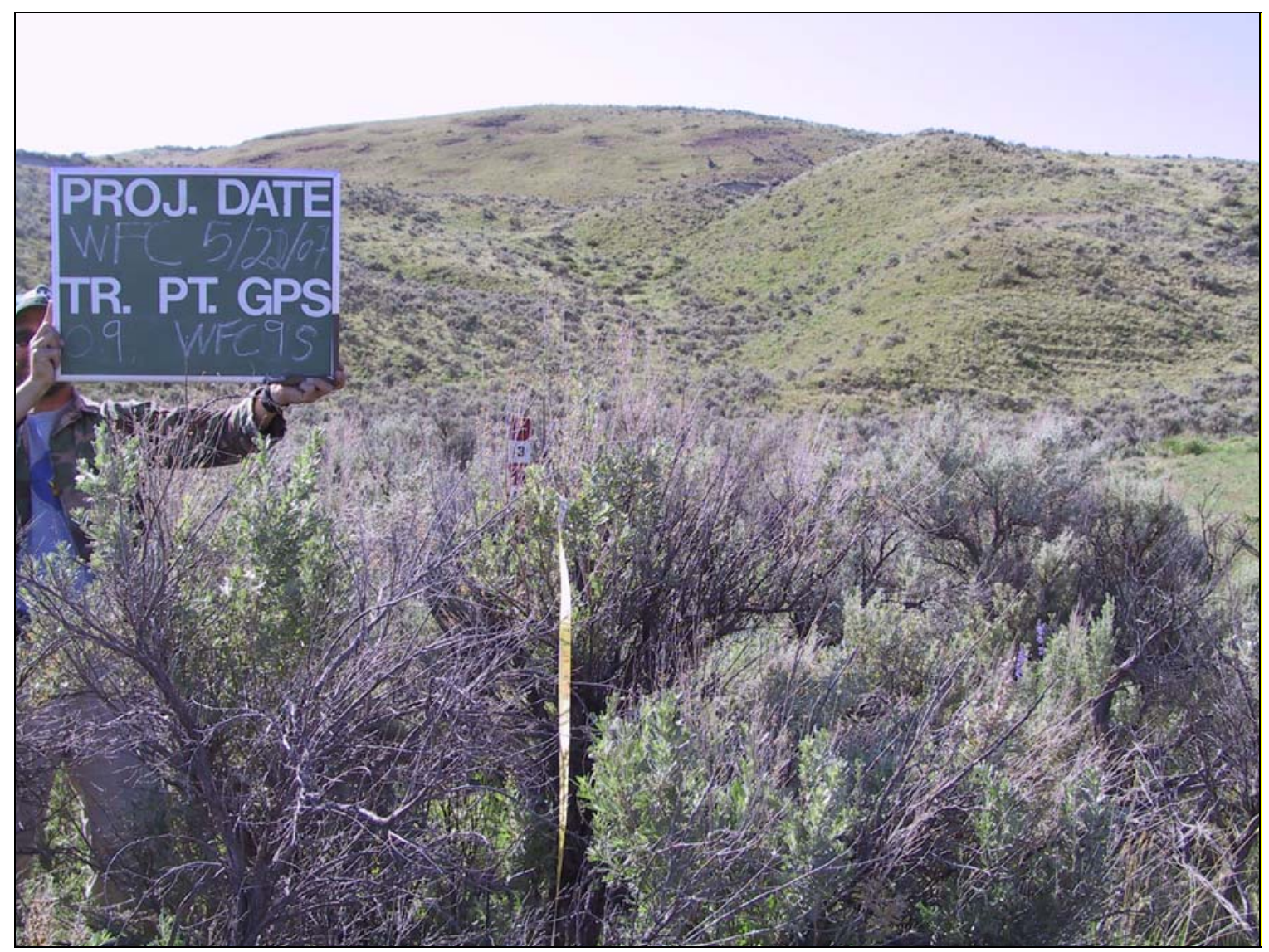

Figure 6. Shrubland component example at West Foster Creek (2007).

The herbaceous stratum on most sites was nearly identical to that found in 1999 (WDFW 2001) and was comprised of both native and introduced species. Grass and forbs species observed 
included bluebunch wheatgrass (Pseudoroegneria spicata), Sandberg bluegrass (Poa secunda), needle-and- thread (Stipa comata), bottlebrush squirrel tail (Sitanion hystrix), Basin wildrye (Leymus cinereus), Indian ricegrass (Achnatherum hymenoides), lupine (Lupinus spp.), balsam root (Balsamhoriza sagittata), yarrow (Achillea millefolium), vetch (Astragalus spp.), cheatgrass (Bromus tectorum), crested wheatgrass (Agropyron cristatum), and mustard (Brassica spp.) to name a few. Examples of native and enhanced grassland plant communities are depicted in Figure 7 and Figure 8 respectively.

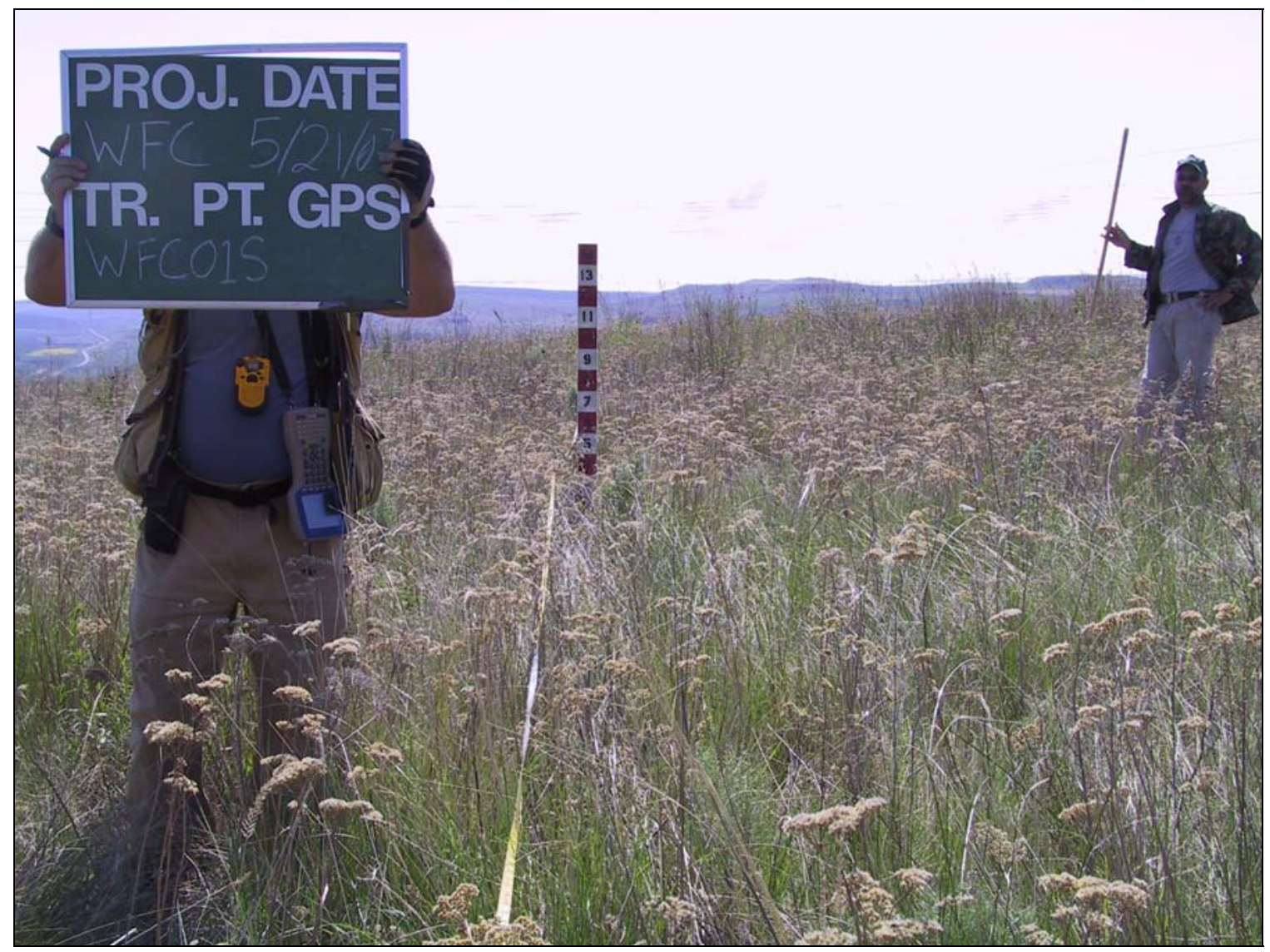

Figure 7. Native grassland example at West Foster Creek (2007). 


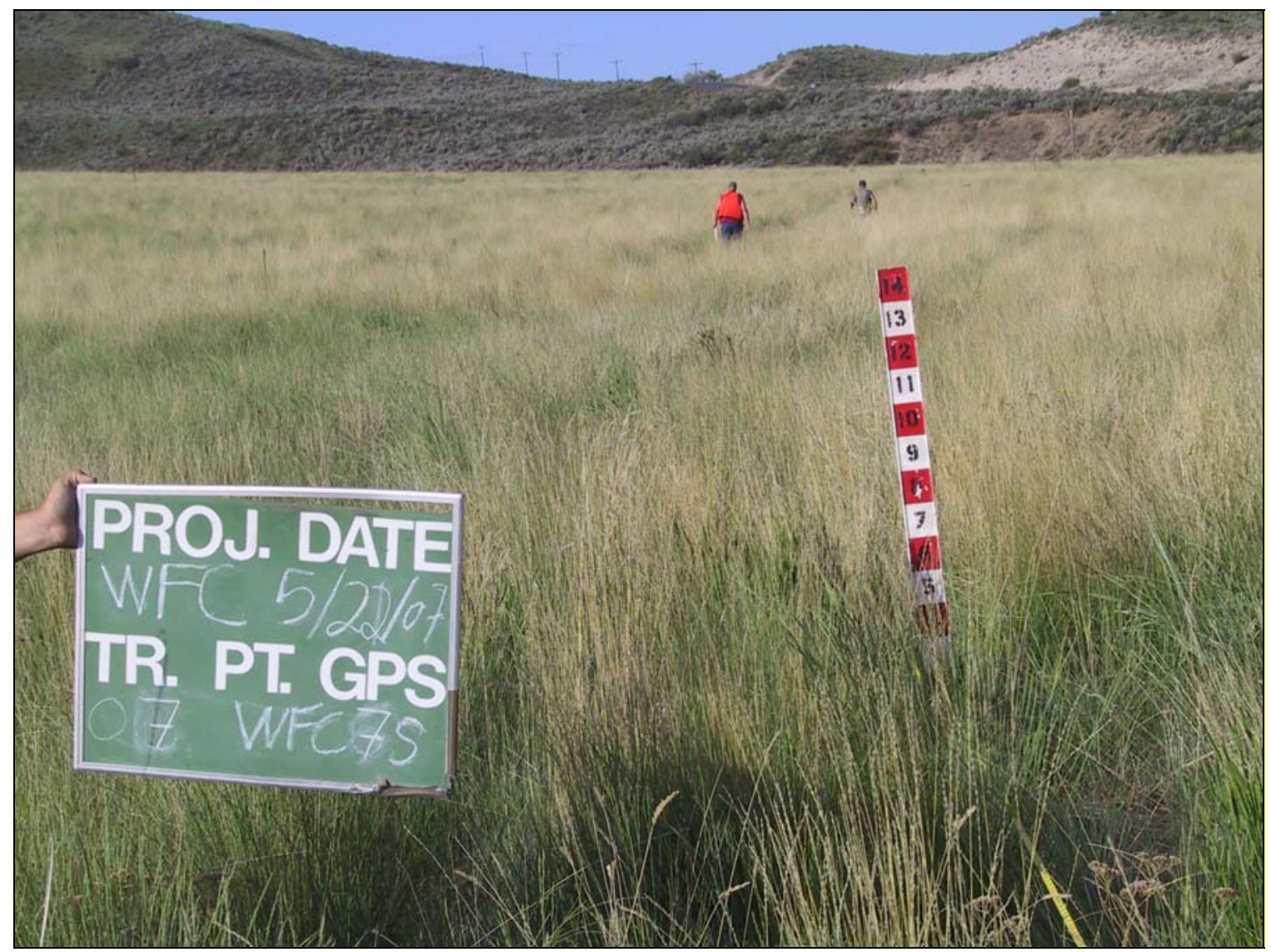

Figure 8. An example of a "planted" grassland at West Foster Creek (2007).

\section{Riparian Shrub}

This cover type is comprised of deciduous shrubs and trees that are predominantly hydrophytic/facultative wetland species. The riparian shrub cover type included both natural occurring elements and enhanced areas where wildlife area staff planted deciduous shrubs and trees.

Results from the one measured riparian transect (Transect 10) along West Foster Creek in 2007 confirmed the presence of water birch (Betula occidentalis), rose (Rosa spp.), willow (Salix spp.), and clematis (Clematis ligusticifolia) at the undeveloped site (Figure 9). Similarily, choke cherry, (Prunus virginiana), water birch, rose, dogwood (Cornus sericea), serviceberry (Amalanchier alnifolia), cottonwood (Populus spp.), and several thousand willow cuttings were planted by WDFW wildlife area staff (D. Peterson, pers. comm.) on several areas along the main channel of West Foster Creek (Figure 10 and Figure 11). Enhanced sites were fenced to protect the woody plantings from deer depredation. 
West Foster Creek (Smith) 2007 Follow-up HEP Report

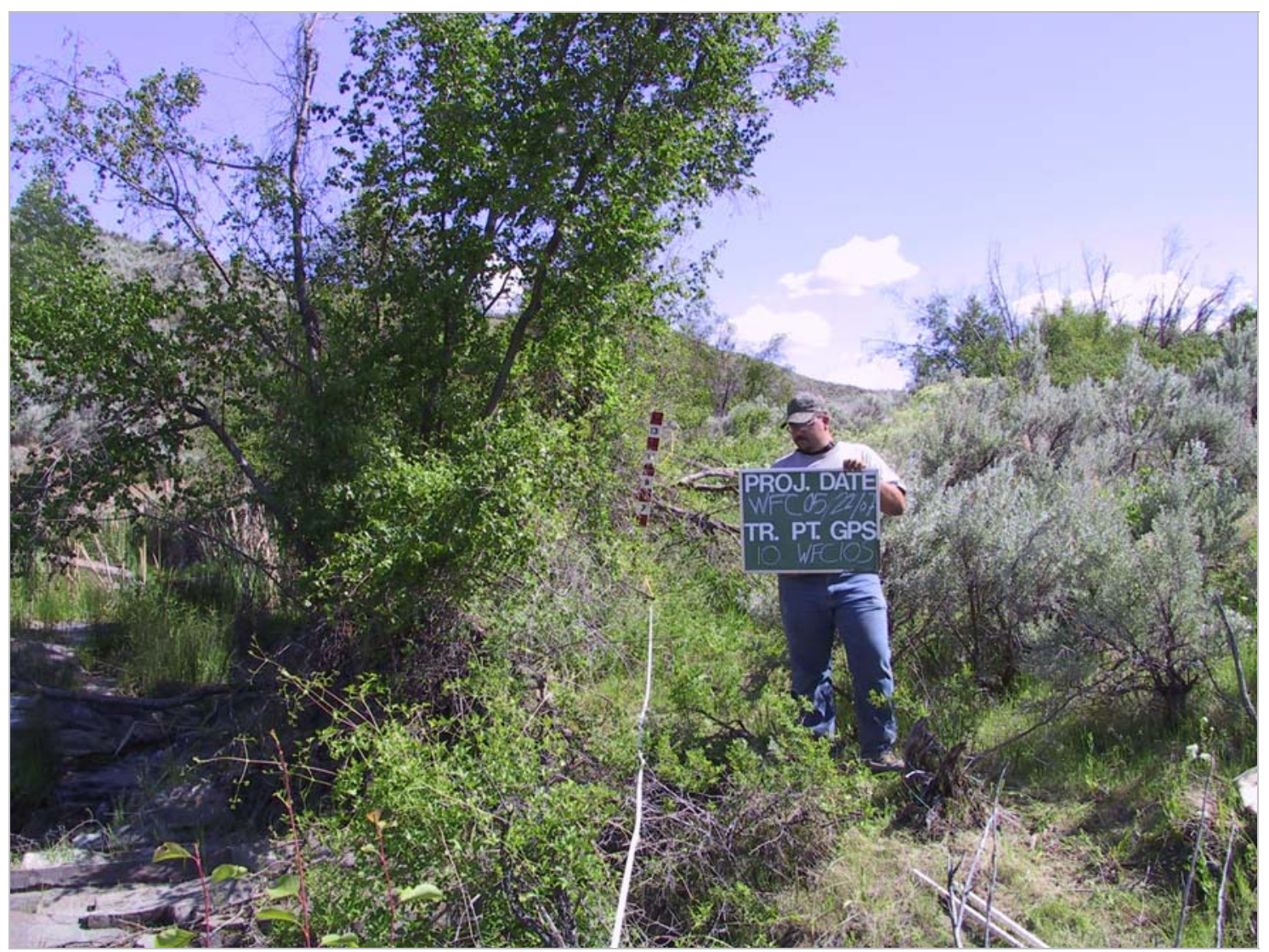

Figure 9. Native riparian habitat along West Foster Creek (2007). 
West Foster Creek (Smith) 2007 Follow-up HEP Report

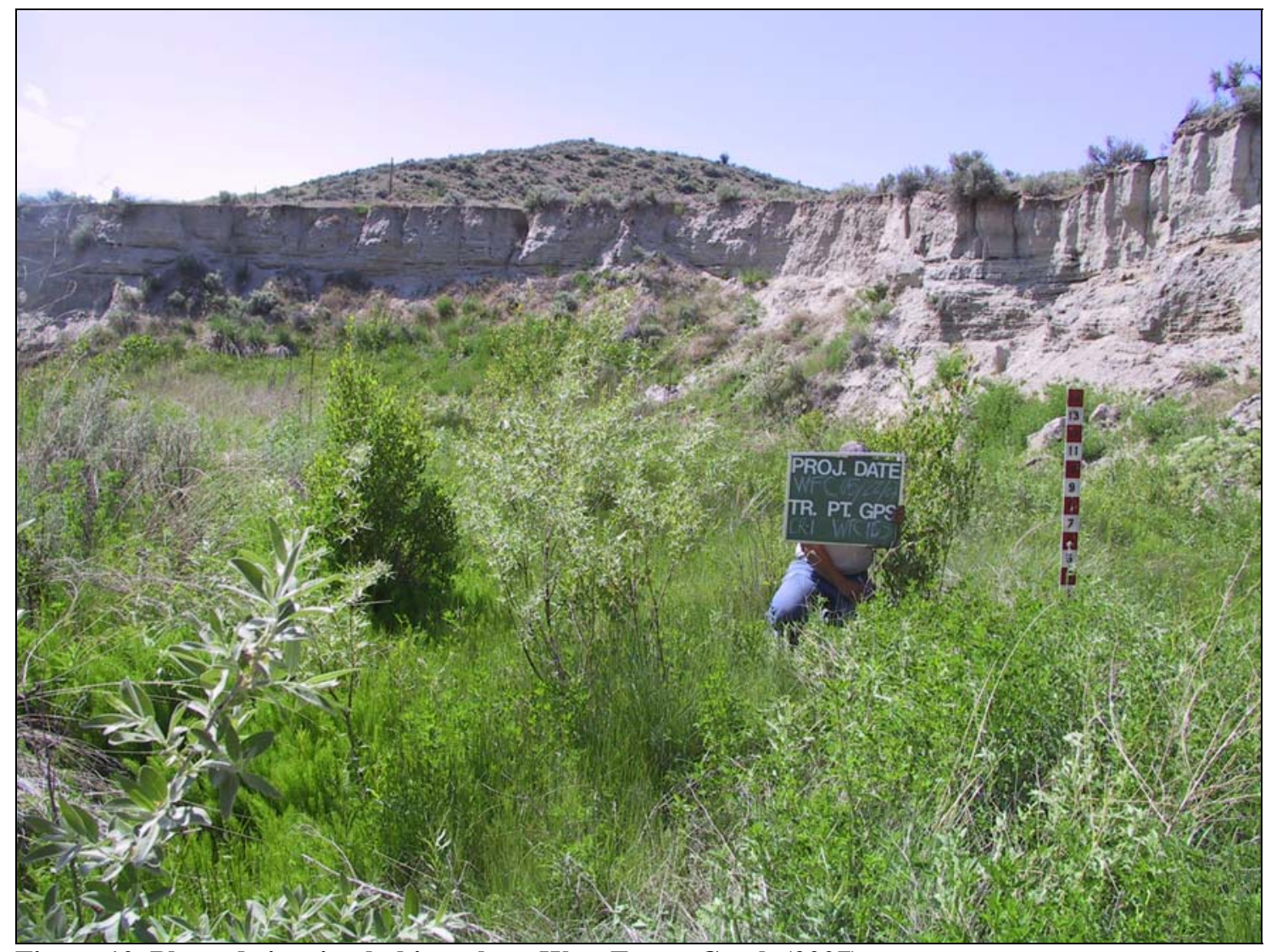

Figure 10. Planted riparian habitat along West Foster Creek (2007).

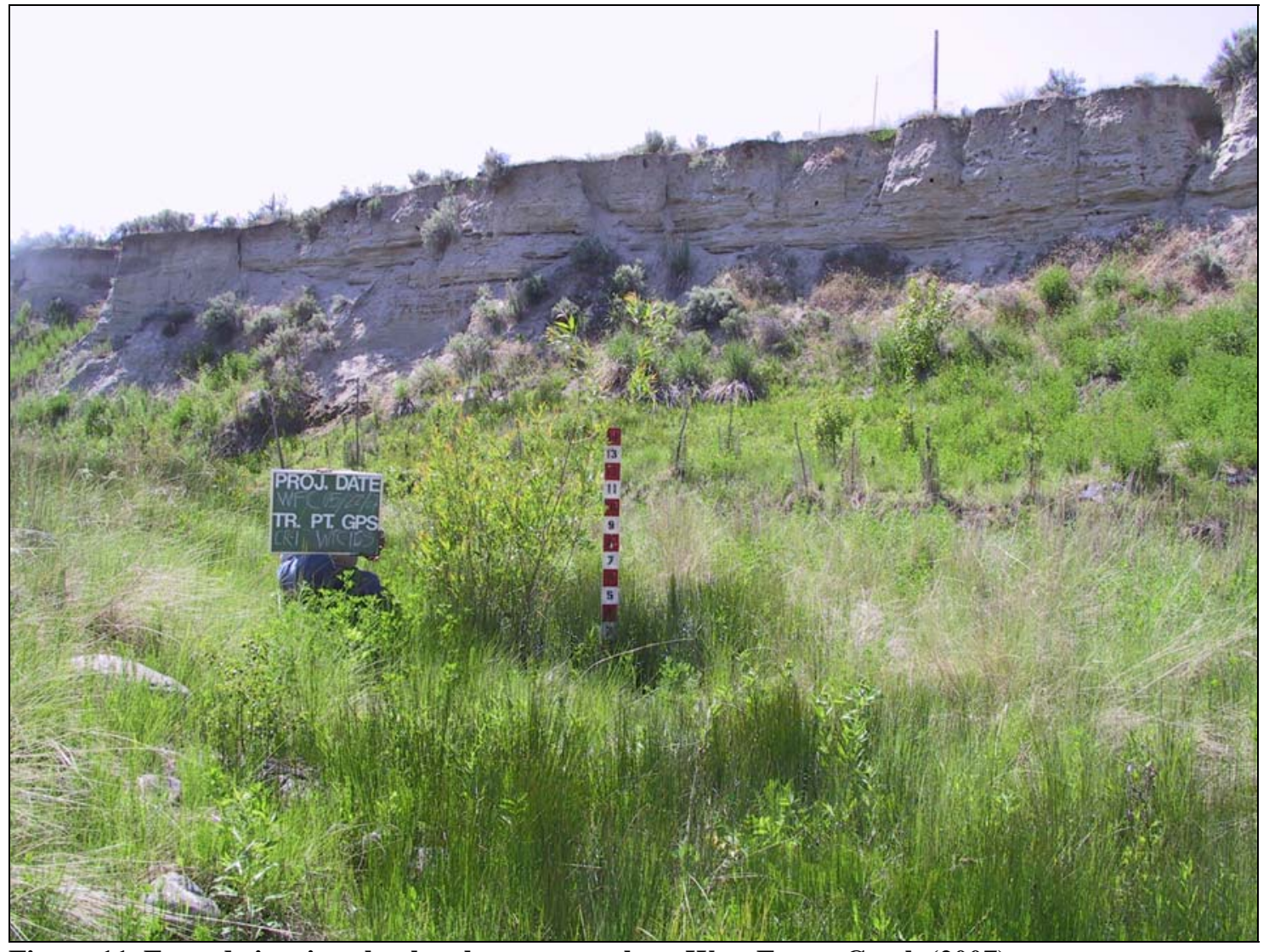

Figure 11. Fenced riparian shrub enhancement along West Foster Creek (2007). 
In addition to the enhancements along West Foster Creek, water birch, rose, and chokecherry were planted and fenced on a two acre upland site on the east side of Bridgeport Hill Road to provide additional winter habitat for sharp-tailed grouse. Currently, the new plantings are artificially maintained with a gravity fed irrigation system. D. Peterson (pers. comm.) stated that irrigation will cease once shrubs and trees are established.

\section{Methods}

\section{Habitat Evaluation Procedures}

A follow-up habitat evaluation procedures analysis was conducted on the West Foster Creek parcel to document changes in baseline habitat suitability/quality. HEP, developed by the U.S. Fish and Wildlife Service (USFWS), is used to quantify the impacts of development, protection, and restoration projects/measures on terrestrial and aquatic habitats by assessing changes, both negative and positive, in habitat quality and quantity (USFWS 1980), (USFWS 1980a).

HEP is a habitat based approach to impact assessment that documents change through use of a habitat suitability index (HSI). The HSI value is derived from an evaluation of the ability of key habitat components to provide the life requisites of selected wildlife and fish species.

The HSI value is an index to habitat carrying capacity for a specific species or guild of species based on a performance measure (e.g. number of deer per square mile) described in HEP species models. The index ranges from 0.0 to 1.0. A HSI of 0.3 indicates that habitat quality/carrying capacity is marginal while a HSI of 0.7 suggests that habitat quality/carrying capacity is relatively good for a particular species (Table 1).

Table 1. Habitat suitability index verbal equivalency table.

\begin{tabular}{|c|c|}
\hline \multicolumn{2}{|c|}{ Table 1. Habitat suitability index verbal equivalency table. } \\
\hline Habitat Suitability Index & Verbal Equivalent \\
\hline $0.0<0.2$ & Poor \\
\hline $0.2<0.4$ & Marginal \\
$0.4<0.6$ & Fair \\
$0.6<0.9$ & Good \\
$0.9<1.0$ & Optimum \\
\hline
\end{tabular}

Each increment of change is identical. For example, a change in HSI from 0.1 to 0.2 represents the same magnitude of change as a change from 0.2 to 0.3 , and so forth. Habitat variables, suggested mensuration techniques, and mathematical aggregations of assessment results are included in HEP evaluation species models.

Habitat units are determined by multiplying the habitat suitability index by the number of acres of habitat (cover type) protected. For example, if the HSI output for a mule deer HEP model is 0.5 and the number of acres of shrubsteppe habitat protected is 100 , then the number of HUs is 50 (0.5 HSI x 100 acres $=50$ HUs). 


\section{HEP Model Selection}

The Regional HEP Team used the same HEP species models in the 2007 follow-up HEP analysis as were used to assess baseline habitat conditions at West Foster Creek in 1999 (WDFW 2001). HEP models for the follow-up HEP surveys included mule deer (Ashley and Berger 1999), western meadowlark (Schroeder and Sousa 1982), and sharp-tailed grouse (Ashley 2003).

WDFW described sharp-tailed grouse as the keystone shrubsteppe obligate HEP species (M. Schroeder, pers. comm.) and mule deer as an important big game resource at this project site. The 2007 follow-up HEP species/cover type matrix is shown in Table 2 while abbreviated HEP models are included in Appendix A.

Table 2. Cover types and associated HEP species models for the West Foster Creek follow-up HEP survey.

\begin{tabular}{|l|c|c|c|}
\hline \multicolumn{1}{|c|}{ Cover Type } & $\begin{array}{c}\text { Western } \\
\text { Meadowlark }\end{array}$ & Sharp-tailed Grouse & Mule Deer \\
\hline Shrubsteppe & $\mathrm{X}$ & $\mathrm{X}$ & $\mathrm{X}$ \\
\hline Riparian Shrub & & $\mathrm{X}$ & \\
\hline
\end{tabular}

\section{HEP Species Model Selection Rationale}

Species selection rationale described in the Grand Coulee Dam Loss Assessment (Howerton et al. 1986) and other sources including WDFW species management plans and documents are summarized in Table 3.

Table 3. HEP model species selection rationale table.

\section{HEP Model}

Mule deer

Western meadowlark

Sharp-tailed Grouse

\section{Rationale}

This species represents wildlife dependent upon shrubsteppe and river breaks.

Represents wildlife species dependent upon grassland and/or shrubsteppe habitats with limited shrub cover. Represents steppe species and associated woody riparian/deciduous cover types.

\section{Sampling Design and Measurement Protocols}

\section{Meta Data}

Level one meta data follows that suggested by Gotelli and Ellison (2004). Field surveys were conducted by the Columbia Basin Fish and Wildlife Authority's Regional HEP Team with assistance from WDFW Wildlife Area Assistant Dan Peterson. Regional HEP Team members included Paul Ashley (RHT Coordinator), Mike Cantonese (Team Leader), Anthony Muse, Paul Walker, and Tiffany Baker (contact Paul Ashley@ 1onepinebutte@comcast.net, or through CBFWA at: [503] 229-0191). 
Funding for the HEP analysis was provided by Bonneville Power Administration with RHT administrative support provided by CBFWA. Specific measurement techniques and protocols are described in detail in Appendix B. Measurements were recorded in standard U.S. units except for the Robel pole (Robel et al. 1975), which was recorded in metric units.

\section{Transect Locations}

UTM coordinates for baseline transects were not available for the 2007 follow-up HEP surveys. As a result, RHT staff estimated baseline transect start point UTM coordinates, azimuths, and transect lengths from 1999 baseline HEP survey maps. The RHT relocated approximately 30\% of the baseline start point stakes using the estimated coordinates. The remaining $70 \%$ of the 2007 follow-up HEP transects are estimated to be within \pm 100 feet of the 1999 baseline transect start point locations ${ }^{5}$.

In a few cases, 1999 HEP baseline transect start, turn, and end stakes were relocated, which allowed the RHT to replicate baseline transect azimuths. This, however, seldom occurred. Generally, only transect start point stakes were relocated. As a result, 2007 follow-up transect azimuths may have deviated up to $\pm 10^{\circ}$ from the 1999 baseline transect azimuths due to differences in skill levels between the individuals who established the 1999 and 2007 transect lines and variability in the equipment (compasses) used to establish transect lines (this may account for some of the variation between the 1999 and 2007 HEP transect results).

All 2007 follow-up transect start, turn, and end points were marked with 12 inch long, $3 / 8$ inch thick rebar stakes with orange safety caps. Transect UTM coordinates (NAD 27) for start, turn, and end points were recorded in the field on a Garmin IIIA ${ }^{\circledR}$ GPS unit. HEP transect UTM coordinates, magnetic azimuths, and lengths are summarized in Table 4 (no additional transects beyond the 1999 baseline transects were surveyed in 2007 at West Foster Creek). Transect start, turn, and end points are depicted in Figure 12. Larger scale transect location maps are illustrated in Figure 13 and Appendix $C^{6}$.

Table 4. West Foster Creek 2007 follow-up HEP transect UTM coordinates, azimuths, and lengths.

\begin{tabular}{|c|r|c|c|c|c|c|}
\hline \multirow{2}{*}{ Transect } & \multirow{2}{*}{ Point } & \multicolumn{2}{|c|}{ GPS } & $\begin{array}{c}\text { Magnetic } \\
\text { Azimuth } \\
\text { (Degrees) }\end{array}$ & $\begin{array}{c}\text { Length } \\
\text { (Feet) }\end{array}$ & Total Length \\
\cline { 3 - 7 } & & E & N & & & \\
\hline \multirow{2}{*}{1} & start & 11 T 0300454 & 5314097 & 275 & 600 & 600 \\
\hline 2 & end & 11 T 0300304 & 5314186 & & & \\
\hline & start & 11 T 0300466 & 5313867 & 342 & 300 & 900 \\
\hline 3 & turn & 11 T 0300468 & 5313856 & 210 & 600 & \\
\hline & end & 11 T 0300321 & 5313827 & & & \\
\hline
\end{tabular}

\footnotetext{
${ }^{5}$ Early GPS data was somewhat inaccurate because of national security concerns. It is very likely that, had the baseline UTM coordinates been available to the Regional HEP Team in 2007; most coordinates would have been imprecise. Therefore, of limited value to the RHT in relocating transect start points. Most transect locations depicted on 1999 baseline maps were manually "adjusted" to better represent actual transect locations (P. Ashley, pers. comm.).

${ }^{6}$ Transect coordinates and map locations were downloaded directly from GPS units.
} 
West Foster Creek (Smith) 2007 Follow-up HEP Report

\begin{tabular}{|c|c|c|c|c|c|c|}
\hline \multirow{2}{*}{ Transect } & \multirow{2}{*}{ Point } & \multicolumn{2}{|l|}{ GPS } & \multirow{2}{*}{$\begin{array}{c}\text { Magnetic } \\
\text { Azimuth } \\
\text { (Degrees) }\end{array}$} & \multirow{2}{*}{$\begin{array}{l}\text { Length } \\
\text { (Feet) }\end{array}$} & \multirow{2}{*}{ Total Length } \\
\hline & & E & $\mathbf{N}$ & & & \\
\hline & end & 11 T 0300012 & 5313699 & & & \\
\hline \multirow[t]{2}{*}{4} & start & 11 T 0299895 & 5313417 & 210 & 600 & 600 \\
\hline & end & 11 T 0299775 & 5313312 & & & \\
\hline \multirow[t]{2}{*}{5} & start & 11 T 0299824 & 5312710 & 219 & 300 & 300 \\
\hline & end & 11 T 0299544 & 5312711 & & & \\
\hline \multirow[t]{2}{*}{6} & start & $11 \mathrm{~T} 0300263$ & 5312892 & 250 & 300 & 300 \\
\hline & end & 11 T 0300181 & 5312887 & & & \\
\hline \multirow[t]{2}{*}{7} & start & 11 T 0300647 & 5312633 & 200 & 600 & 600 \\
\hline & end & 11 T 0300530 & 5312480 & & & \\
\hline \multirow[t]{3}{*}{8} & start & $11 \mathrm{~T} 0300755$ & 5312564 & 175 & $\approx 500$ & 600 \\
\hline & turn & $11 \mathrm{~T} 0300727$ & 5312407 & $\approx 090$ & $\approx 100$ & \\
\hline & end & 11 T 0300748 & 5312392 & & & \\
\hline \multirow[t]{3}{*}{9} & start & 11 T 0300936 & 5312463 & 123 & 600 & 900 \\
\hline & turn & 11 T 0301024 & 5312321 & 228 & 300 & \\
\hline & end & 11 T 0300944 & 5312312 & & & \\
\hline \multirow[t]{2}{*}{10} & start & $11 \mathrm{~T} 0300464$ & 5311966 & Greenline & 300 & 300 \\
\hline & end & 11 T 0300482 & 5311896 & & & \\
\hline \multirow[t]{2}{*}{11} & start & 11 T 0301638 & 5313448 & 353 & 900 & 900 \\
\hline & end & & & \multicolumn{3}{|c|}{ (Missing Waypoint) } \\
\hline \multirow[t]{2}{*}{12} & start & 11 T 0301839 & 5313761 & 340 & 900 & 900 \\
\hline & end & $11 \mathrm{~T} 0301803$ & 5314035 & & & \\
\hline \multirow[t]{2}{*}{13} & start & 11 T 0301897 & 5313556 & 342 & 300 & 300 \\
\hline & end & 11 T 0301884 & 5313644 & & & \\
\hline
\end{tabular}


West Foster Creek (Smith) 2007 Follow-up HEP Report

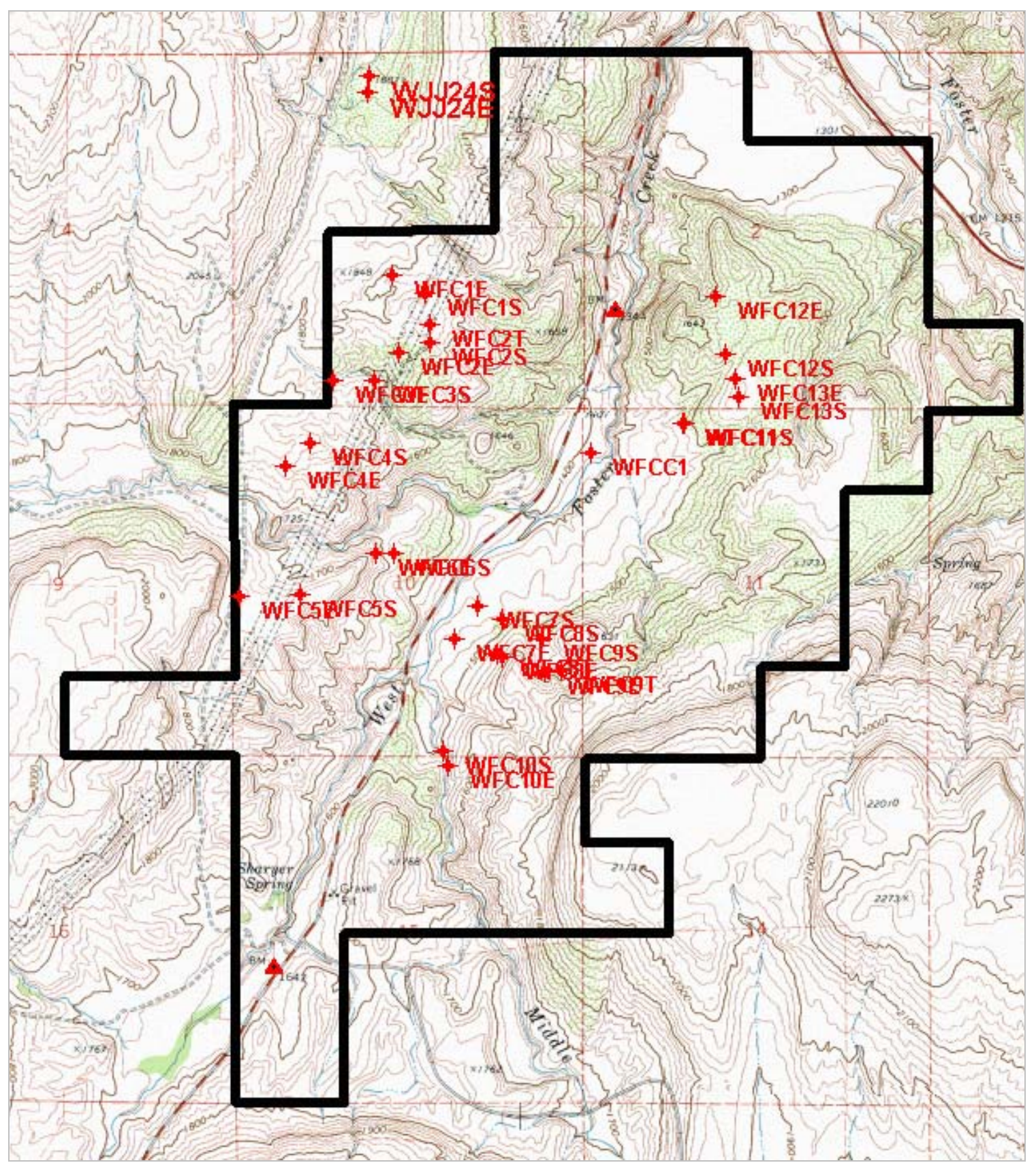

Figure 12. West Foster Creek follow-up transect location summary map ${ }^{7}$.

\footnotetext{
${ }^{7}$ Note that WFC refers to "West Foster Creek" and the suffix "S" is for "start point" while "T" and "E" refers to "turn" and "end" points
} 


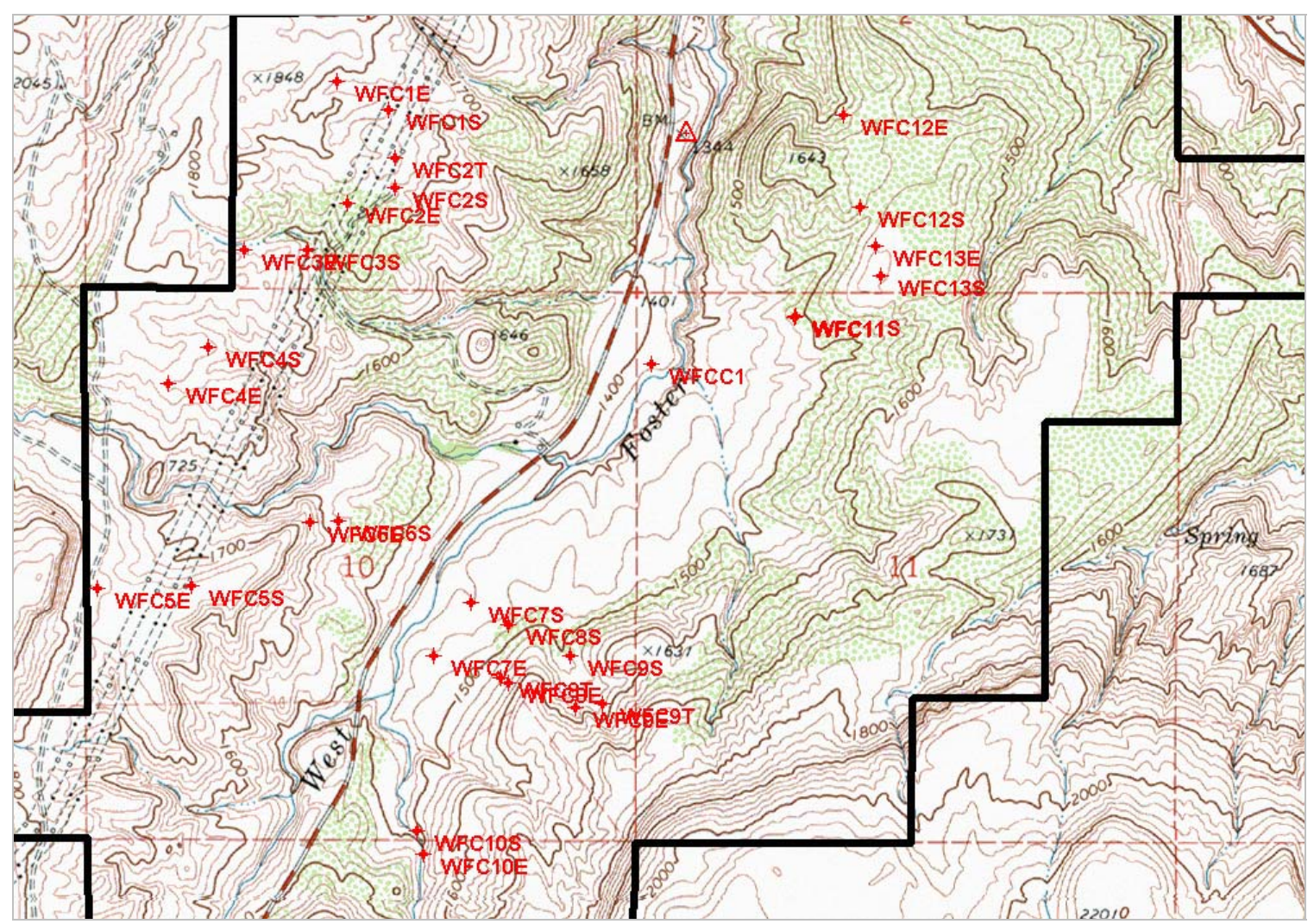

Figure 13. Expanded map showing locations of the 2007 follow-up HEP transects ${ }^{7}$.

\section{Transect Methods}

In 2007, the Regional HEP Team collected HEP model habitat variable data using the same techniques employed on the 1999 baseline transects. This generally entailed following measurement techniques and protocols described in HEP models to evaluate habitat variables; however, ocular estimations were used when direct measurements could not be taken. Measurement techniques were occasionally modified to meet unique habitat and/or physiographic conditions.

Metrics generally followed those described by Hays et al. (1981) and/or Avery (1994). Ashley (2006) summarized the methods and protocols used by Regional HEP Team staff to collect HEP model variable data and additional floristic information (Appendix B).

Transects were established and documented using global positioning system (GPS) units and UTM coordinates while transect start $(\mathrm{S})$, turn $(\mathrm{T})$, and end $(\mathrm{E})$ points were marked with rebar stakes. Field data was collected, tallied, and applied to HEP model variables to determine habitat suitability indices and habitat units for each HEP species model. Field data collection and processing procedures are illustrated in Figure 14 and summarized as follows.

HEP model variable field data was entered onto Allegro CE® data logger spreadsheets (1), or recorded on paper data sheets (2). The raw field data (3) was downloaded from the data loggers or manually entered from paper data sheets onto computers (transect photos were also 
downloaded and stored on field computers). The raw data and photos were compiled for each transect into three basic products/files (4) that are provided to project managers as report appendices and/or separate CD files.

Product files included raw field data downloaded from the data loggers (5), data summary spreadsheets (6) which are the results of compiling/processing the raw data, and transect photo files (7). Summarized/processed data from each transect was applied to appropriate HEP model variables to determine suitability index (SI) ratings that were combined on habitat suitability index (HSI) spreadsheets (8) to determine the HSI for a particular HEP species model/cover type. The habitat suitability index was then multiplied by the number of cover type acres to determine the number of habitat units (9).

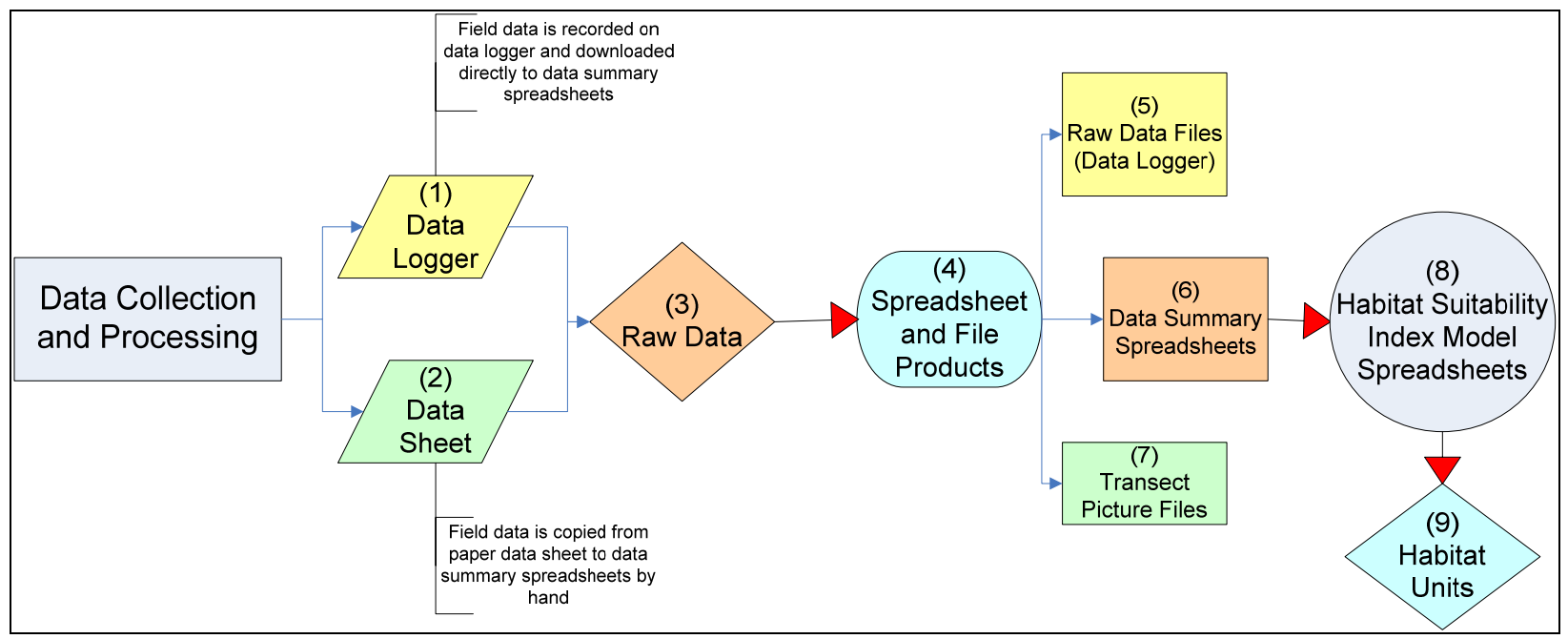

Figure 14. HEP data collection and processing flow chart.

\section{Transect Photo Documentation}

Transects were photographed with a Canon G1® 3.3 mega pixal digital camera (with and without magnification). Transect photographs are included in Appendix D.

\section{Photo Methods}

Photo points were established at the start point of each transect to document extant habitat conditions. Digital photographs were recorded from a height of three feet at the beginning of each transect facing the same direction as the transect azimuth. A transect reference board ${ }^{8}$ was placed at the 15 foot interval while a cover board, divided into 3 inch x 4 inch $(8 \mathrm{~cm} \times 10 \mathrm{~cm})$ rectangles, was set at the 30 foot mark on each transect. Panoramic photographs were also recorded to document dense vegetation, linear/narrow cover types, etc. An example of a photo documentation point is illustrated in Figure 15.

\footnotetext{
${ }^{8}$ Showing transect number, project name, date, and/or GPS reference number
} 


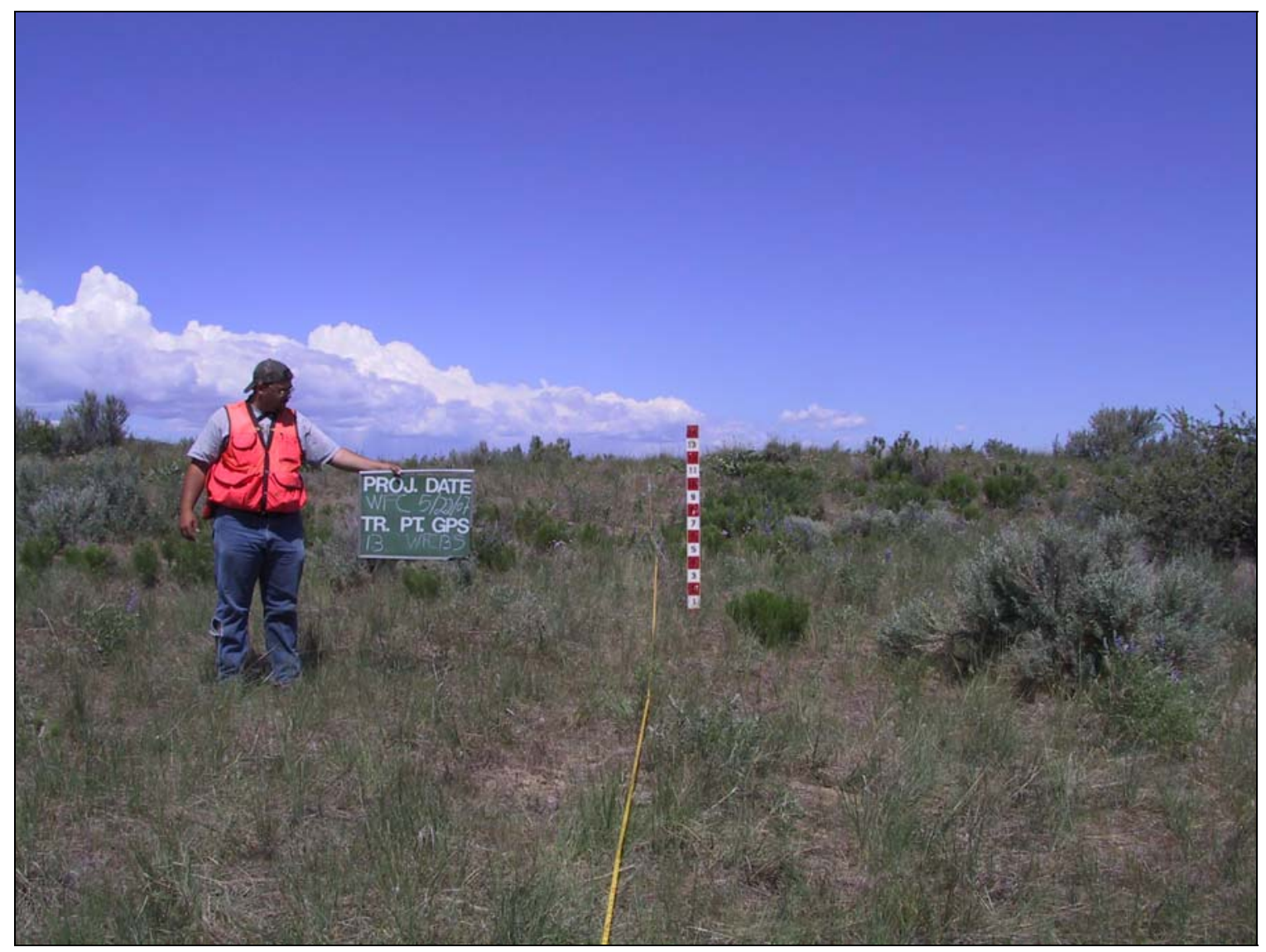

Figure 15. Transect photograph example.

\section{Results}

The follow-up HEP analysis was conducted on the West Foster Creek wildlife mitigation site in May 2007 to document current habitat quality/suitability, and when compared to baseline HEP results, determine the number of additional habitat units to credit Bonneville Power Administration for providing funds to enhance, and maintain the project site. The 2007 follow-up HEP analysis yielded 1,380.26 sharp-tailed grouse habitat units, 879.40 mule deer HUs, and 722.29 western meadowlark habitat units (Table 5).

In summary, the West Foster Creek 2007 follow-up HEP survey generated 2,981.96 habitat units (HU) or $1.51 \mathrm{HUs}$ per acre for a $34 \%$ increase (+751.34 HUs) above baseline HU credit. In comparison, the 1999 baseline HEP survey generated 2,230.62 habitat units or 1.13 HUs per acre. The additional 751.34 habitat units resulted from WDFW's recent passive and active restoration activities. 
West Foster Creek (Smith) 2007 Follow-up HEP Report

Table 5. West Foster Creek 2007 follow-up HEP results summary.

\begin{tabular}{|c|c|c|c|c|c|c|c|c|}
\hline Cover Type & Acres & Model & Variable & SI & HSI & HUs & & \\
\hline \multirow{22}{*}{ Shrubsteppe/Grassland } & \multirow{5}{*}{$1,958.00$} & \multirow{5}{*}{ Western Meadowlark } & V1: \% C.C. Herb. Plants & 0.78 & 0.37 & 722.29 & & \\
\hline & & & V2: \% Herb. C.C. Composed of Grass & 0.84 & & & & \\
\hline & & & V3: Ave. Ht. of Herb. Canopy & 0.95 & & & & \\
\hline & & & V4: Distance to Perch Sites & 0.98 & & & & \\
\hline & & & V5: \% Shrub Canopy Cover & 0.48 & & & & \\
\hline & \multirow{10}{*}{$1,958.00$} & \multirow{10}{*}{ Mule Deer } & $\begin{array}{l}\text { V1: Percent cover of preferred } \\
\text { shrubs }<1.5 \text { meters in height }\end{array}$ & 0.95 & 0.45 & 879.40 & WFI & 0.45 \\
\hline & & & V2: Percent cover of all shrubs $<1.5$ meters in height. & 0.95 & & & WCl & 0.80 \\
\hline & & & V3: Mean shrub height. & 0.60 & & & & \\
\hline & & & V4: Number of preferred shrub species. & 0.50 & & & & \\
\hline & & & V5: Percent cover of palatable herbaceous species. & 1.00 & & & & \\
\hline & & & $\begin{array}{l}\text { V6: Presence of suitable agricultural crops } \\
\text { within } 1.6 \text { kilometers (1 mile) of study area }\end{array}$ & 0.10 & & & & \\
\hline & & & V7: Aspect & 0.50 & & & & \\
\hline & & & V8: Road density & 0.80 & & & & \\
\hline & & & V9: Topographic diversity & 1.00 & & & & \\
\hline & & & $\begin{array}{l}\text { V10: Percent evergreen canopy } \\
>1.5 \text { meters in height }\end{array}$ & 0.00 & & & & \\
\hline & \multirow{7}{*}{$1,958.00$} & \multirow{7}{*}{ Sharp-tailed Grouse } & V1: Mean VOR - Landscape (all vegetation including residual) & 0.78 & 0.70 & $1,378.66$ & Nest/brood HSI & \\
\hline & & & V2: Percent Slope & 0.76 & 0.64 & & Brood HSI & \\
\hline & & & V3: Percent Cover Grass & 0.88 & 0.77 & & Nesting HSI & \\
\hline & & & V4: Percent Cover Forbs & 0.41 & & & & \\
\hline & & & V5: Percent Cover Introduced Herbaceous Species & 0.75 & & & & \\
\hline & & & V6: Percent Equivalent Optimum Area Providing Nest/Brood Cover & 1.00 & & & & \\
\hline & & & V7: Distance Between Nesting/Brood Rearing and Winter Habitat & 1.00 & & & & \\
\hline Subtotal & $1,958.00$ & & & & & $2,980.36$ & & \\
\hline \multirow{3}{*}{ Riparian Shrub } & \multirow{3}{*}{16.00} & \multirow{3}{*}{ Sharp-tailed Grouse } & V8: Percent Cover Deciduous shrubs and Trees & 1.00 & 0.1 & 1.60 & & \\
\hline & & & V9: Deciduous Shrub and Tree Composition/Wheat Availability & 1.00 & & & & \\
\hline & & & V10: Percent Equivalent Optimum Area Providing Winter Habitat & 0.10 & & & & \\
\hline Parcel Total & $1,974.00$ & & & & & 2,981.96 & & \\
\hline
\end{tabular}


West Foster Creek (Smith) 2007 Follow-up HEP Report

\section{Discussion}

Mule deer and sharp-tailed grouse habitat units increased by $346.42 \mathrm{HUs}$ and $470.62 \mathrm{HUs}$ respectively over baseline (1999) HEP survey results. In contrast, the western meadowlark generated slightly fewer habitat units in 2007 (-67.31) than in 1999 (Table 6).

Table 6. Follow-up and baseline HEP results comparison/summary.

\begin{tabular}{|c|c|c|c|c|c|c|}
\hline \multirow{2}{*}{ Cover Type } & \multirow{2}{*}{ Acres } & \multirow{2}{*}{ HEP Model } & \multicolumn{2}{|c|}{2007 Follow-up HEP } & \multicolumn{2}{|c|}{1999 Baseline HEP } \\
\hline & & & HSI & HUs & HSI & HUs $^{1}$ \\
\hline \multirow{3}{*}{ Shrubsteppe/Grassland } & \multirow{3}{*}{$1,958.00$} & Western Meadowlark & 0.37 & 722.29 & 0.40 & 789.60 \\
\hline & & Mule Deer & 0.45 & 879.40 & 0.27 & 532.98 \\
\hline & & Sharp-tailed Grouse & 0.70 & $1,378.66$ & 0.46 & 908.04 \\
\hline Subtotal & $1,958.00$ & & & $2,980.35$ & & $2,230.62$ \\
\hline Riparian Shrub & 16.00 & Sharp-tailed Grouse & 0.10 & 1.60 & 0.00 & 0.00 \\
\hline Parcel Total & $1,974.00$ & & & $2,981.95$ & & $2,230.62$ \\
\hline
\end{tabular}

\section{Shrubsteppe}

The additional mule deer habitat units are the result of increased shrub cover and palatable herbaceous vegetation. Similarly, sharp-tailed grouse habitat suitability exceeded the baseline HSI due primarily to increased herbaceous cover, which was recorded as visual obstruction readings (VOR). On the other hand, western meadowlark habitat suitability and associated habitat units decreased slightly compared to 1999 baseline HEP results, due to elevated shrub cover (Table 7).

Changes in habitat suitability and habitat units are attributed primarily to WDFW's post acquisition management decision to stop livestock grazing, which allowed the herbaceous stratum to recover through passive restoration (eventually, however, some form of disturbance may be necessary to maintain a robust herbaceous plant community). Since 1999, WDFW wildlife area staff have also replanted two abandoned ${ }^{9}$ and two active agriculture fields with native-like herbaceous species while an orchard was removed and rehabbed as grassland (M. Hallet, pers. comm.). In addition, WDFW initiated an aggressive weed control program on the wildlife area.

Results from the 2007 follow-up HEP survey confirmed that percent shrub cover increased on 11 out of 12 (92\%) shrubsteppe transects (Table 7). Mean shrub cover for all shrubsteppe transects was $18.75 \%$ in 1999 and $28.3 \%$ in 2007 ; nearly a $51 \%$ increase. Increased shrub cover is primarily the result of passive restoration; however, modest deviations in 2007 HEP transect placement may also have contributed towards the significant increase in percent shrub cover. Several examples of 1999 and 2007 shrubsteppe transects are compared in Figure 16 through Figure 21.

\footnotetext{
${ }^{9}$ See Figure 16 and Figure 17 for a photo comparison of an abandoned agriculture field that was rehabbed.
} 
West Foster Creek (Smith) 2007 Follow-up HEP Report

\begin{tabular}{|c|c|c|c|c|c|c|c|c|c|c|c|c|c|c|c|c|c|c|c|c|c|c|c|c|}
\hline \multirow{3}{*}{ Shrub Species } & \multirow{2}{*}{\multicolumn{2}{|c|}{$\begin{array}{l}\text { Transect } 001 \\
\text { Percent Cover }\end{array}$}} & \multirow{2}{*}{\multicolumn{2}{|c|}{$\begin{array}{c}\text { Transect } 002 \\
\text { Percent Cover }\end{array}$}} & \multirow{2}{*}{\multicolumn{2}{|c|}{$\begin{array}{l}\text { Transect } 003 \\
\text { Percent Cover }\end{array}$}} & \multirow{2}{*}{\multicolumn{2}{|c|}{$\begin{array}{c}\text { Transect } 004 \\
\text { Percent Cover }\end{array}$}} & \multirow{2}{*}{\multicolumn{2}{|c|}{$\begin{array}{l}\text { Transect } 005 \\
\text { Percent Cover }\end{array}$}} & \multirow{2}{*}{\multicolumn{2}{|c|}{$\begin{array}{l}\text { Transect } 006 \\
\text { Percent Cover }\end{array}$}} & \multirow{2}{*}{\multicolumn{2}{|c|}{$\begin{array}{c}\text { Transect } 007 \\
\text { Percent Cover }\end{array}$}} & \multirow{2}{*}{\multicolumn{2}{|c|}{$\begin{array}{c}\text { Transect } 008 \\
\text { Percent Cover }\end{array}$}} & \multirow{2}{*}{\multicolumn{2}{|c|}{$\begin{array}{c}\text { Transect } 009 \\
\text { Percent Cover }\end{array}$}} & \multirow{2}{*}{\multicolumn{2}{|c|}{$\begin{array}{l}\text { Transect } 011 \\
\text { Percent Cover }\end{array}$}} & \multirow{2}{*}{\multicolumn{2}{|c|}{$\begin{array}{l}\text { Transect } 012 \\
\text { Percent Cover }\end{array}$}} & \multirow{2}{*}{\multicolumn{2}{|c|}{$\begin{array}{r}\text { Transect } 013 \\
\text { Percent Cove }\end{array}$}} \\
\hline & & & & & & & & & & & & & & & & & & & & & & & & \\
\hline & 1999 & 2007 & 1999 & 2007 & 1999 & 2007 & 1999 & 2007 & 1999 & 2007 & 1999 & 2007 & 1999 & 2007 & 1999 & 2007 & 1999 & 2007 & 1999 & 2007 & 1999 & 2007 & 1999 & 2007 \\
\hline Big Sagebrush & 0.10 & 1.75 & 40.00 & 43.80 & 8.00 & 11.00 & 1.00 & 0.00 & 18.00 & 23.20 & 0.00 & 0.70 & 5.00 & 23.20 & 34.00 & 35.70 & 6.00 & 26.70 & 31.00 & 24.00 & 10.00 & 27.80 & 2.00 & 2.70 \\
\hline Three-tip Sagebrush & 0.00 & 0.00 & 4.00 & 1.00 & 5.00 & 7.30 & 1.00 & 7.70 & 6.00 & 6.40 & 5.00 & 13.30 & 0.00 & 6.30 & 0.00 & 0.30 & 6.00 & 0.20 & 0.00 & 0.20 & 0.50 & 0.00 & 0.50 & 5.30 \\
\hline Bitterbrush & 0.00 & 0.00 & 0.00 & 0.00 & 0.00 & 0.00 & 0.00 & 0.00 & 1.00 & 0.00 & 0.00 & 0.00 & 0.00 & 0.00 & 12.00 & 0.30 & 0.50 & 0.00 & 6.00 & 18.00 & 28.00 & 9.80 & 1.00 & 0.00 \\
\hline Gray Rabbitbrush & 0.00 & 0.00 & 0.00 & 3.30 & 0.50 & 1.00 & 0.00 & 0.30 & 0.00 & 0.60 & 2.00 & 2.00 & 22.00 & 0.60 & 3.00 & 0.70 & 2.00 & 1.10 & 2.00 & 1.80 & 2.00 & 4.40 & 3.00 & 2.00 \\
\hline Green Rabbitbrush & 0.10 & 1.75 & 0.00 & 0.00 & 0.00 & 0.00 & 0.00 & 0.00 & 0.00 & 0.00 & 0.50 & 0.00 & 0.00 & 0.00 & 1.00 & 5.70 & 0.50 & 0.00 & 4.00 & 2.90 & 4.00 & 8.90 & 0.50 & 2.70 \\
\hline Gray Horsebrush & 0.00 & 0.00 & 0.00 & 0.00 & 0.00 & 0.00 & 0.00 & 0.00 & 0.00 & 0.00 & 0.50 & 0.00 & 0.00 & 0.00 & 0.00 & 0.00 & 0.50 & 0.00 & 0.00 & 0.00 & 1.00 & 0.00 & 0.50 & 0.00 \\
\hline Total Percent Cover & 0.20 & 3.50 & 44.00 & 48.10 & 13.50 & 19.30 & 2.00 & 8.00 & 25.00 & 30.20 & 8.00 & 16.00 & 27.00 & 30.10 & 50.00 & 42.70 & 15.50 & 28.00 & 43.00 & 46.90 & 45.50 & 50.90 & 7.50 & 12.70 \\
\hline
\end{tabular}




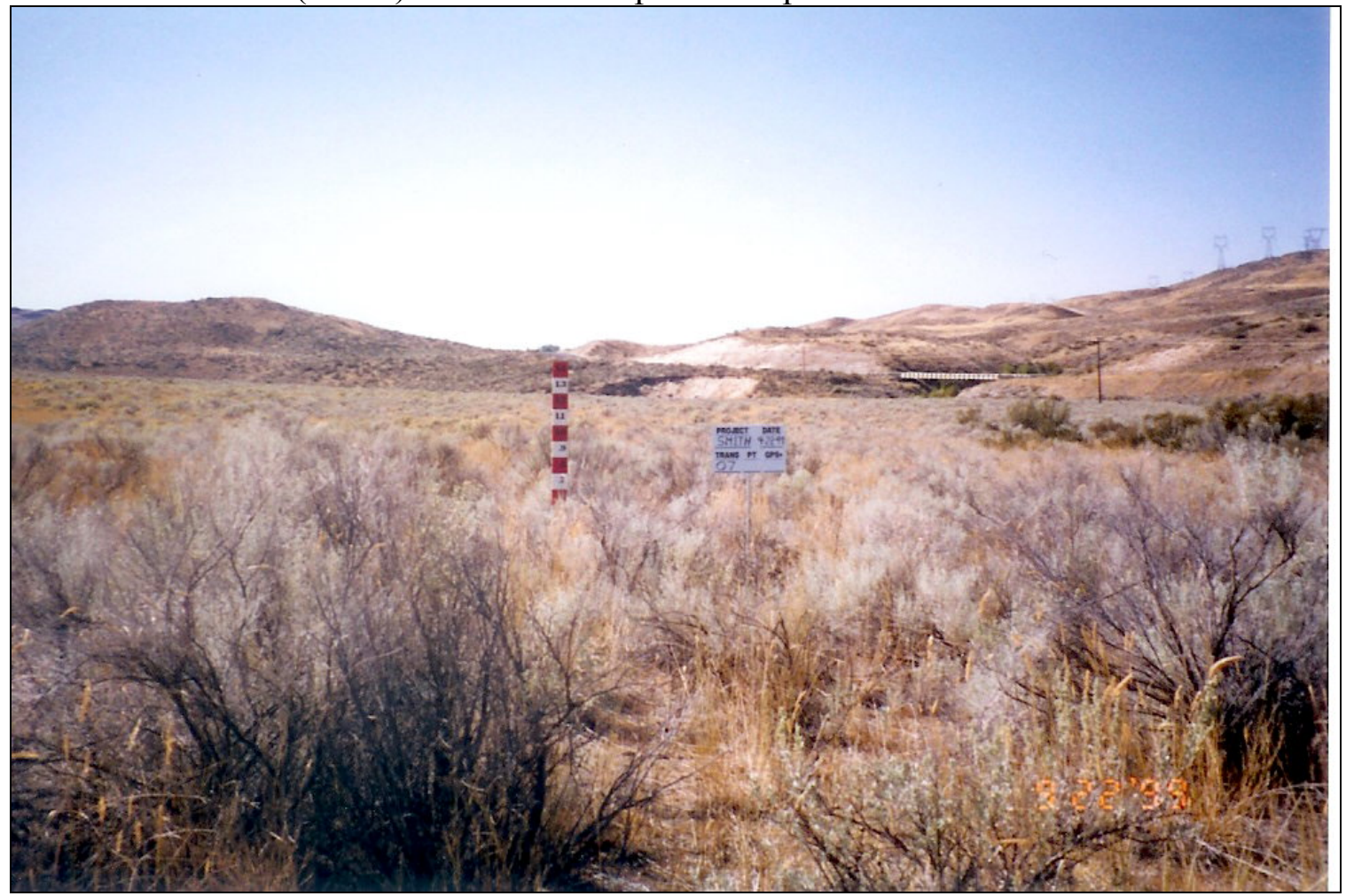

Figure 16. Transect 7 - an abandoned agricultural field in 1999.

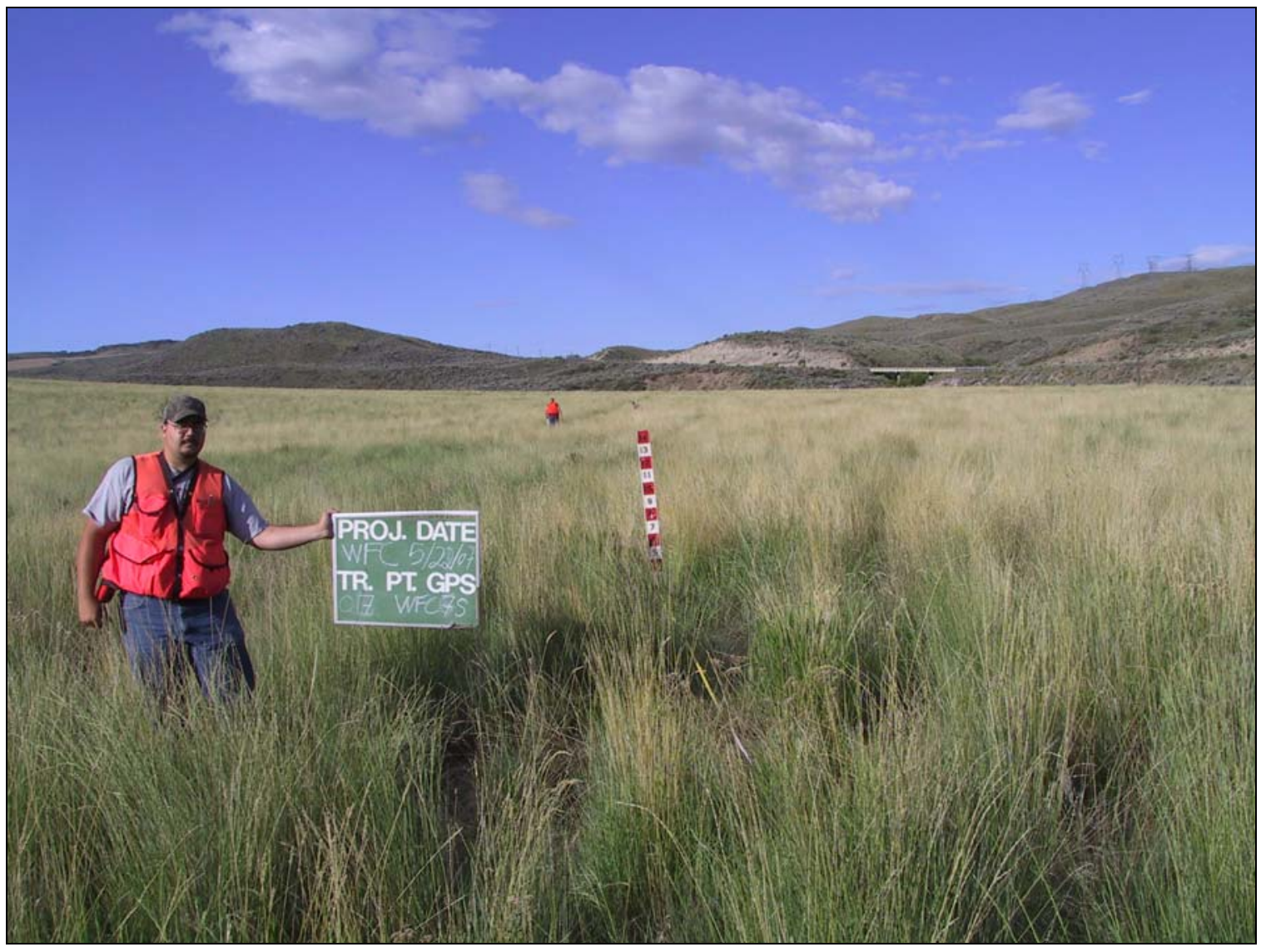

Figure 17. Transect 7 - rehabbed grassland in 2007. 


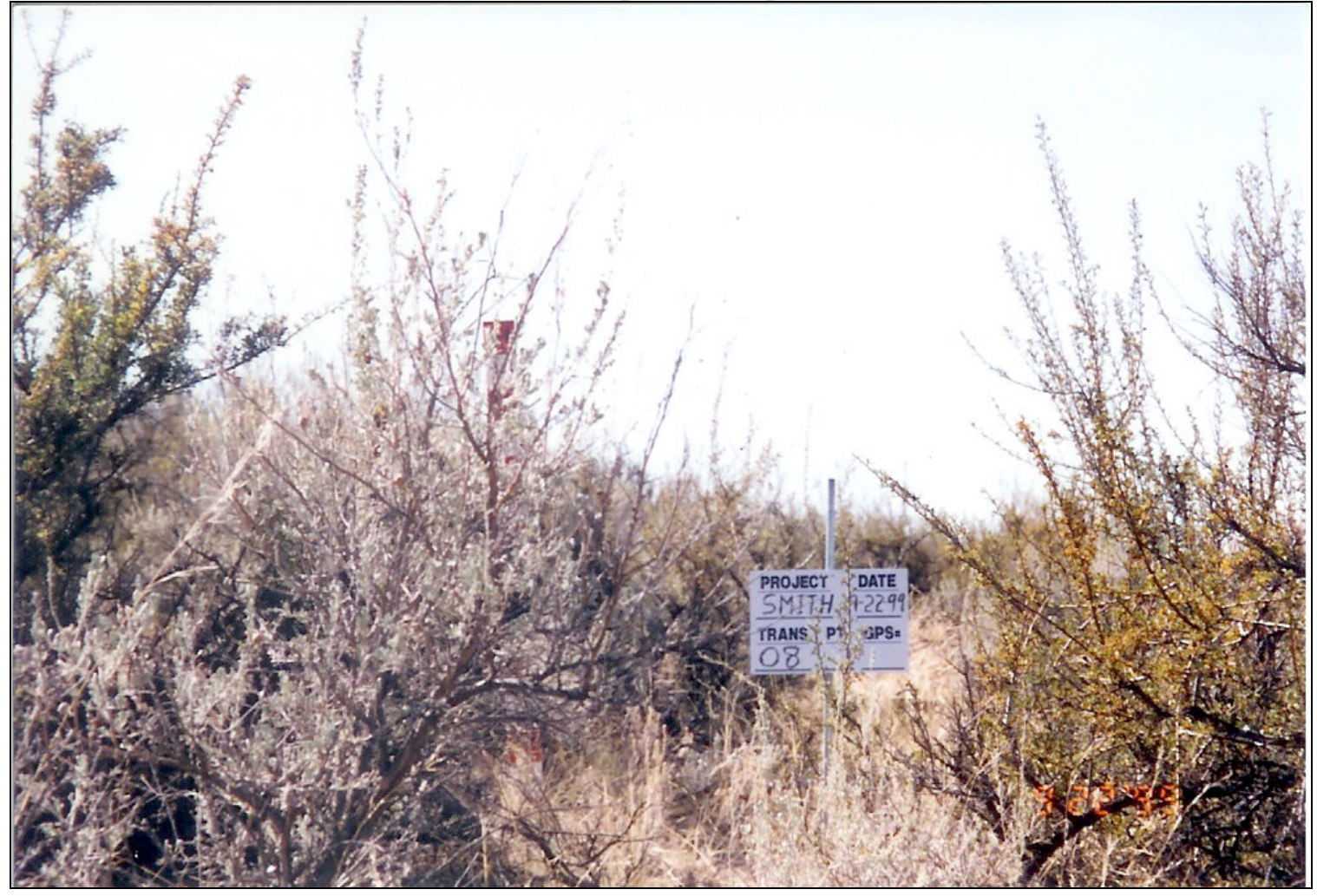

Figure 18. Transect 8 - shrubsteppe cover type in 1999.

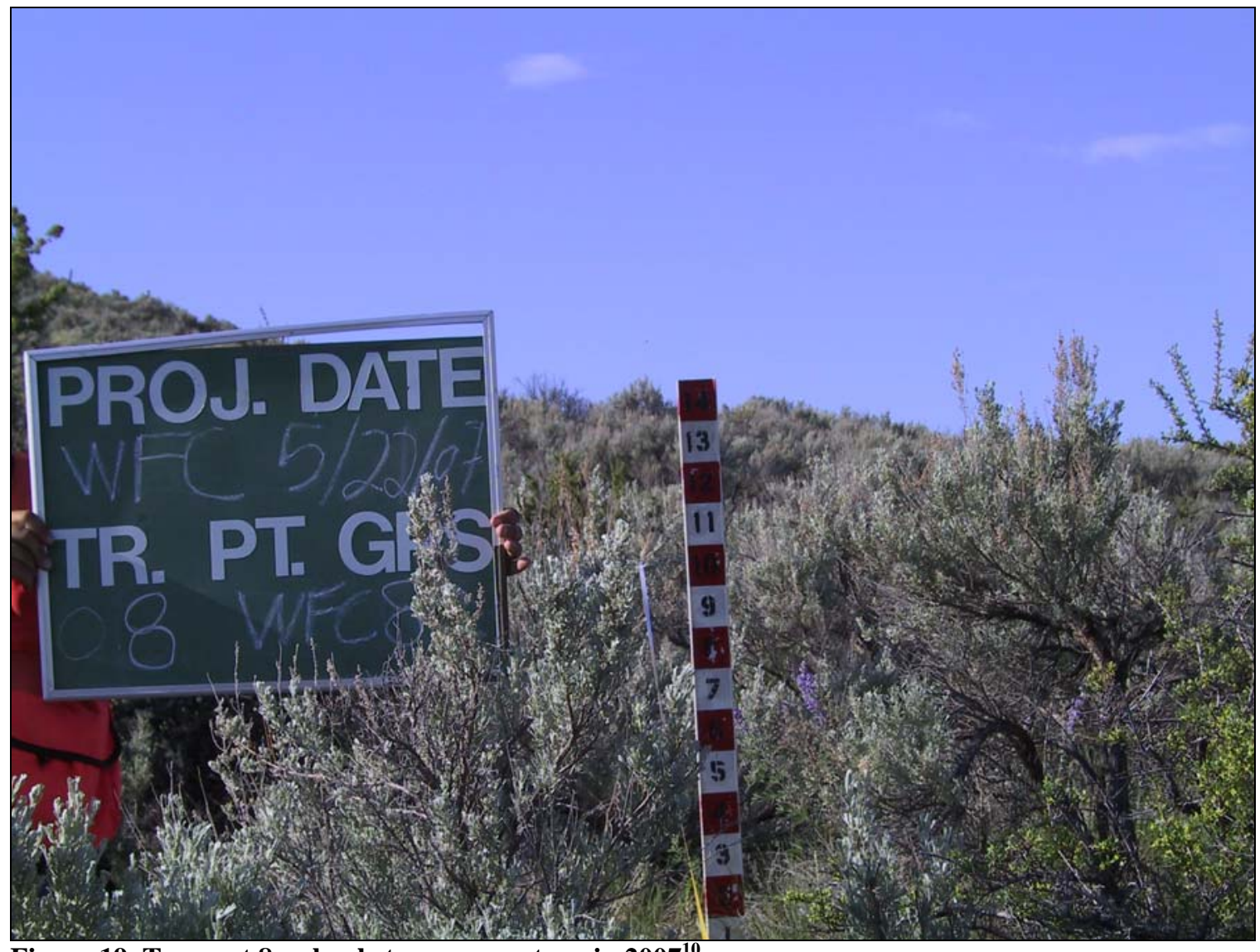

Figure 19. Transect 8 - shrubsteppe cover type in $2007^{10}$.

${ }^{10}$ The position of Transect 8 (2007) is approximately seven feet east (left) of the 1999 transect (Figure 18). 
West Foster Creek (Smith) 2007 Follow-up HEP Report

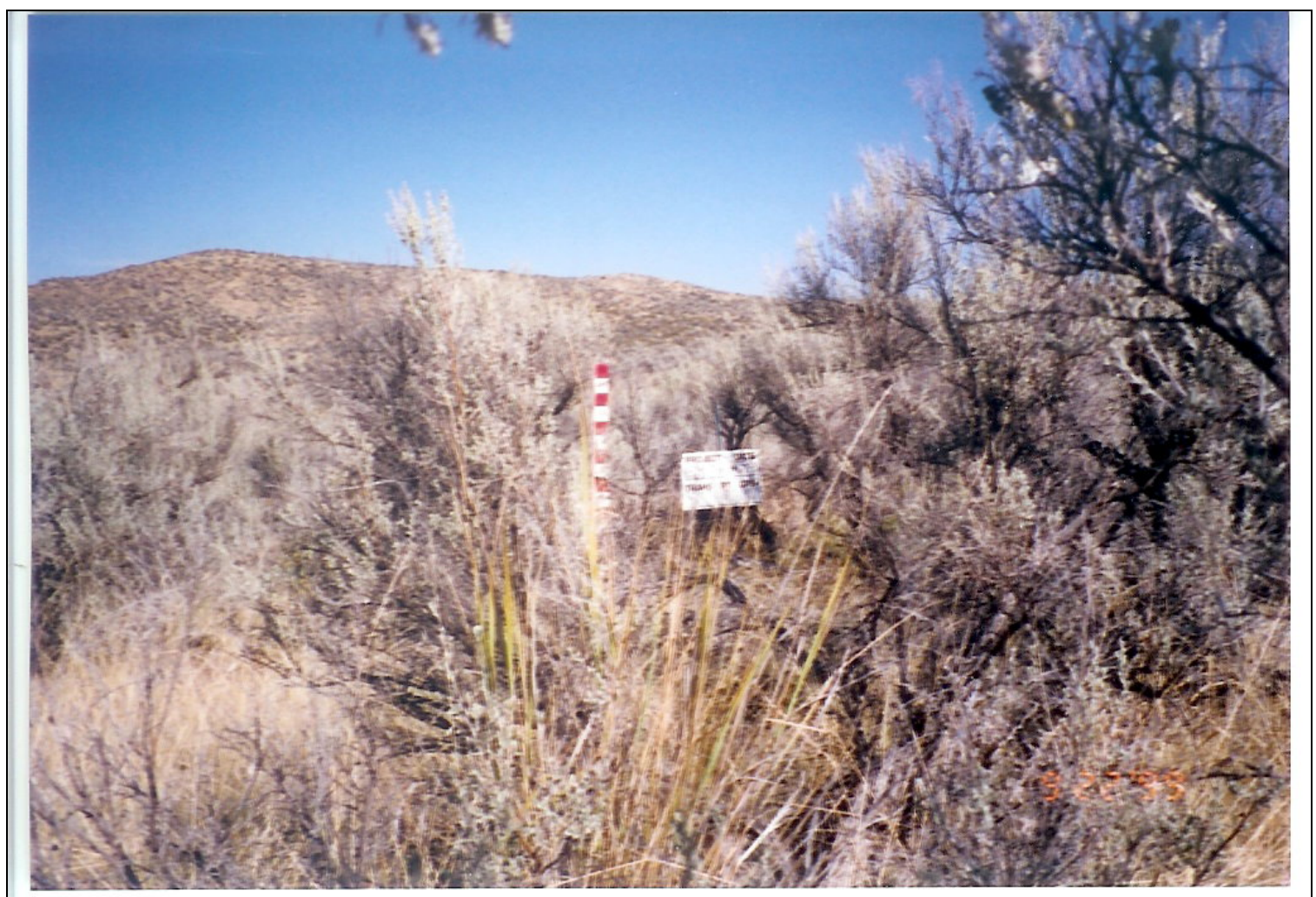

Figure 20. Transect 11 - shrubsteppe cover type in 1999.

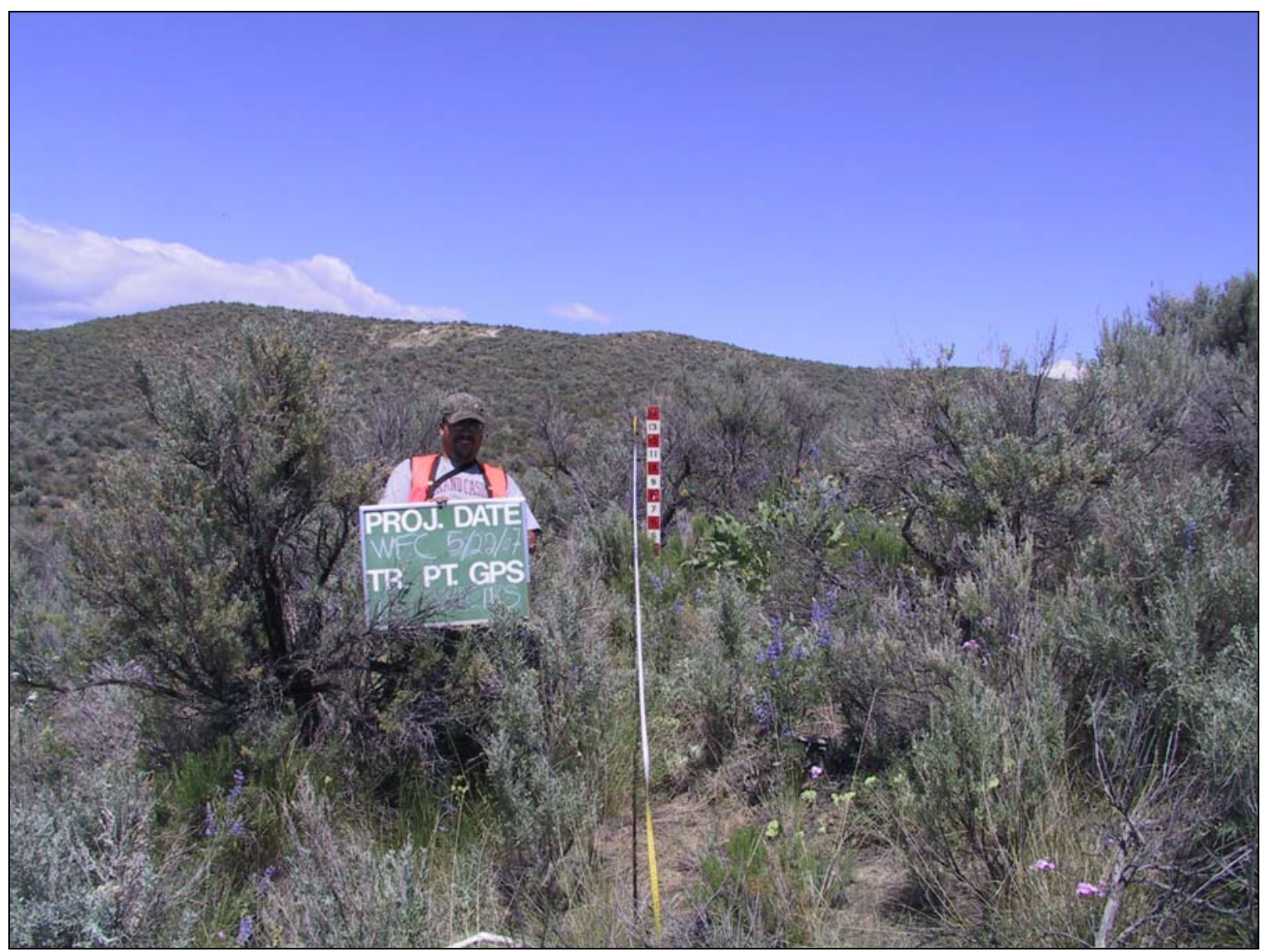

Figure 21. Transect 11 - shrubsteppe cover type in 2007. 


\section{Riparian Shrub}

The winter portion of the sharp-tailed grouse model (Appendix A) was used to evaluate riparian shrub habitat quality. Model output indicated habitat variables pertaining to woody species composition and quantity (percent cover) were optimum; however, the small amount of this cover type present at West Foster Creek limits the model's overall HSI performance.

Photographs from the 1999 baseline HEP survey were not available for inclusion into this report. Conversely, photographs from the 2007 follow-up HEP surveys are included in Figures 9, 10, and 11 .

\section{Acknowledgements}

I gratefully acknowledge the hard work and effort provided by WDFW Sagebrush Flat Wildlife Area Assistant Manager Dan Peterson and Regional HEP Team members Mikael Cantonese, Tiffany Baker, Tony Muse, and Paul Walker. I also want to thank John Talmadge (WDFW) for providing GIS support and Dan Budd (WDFW Real Estate Division) for responding to a myriad of acquisition related questions in a timely manner. A special thank you goes to WDFW Wildlife Area Manager Marc Hallet for addressing my numerous questions. 


\section{References}

Ashley, P. R., and M. Berger 1999. Habitat suitability model mule deer (winter). Washington Department of Fish and Wildlife. Olympia WA. Colville Confederated Tribes. Nespelem, WA.

Ashley. P. R. 2003. Sharp-tailed grouse HSI model (draft). Washington Department of Fish and Wildlife. Olympia WA.

. 2005. White-tailed deer HEP model (draft). Columbia Basin Fish and Wildlife Authority. Portland, OR. Spokane Tribe of Indians. Wellpinit, WA.

.2006. Habitat evaluation procedures standard measurement protocols and techniques (draft). Columbia Basin Fish and Wildlife Authority (CBFWA). Portland, OR.

Avery, T.E., H. E. Burkhart. 1994. Forest measurements. $4^{\text {th }}$ edition. New York, NY: John Wiley and Sons.

Berger, M. T. and D. Kuehn. 1992. Wildlife impact assessment Chief Joseph Dam Project. Project N0. 88-44. Bonneville Power Administration. Portland, OR.

BPA/WDFW. 1996. Memorandum of Agreement between the Washington Department of Fish and Wildlife and Bonneville Power Administration for the disbursal of wildlife mitigation funds and mitigation crediting. WDFW. Olympia, WA. BPA. Portland, OR.

Gotelli, N. J., A. M. Ellison. 2004. A primer of ecological statistics. Sinauer Associates, Inc. Sunderland, MA.

Hays, R. L., C. Summers, and W. Seitz. 1981. Estimating habitat variables. Western Energy and land Use Team. Fort Collins, CO: U.S. Fish and Wildlife Service.

Howerton, J., J. Creveling, and B. Renfrow. 1986. Wildlife protection, mitigation, and enhancement planning for Grand Coulee Dam. Olympia, WA: Washington Department of Fish and Wildlife.

Husch, B., T.W. Beers, and J.A. Kershaw, Jr. 2003. Forest mensuration- $4^{\text {th }}$ edition. Hoboken, NJ: Wiley and Sons, Inc.

Ohmann, J. L., M. J. Gregory, and J. S. Fried. 2006. The Pacific Northwest Regional GAP Analysis Project. Final report on Mapping of forest ecological systems of map zones 8 and 9 with gradient nearest neighbor imputation. Gap Analysis Program-Biological Resources Division, U.S. Geolical Survey. Pacific Northwest Research Station. USDA Forest Service. Corvallis, OR. 
Robel, R. J., J. N. Dayton, and A.D. Hulbert. 1975. Relationship between visual obstruction measurements and weight of grassland vegetation. Journal of Range Management. 23: 295.

Schroeder, R.L., and P.J. Sousa. 1982. Habitat suitability index models:

Eastern meadowlark. U.S. Department of the Interior, Fish and Wildlife

Service. FWS/OBS-82/10.29.

USFWS. 1980. Habitat as a Basis for Environmental Assessment, Ecological Services Manual (ESM) 101. Division of Ecological Services, U. S. Fish and Wildlife Service, Washington, DC: Department of the Interior.

. 1980a. Habitat Evaluation Procedures (HEP), Ecological Services Manual (ESM) 102. Division of Ecological Services, U.S. Fish and Wildlife Service, Washington, DC: Department of the Interior.

WDFW. 2001. Sagebrush Flat Wildlife Area Work Plan Addendum - 2001. Washington Department of Fish and Wildlife. Olympia, WA. 


\section{Appendix A - Abbreviated HEP Models}

\section{Mule Deer}

V1: Percent palatable shrub cover

$<5 \mathrm{ft}$ in height

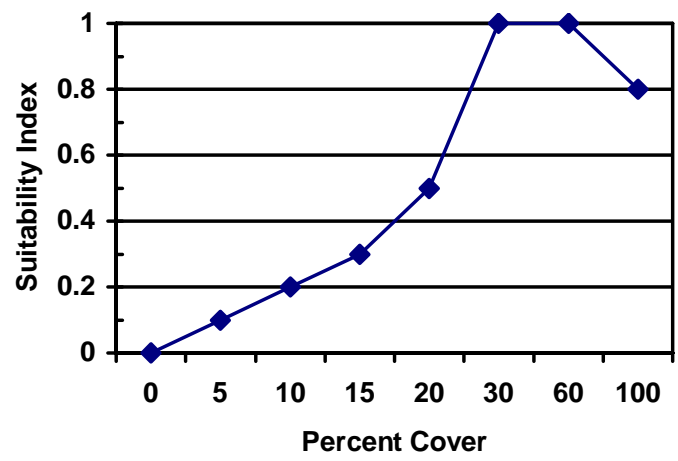

V2: Percent cover all shrubs $<5 \mathrm{ft}$ in height

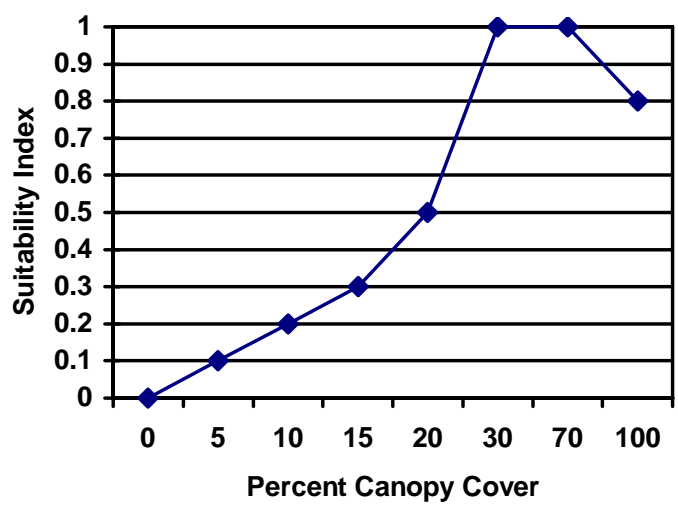

V3: Mean shrub height

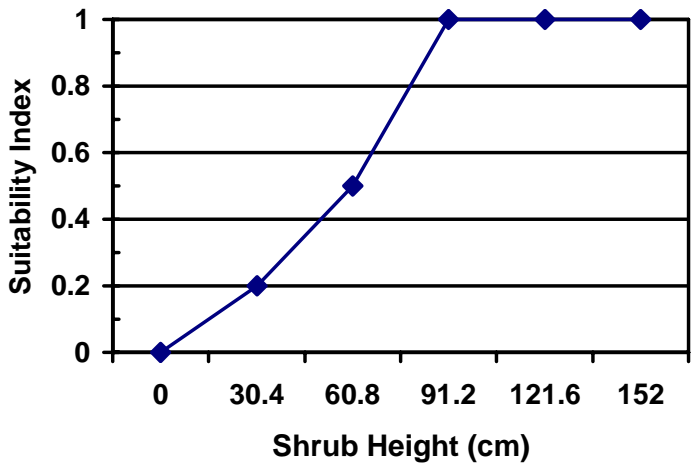


V4: No. of preferred shrub species

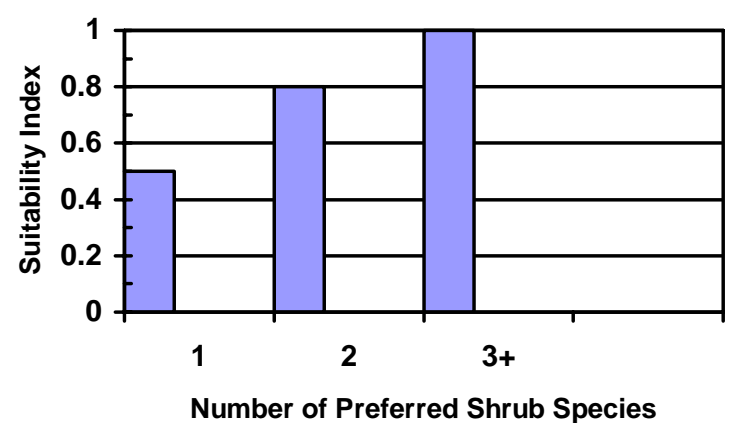

V5: Percent cover palatable herbaceous species

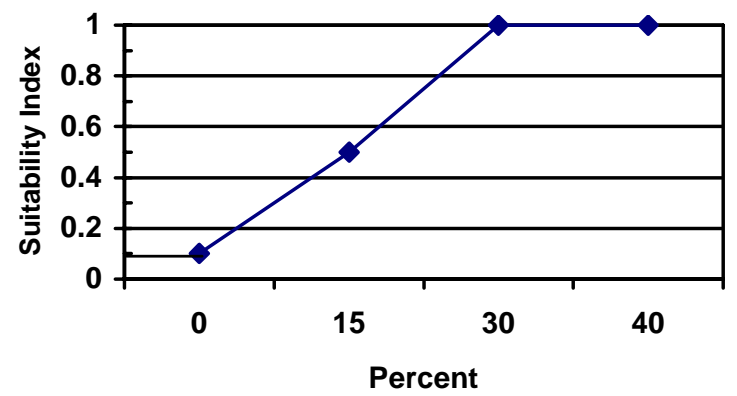

V6: Presence of suitable agricultural crops within 1.6 kilometers (1 mile) of study area Yes: 0.1

No: 0.0 
V7: Aspect

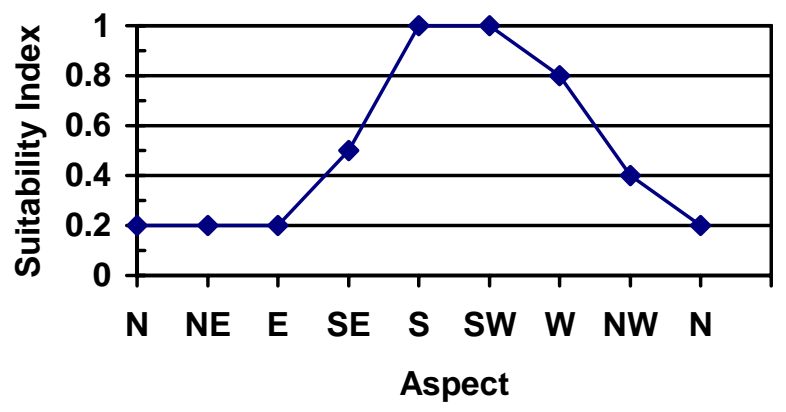

V8: Road density

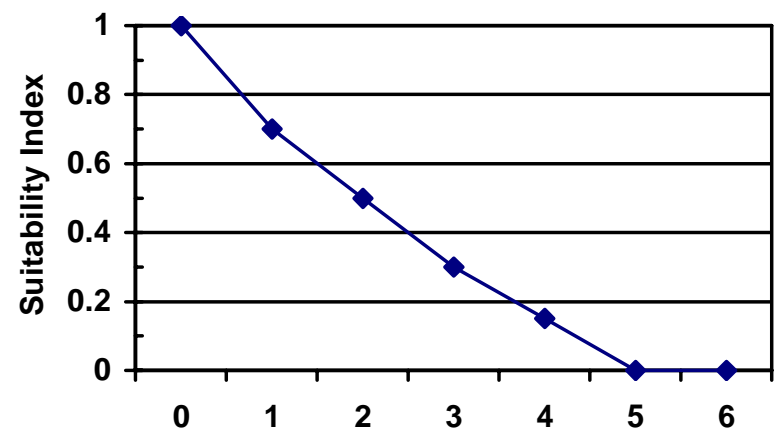

Kilometers of Open Road per Square Kilometer

V9: Topographic diversity

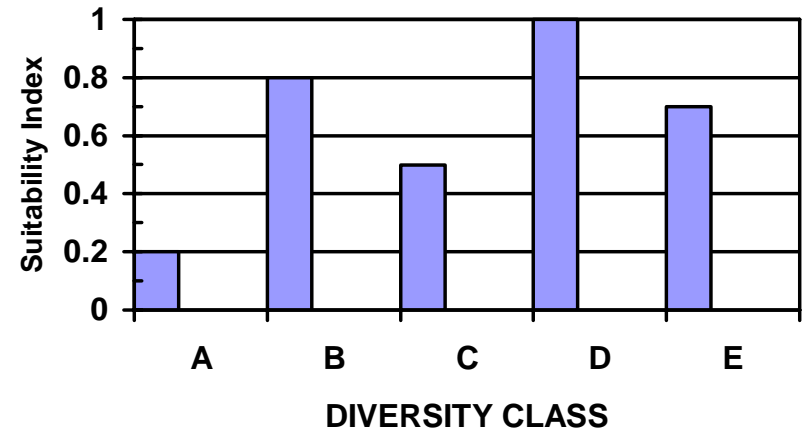


$\mathrm{V}_{9} \quad$ Topographic diversity.
A: Level terrain less than 5 percent slope.
B: Level terrain broken by drainages.
C: Rolling terrain 5 to 25 percent slope.
D: Rolling terrain with rims, ridges, and/or drainages.
E: Mountainous terrain with slopes greater than 25 percent.

V10: Percent evergreen cover $>5 \mathrm{ft}$ in height

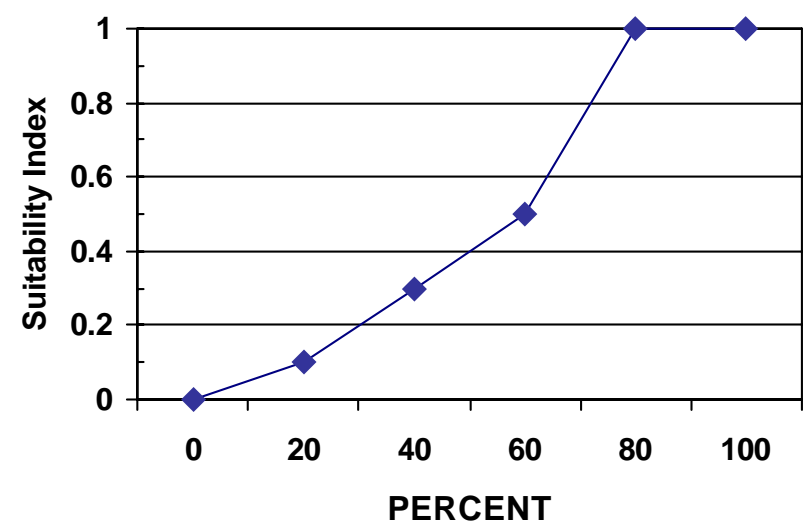

Shrubsteppe $\mathrm{HSI}=$ minimum value $\mathrm{WFI}$ or $\mathrm{WCI}$

$\mathrm{WFI}=\left(\left(\left(\mathrm{V} 1(\mathrm{~V} 2 \times \mathrm{V} 3 \times \mathrm{V} 4 \times \mathrm{V} 5)^{1 / 4}\right)+\mathrm{V6}\right) \times \mathrm{V} 7\right)^{\wedge}{ }^{.625} \times \mathrm{V} 8$

Steps in calculating WFI with a hand calculator:

1. Obtain geometric mean of V2, V3, V4, and V5

2. Multiply product from step one by V1 and add V6

3. Multiply sum obtained in step two by V7

4. Take the $1.66 \operatorname{root}\left({ }^{\wedge} .6\right.$ on your computer)of product from step 3

5. Multiply result from step 4 by V8 to obtain WFI

$\mathrm{WCI}_{S S}=(\mathrm{V9} \times .8)+\mathrm{V} 10$

Conifer Forest HSI = Lower Value Between:

WFI $=\left(((V 1(V 2 \times \text { V3 } x \text { V4 } x \text { V5) } 1 / 4)+V 6) \times V 7)^{\wedge}{ }^{.625} \times\right.$ V8

$W C I_{F}=2(V 10)+V 9$ 
West Foster Creek (Smith) 2007 Follow-up HEP Report

\section{Sharp-tailed Grouse}

V1: Mean VOR - Landscape (all vegetation including residual)

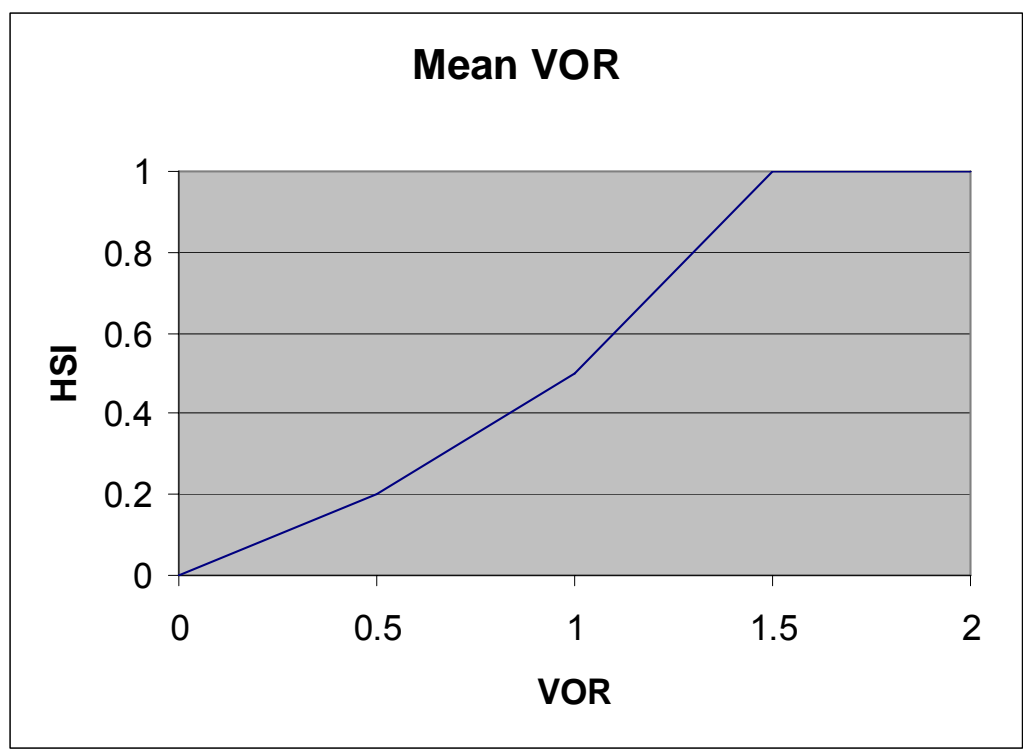

V2: Percent Slope

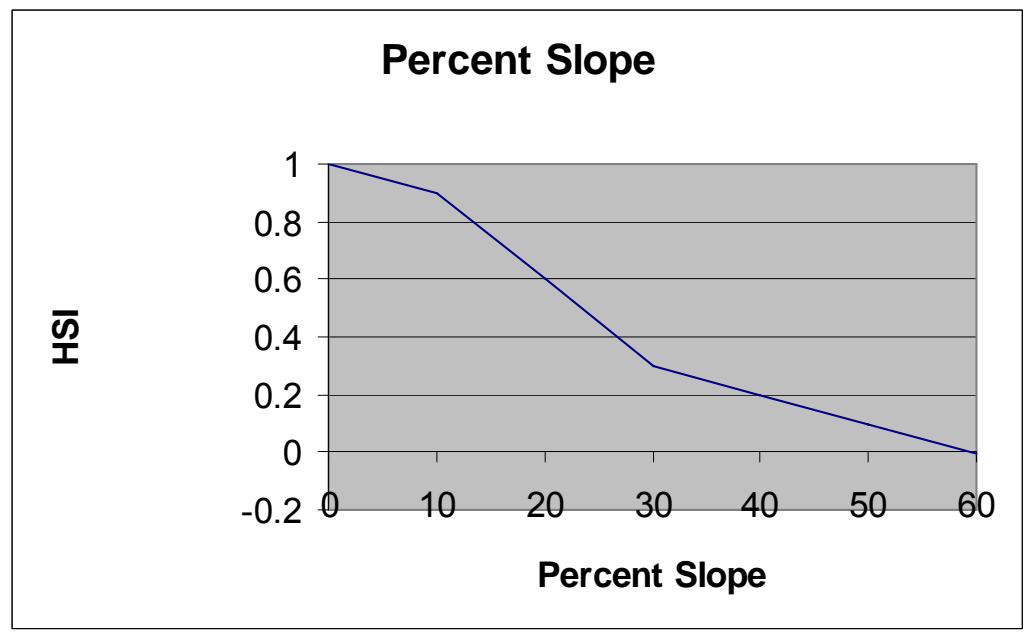

Nesting Habitat HSI Equation: $\left(V 1 \times\right.$ V2 $\times$ V6) ${ }^{1 / 2}$ 
West Foster Creek (Smith) 2007 Follow-up HEP Report

Brood Rearing Habitat

V3: Percent Cover Grass

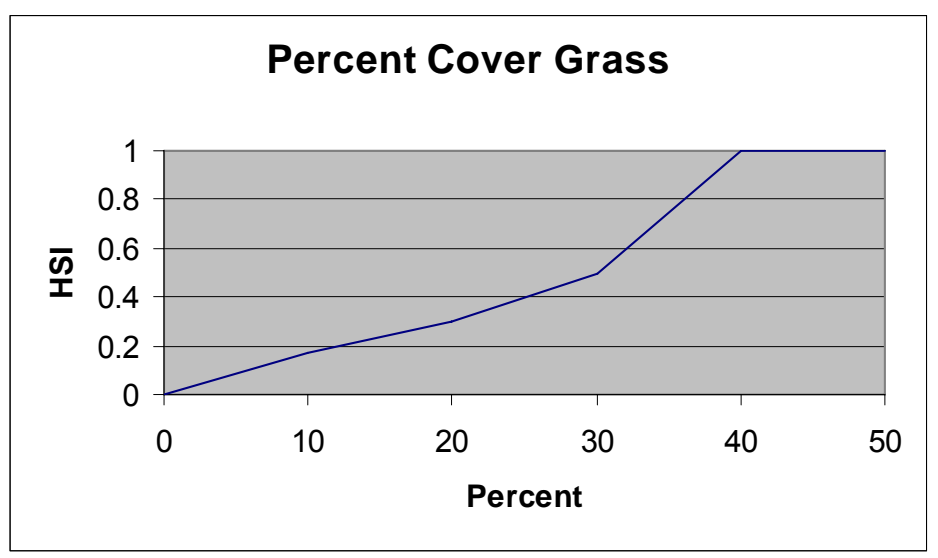

V4: Percent Cover Forbs

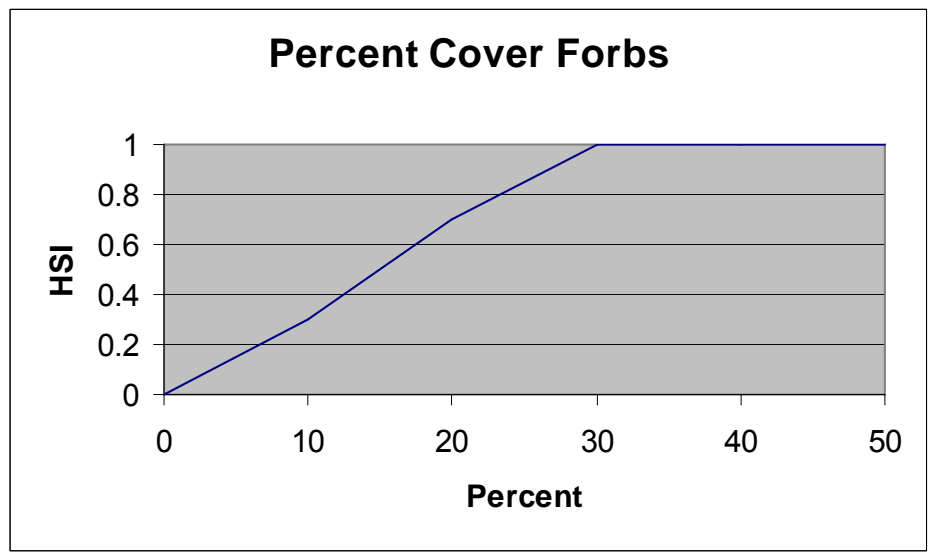

V5: Percent Cover Introduced Herbaceous Species

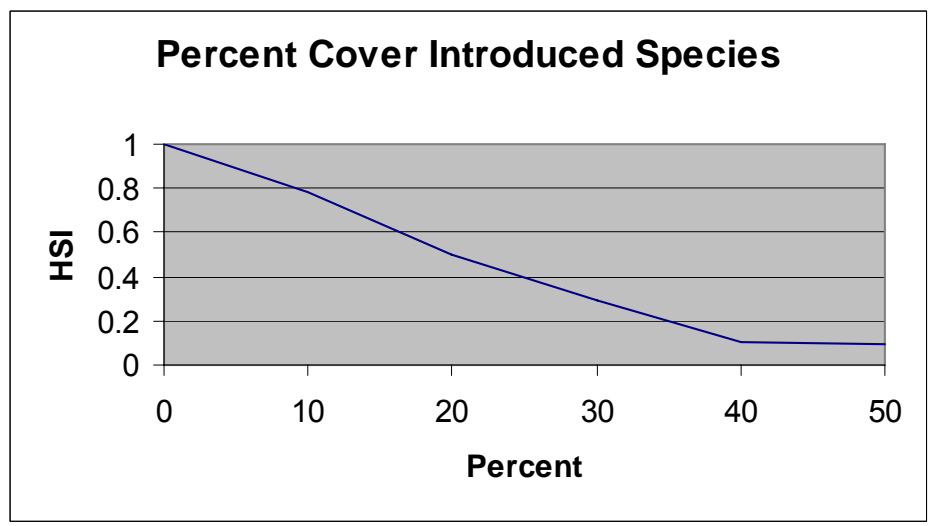


West Foster Creek (Smith) 2007 Follow-up HEP Report

V7: Distance Between Nesting/Brood Rearing and Winter Habitat

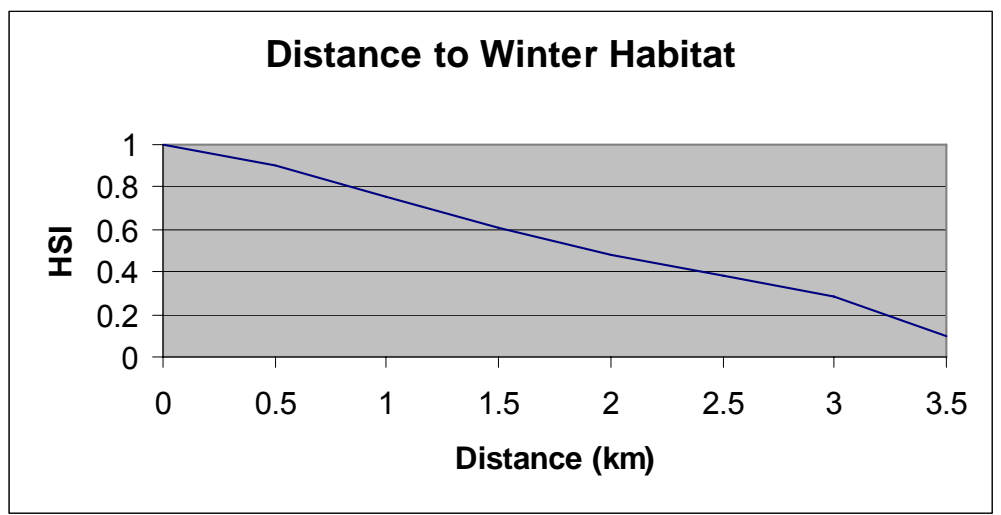

Brood Rearing HSI Equation: $\left[[((\mathrm{V} 3+\mathrm{V} 4) / 2)(\mathrm{V} 6)(\mathrm{V} 7)]^{1 / 3}(\mathrm{~V} 5)\right]$ Nesting/Brood Rearing HSI $=(\text { Nesting HSI } x \text { Brood Rearing HSI })^{1 / 2}$

\section{Winter Habitat}

V8: Percent Cover Deciduous Shrubs and Trees

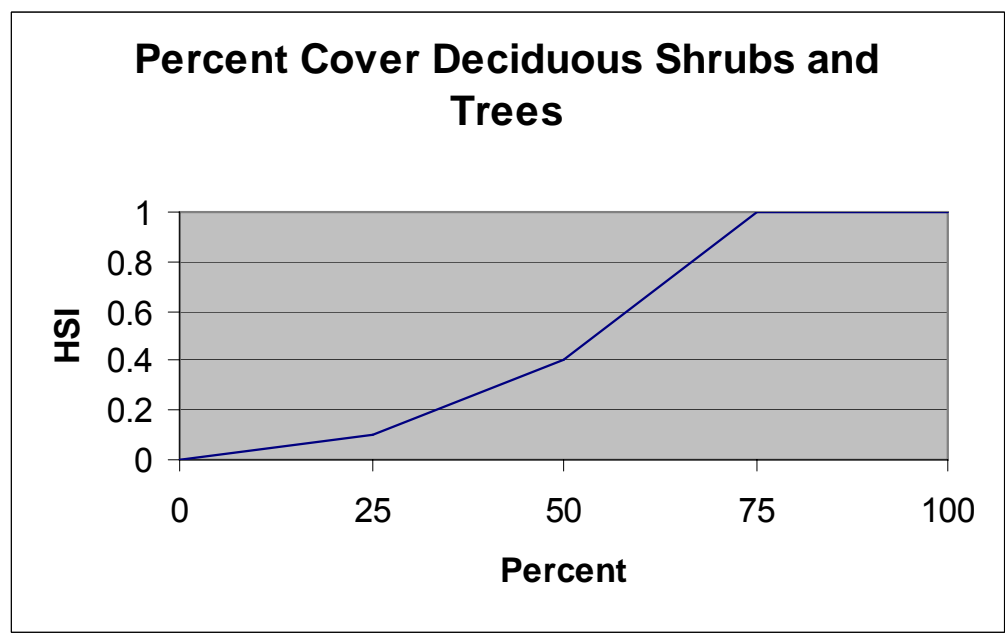

V9: Deciduous Shrub and Tree Composition/Wheat Availability

\begin{tabular}{|c|c|c|}
\hline Attribute & Species & SI \\
\hline Upper Canopy & Water Birch, Aspen, Cottonwood & 0.5 \\
\hline Mid Canopy & $\begin{array}{c}\text { Serviceberry, Hawthorn, } \\
\text { Chokecherry }\end{array}$ & 0.3 \\
\hline Lower canopy & Rose, Snowberry & 0.2 \\
\hline $\begin{array}{c}\text { Agricultural } \\
\text { Fields }\end{array}$ & Standing Wheat or Wheat Stubble & 0.2 \\
\hline HSI & Additive : Not to exceed 1.0 & $1.2=$ \\
& & 1.0 \\
\hline
\end{tabular}


West Foster Creek (Smith) 2007 Follow-up HEP Report

V10: Percent Area Providing Winter Habitat

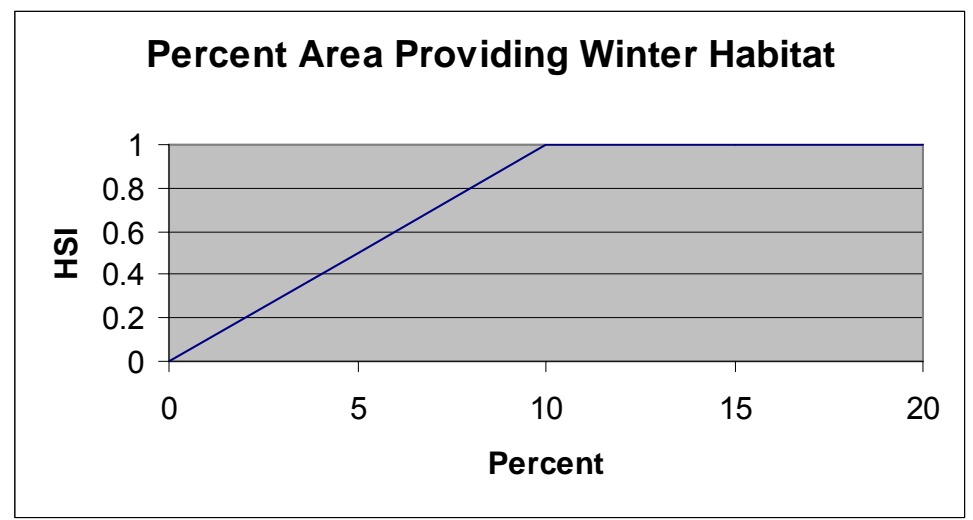

Winter HSI Equation: ((V8 x V9) ${ }^{1 / 2} \times$ V10)

Model HSI: Consists of two HSI's: Nesting/Brood Rearing HSI and Winter HSI.

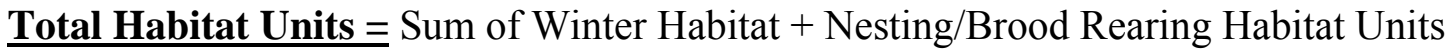


West Foster Creek (Smith) 2007 Follow-up HEP Report

\section{Western Meadowlark}

\section{WESTERN MEADOWLARK}

Modified from Schroeder and Sousa, 1982.

Cover Types: Grassland, Shrubgrass, Shrubland, Pasture, Shrub-steppe

V1: Percent canopy cover of herbaceous plants

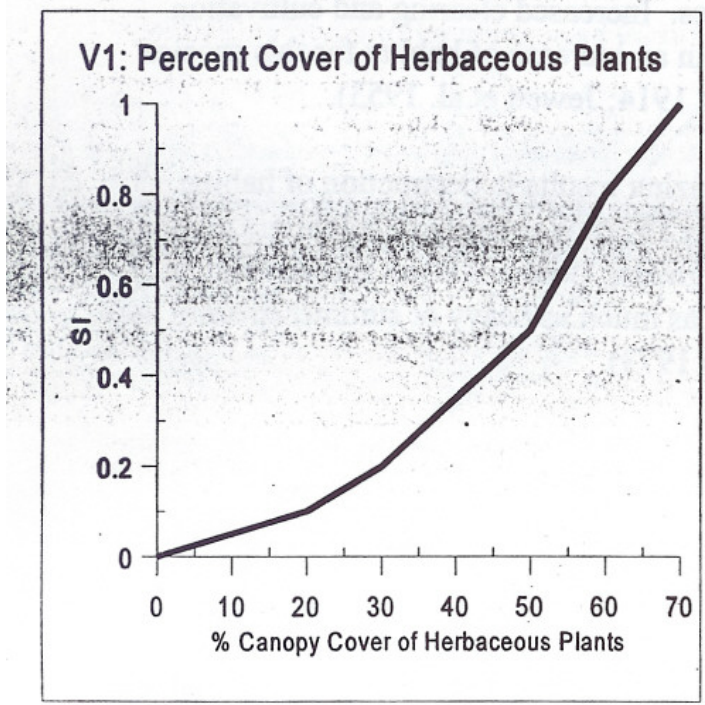

\section{Cover Requirements}

Western meadowlarks are adapted to short grass and mixed grass prairies, preferring large fields with short vegetation and good drainage. Western meadowlarks exhibit tolerance for a wide variety of plant associations and are widely distributed in Washington-commonly occurring in meadows, orchards, thickets, and cultivated areas. Conversion of woodlands to agricultural fields has favored western meadowlark populations in Washington. 
West Foster Creek (Smith) 2007 Follow-up HEP Report

V3: Average height of herbaceous canopy (inches)

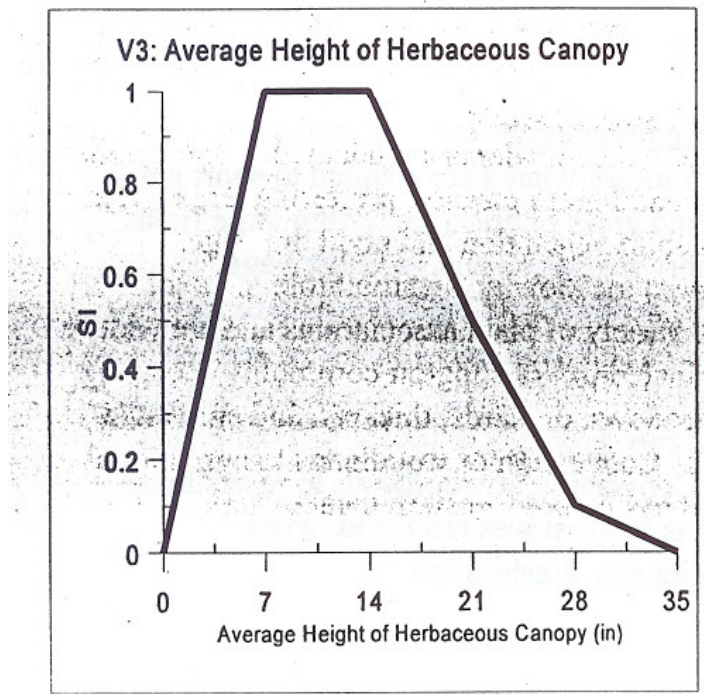

V4: Distance to Perch Sites (feet)

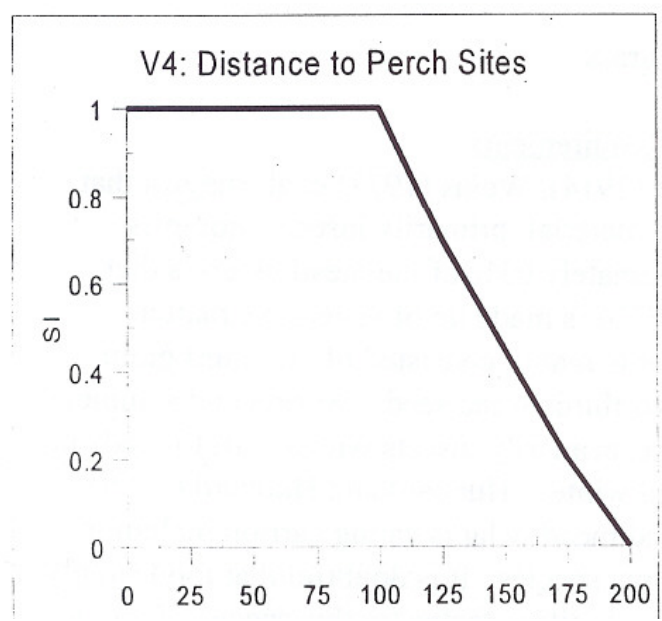

Because of its habitat preferences, western meadowlarks are affected by agricultural activities. Increased clearing and cultivation results in an increase of habitat for this species (Bryant 1914; Jewett et.al. 1953).

Overgrazing results in destruction of habitat (Rohwer 1972, Weins 1973). Light grazing of winter grazing does not affect meadowlark habitat as much as heavy or summer grazing (Weins 1973).

Reproductive Requirements Males require elevated perches, such as shrubs, fence posts, or telephone poles as singing sites. Nests are located on the ground, often in depressions or under shrub cover or tussocks of grass (Bent 1958). 
West Foster Creek (Smith) 2007 Follow-up HEP Report

V5: Percent Shrub Canopy Cover

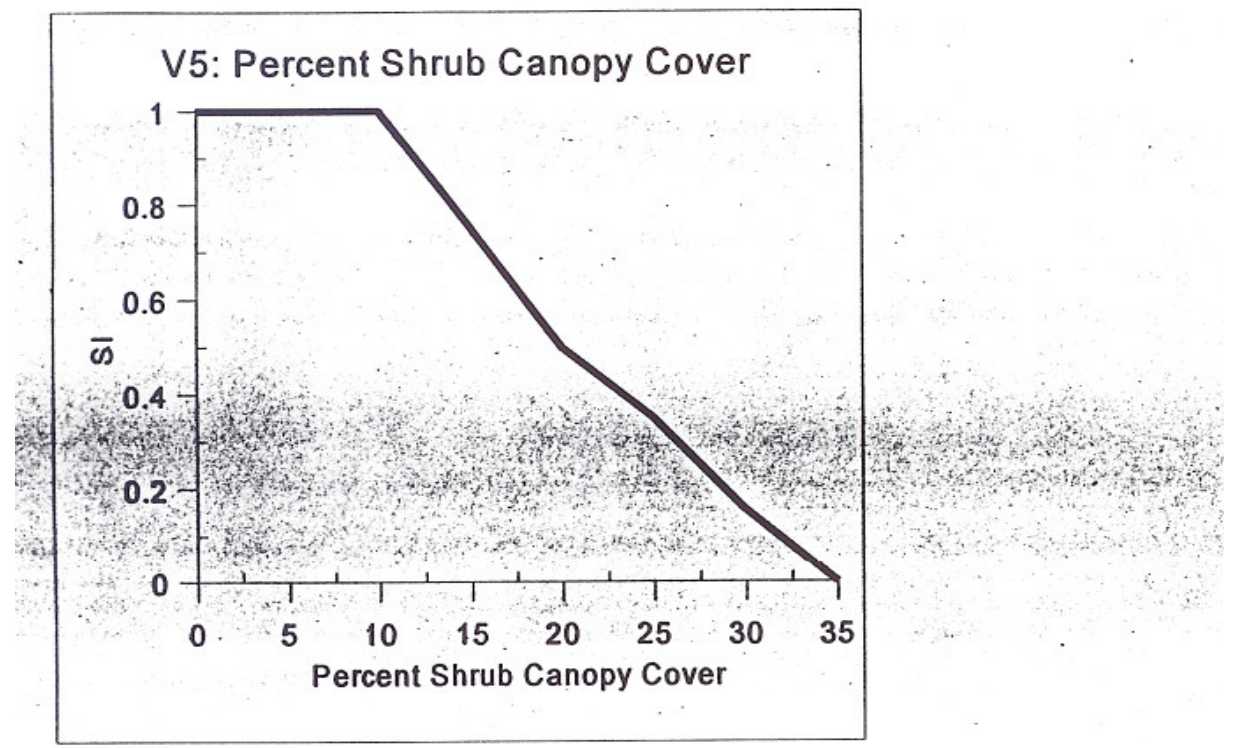

Model Equation:

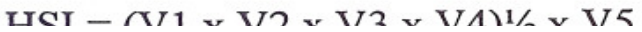

$\mathrm{HSI}=(\mathrm{V} 1 \times \mathrm{V} 2 \times \mathrm{V} 3 \times \mathrm{V} 4)^{1 / 2} \times \mathrm{V} 5$ 


\section{Appendix B - Measurement Protocols}

\section{HABITAT EVALUATION PROCEDURES}

STANDARD MEASUREMENT PROTOCOLS AND TECHNIQUES (Draft)

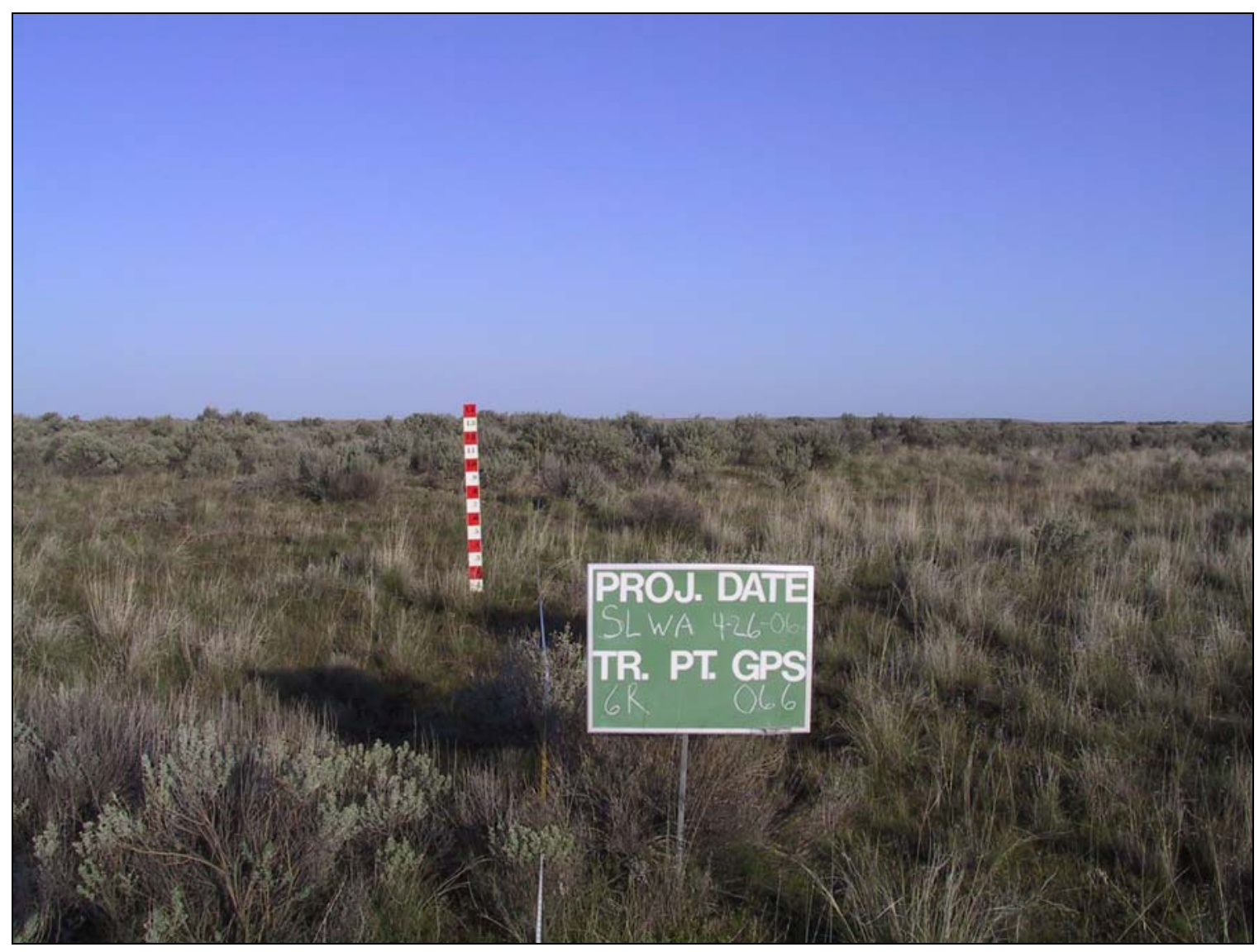

Compiled By

Paul R Ashley - RHT Coordinator

November 2006 
West Foster Creek (Smith) 2007 Follow-up HEP Report

\section{HEP Sampling Design and Measurement Protocols}

\section{Introduction}

This document was developed to fulfill a request by the Upper Columbia United Tribes (UCUT) and Bonneville Power Administration (BPA) to develop a "stand alone" reference for Habitat Evaluation Procedures (HEP) transect protocols used by the Regional HEP Team (RHT). General and specific protocols are described. General protocols include a brief description of pre HEP survey pilot studies; transect establishment guidelines, and photo documentation parameters. In contrast, specific metrics detail actual habitat variable measurement techniques including diagrams where additional explanation is needed.

Specific metrics are identified with an alpha-numeric code. This allows project managers and others to identify specific measurement techniques in report tables without lengthy, redundant explanations. This report is intended to be a "living" document and will be modified as needed. The following standardized protocols and measurement techniques are used by the Regional HEP team to measure habitat variables described in HEP models.

\section{General Protocols}

\section{Pilot Studies}

Pilot studies are conducted in new habitat types and/or familiar habitat types that are comprised of unique structural conditions/key ecological correlates. Pilot study data is used to estimate the sample size needed for a confidence level $\geq 80 \%$ with a $10 \%$ tolerable error level (Avery 1994) and to determine the most appropriate sampling unit ${ }^{11}$ for the habitat variable of interest i.e., a coefficient of variation analysis (BLM 1998). In addition, a power analysis is conducted on pilot study data (and periodically throughout data collection) to ensure that sample sizes are sufficient to identify a minimal detectable change of $20 \%$ in the variable of interest with a Type I error rate $\leq 0.10$ and $\mathrm{P}=0.9$ (BLM 1998, Block et al. 2001). All field data is recorded on data loggers or data sheets and downloaded/transferred to data summary spreadsheets.

Transects

Transect cover sheets are used to document specific transect information including transect identification, cover type, HEP Team members, global positioning system (GPS) coordinates, and other pertinent information.

Transects are established at least 300 feet (100 meters), where possible, from ecotones, roads, and other anthropogenic influences. Transect starting points and azimuths (direction) are randomly selected for each cover type. Start points are selected based on superimposing a UTM grid over cover type maps and identifying specific X/Y coordinates with the aid of a random numbers table, or computer generated random number generator/point locater program.

\footnotetext{
${ }^{11}$ Includes micro-plot grid size and shape etc.
} 
Transect start, turn, and end points are marked with 14-inch (36 centimeter) 0.25 inch ( 0.6 centimeter) diameter rebar stakes ${ }^{12}$ painted fluorescent orange or red. GPS positions (UTM coordinates-NAD 27) are recorded at start, turn, and end points. If cover types change or transect length is greater than 300 feet, another transect azimuth is randomly selected, or the original azimuth is varied by 45 degrees (direction [left or right] is determined by the flip of a coin where more than one choice is possible). Compass azimuths (headings) are magnetic bearings i.e., not corrected for local declination. Transects are divided into 100 foot (30 meter) sample units for statistical purposes.

\section{Photo Points}

Photo points are established at the start point of each transect. Pictures are recorded from a height of three feet at the beginning of each transect while facing in the direction of the transect azimuth. A transect reference board (includes transect number, project name, date, GPS reference number) is placed at the 15 foot interval while a cover board is placed at the 30 foot mark on each transect. Occasionally, panoramic photographs are also needed e.g., dense vegetation, linear/narrow cover types. Habitat conditions are photographed with a Canon G1 ${ }^{\circledR} 3.3$ mega pixal digital camera (with and without magnification).

\section{Specific Metrics}

Metrics generally follow those described by Hays et al. (1981) and/or Avery (1994) unless otherwise noted. Some metrics have been modified due to extreme field conditions and/or to better meet Regional HEP Team needs.

\section{Herbaceous Measurements}

\section{Percent Cover}

1. Herbaceous percent cover measurements are recorded at 20 or 25 -foot intervals on the right side of the transect tape (the right side is determined by standing at 0 feet and facing the line of travel/transect azimuth). RHT members walk on the left side of the transect line to reduce sample disturbance. A square $0.1 \mathrm{~m}^{2}$ micro-plot grid is used in grasslands to estimate percent cover of herbaceous vegetation while a rectangular $0.5 \mathrm{~m}^{2}$ grid is generally used in shrublands (the $0.5 \mathrm{~m}^{2}$ grid may also be used in grasslands if desired). The near right hand corner of the grid is placed at the sampling interval (rectangle grids are placed with the long axis perpendicular to the tape, and the lower right corner on the sampling interval). An example of micro-plot grid placement is shown in Figure 1. Approximately $20 \%$ of the micro plot is covered by vegetation in the example. Grid samples are considered independent samples for statistical purposes.

1A: $0.1 \mathrm{~m}^{2}$ micro-plot grid/20' interval

\footnotetext{
${ }^{12}$ Marking transect points with rebar stakes is at the discretion of the project proponent. Therefore, not all transects are marked in this manner.
} 
1B: $0.1 \mathrm{~m}^{2}$ micro-plot grid $/ 25$ interval

1C: $0.5 \mathrm{~m}^{2}$ micro-plot grid/20' interval

1D: $0.5 \mathrm{~m}^{2}$ micro-plot grid $/ 25$ ' interval

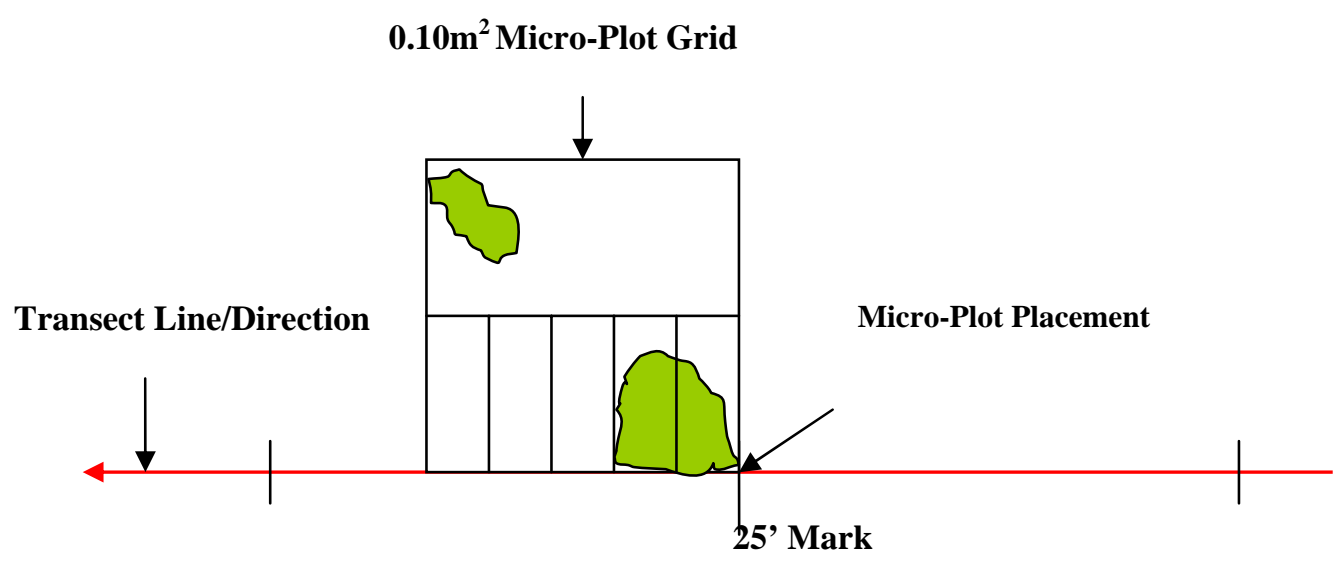

Figure 1. Micro-plot grid placement and percent cover example.

\section{Height}

2. Herbaceous height is measured with a measuring rod placed within the grid frame (scale $=10$ ths $/ \mathrm{ft}$.). Three evenly spaced measurements are recorded and averaged for each sample. Only leaf material is measured (leaves provide the greatest amount of cover). "Leaf material" may include residual cover and/or new growth predicated on HEP model variable requirements. Grass inflorescence is not included in height measurements.

2A. Four measurements, one from each corner of the micro plot grid, are recorded and averaged for each sample. Only leaf material is measured (leaves provide the greatest amount of cover). Grass inflorescence is not included in height measurements.

2B. A measuring rod is held vertical at the interval point: the highest vegetation to cross the measuring rod at that point is measured to the nearest tenth of a foot.

2B-1: 10' interval

2B-2: 20' interval

2B-3: 25 ' interval

\section{Visual Obstruction Readings (VOR)}


3. A Robel pole (Robel 1975) is used to document vertical and/or horizontal cover for herbaceous vegetation i.e., visual obstruction readings (VOR). Measurements are recorded at 20,25, or 50-foot intervals. Intervals are determined by the length of each transect, i.e., a minimum of 12 measurements are required for each transect, or cover type heterogeneity (structurally diverse cover types generally require larger sample sizes).

The Robel pole (Robel 1975) is placed on the transect line at the appropriate interval. Four observations are taken from a distance of four meters from the Robel pole and averaged to obtain a single visual obstruction reading or VOR. Observers sight over a one meter pole and record how much of the Robel pole is totally obscured from the ground up (Figure 2). Measurements are reported in 0.25 decimeter increments.

Two measurements are taken on the transect line on opposite sides of the Robel pole; two identical measurements are taken from the same point perpendicular to the transect line for a total of four "readings" (Figure 3). Sample size is determined to be adequate when the "running mean" varies $\leq 10 \%$ of the mean. VOR samples are considered independent for statistical purposes.

3A: 20 ' interval

3B: 25 ' interval

$3 \mathrm{C}$ : 50 ' interval

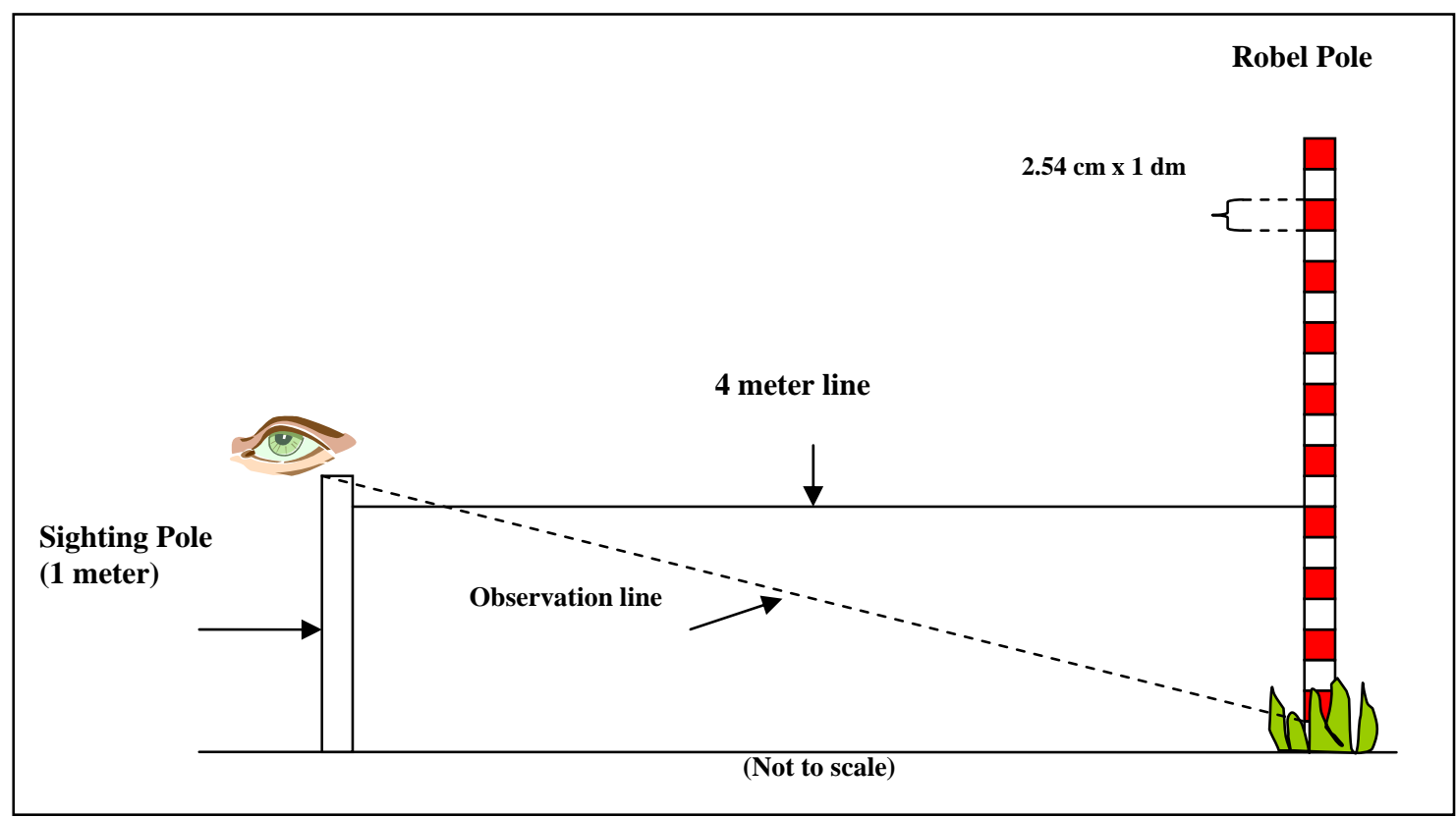

Figure 2. Visual obstruction reading diagram. 


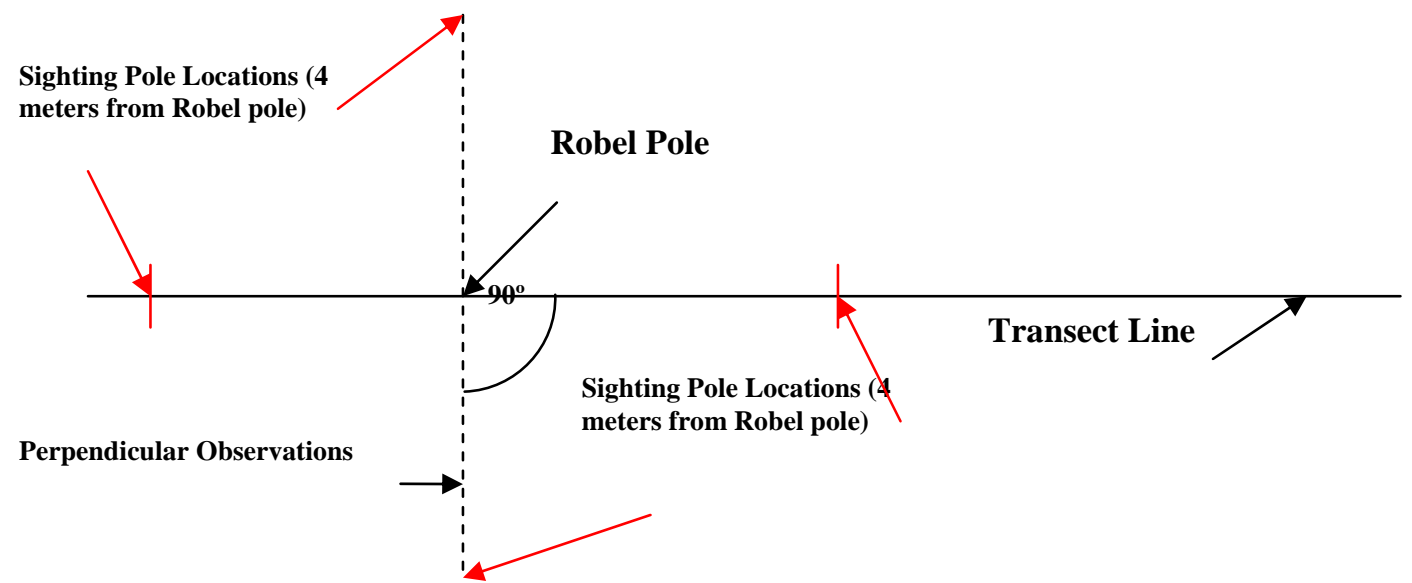

(“Birds eye” View)

Figure 3. Robel pole "readings" layout diagram.

\section{Shrub Measurements}

\section{Percent Cover}

4. Line intercept or point intercept (USFWS 1981) is used to determine shrub cover. Line intercept is generally used when shrub cover is estimated at $<5 \%$ (the most accurate results are obtained using the line intercept method). In contrast, the point intercept method is used if shrub cover is estimated at $>5 \%$.

4A: Line intercept is used to measure the amount of cover that intercepts the transect line as illustrated by the red lines shown in Figure 4. Measurements are in $10^{\text {ths }}$ of feet. Gaps in vegetation less than four tenths of a foot (5 inches) are ignored. The amount covered by shrubs is added to determine shrub intercept for each transect. For example, if 7.5 feet of a 100 -foot long transect is covered by shrubs, percent cover is $7.5 \%$.

Shrub cover is recorded by species. Where shrubs overlap, shrub intercept is recorded for the tallest shrub and noted for the lower shrub(s). 


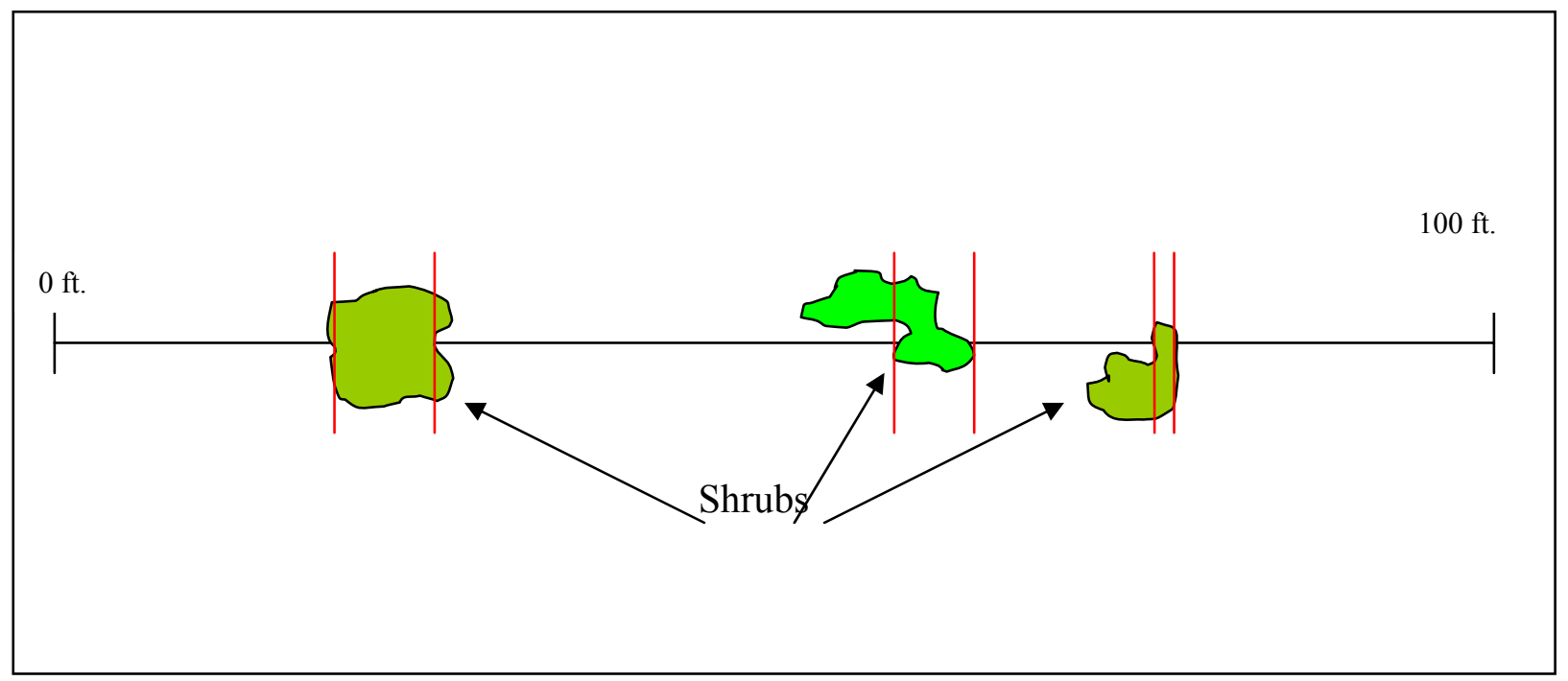

Figure 4. Line intercept method example.

4B: Point intercept is used when shrub canopy cover is estimated at $\geq 5 \%$. Shrub cover is determined by recording the number of "hits" at specific intervals along a transect line. To be counted as a "hit", a portion of the shrub must cross the transect tape's interval number line e.g., 2', 4', 6'... nth. If a portion of the shrub does not break the vertical plane at the interval number line, it is reported as a miss (Figure 5). Either a "hit" or "miss" is recorded on data loggers and/or paper data sheets for each designated interval.

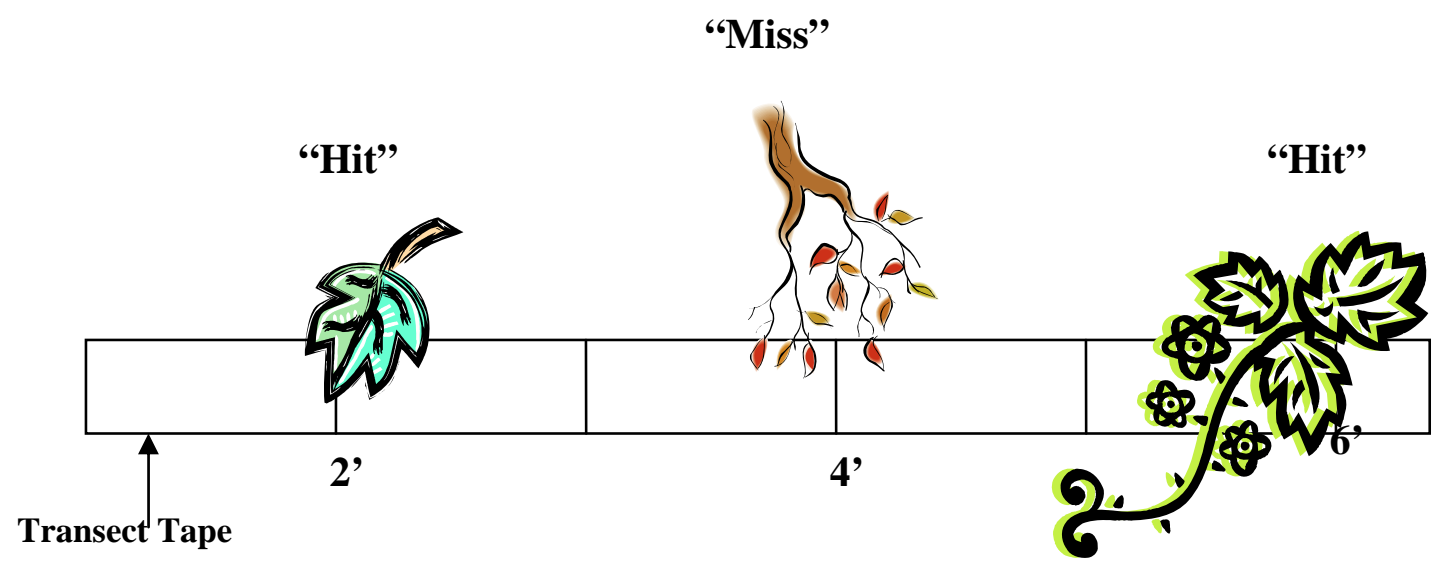

Figure 5. Point intercept method example showing "hits" and "misses" at two foot intervals. 
From $5 \%$ to $20 \%$ cover, point data is collected at two-foot intervals (50 possible "hits" per $100 \mathrm{ft}$. sample unit). If shrub cover is estimated at $>20 \%$, shrub point data is collected at five foot intervals (20 possible "hits" per 100 $\mathrm{ft}$. sample unit). On rare occasions, ten-foot intervals may be used when shrub cover exceeds 50\% (10 possible "hits" per $100 \mathrm{ft}$. sample unit). The ten-foot interval is generally applied to shrub monocultures, or areas with few shrub species that exhibit relatively equal shrub distribution/density.

Shrub "hits" are recorded by species. Where shrubs overlap, shrub intercept is recorded for the tallest shrub and noted for the lower shrub(s).

4B-1: 2' interval

4B-2: 5 ' interval

4B-3: 10' interval

4C: Modified point method is used when shrub cover is impenetrable or otherwise inaccessible. A baseline transect is established along the shrub edge. A six-foot measuring rod is then inserted into the shrub cover at right angles to the baseline tape at appropriate intervals. Recorders estimate shrub "hits", species information, and height data where the end of the six-foot measuring rod intercepts the shrub cover (Figure 6). As with point intercept, intervals may very. Shrubs are identified by species.

4C-1: 2' interval

4C-2: 5 ' interval

4C-3: 10' interval

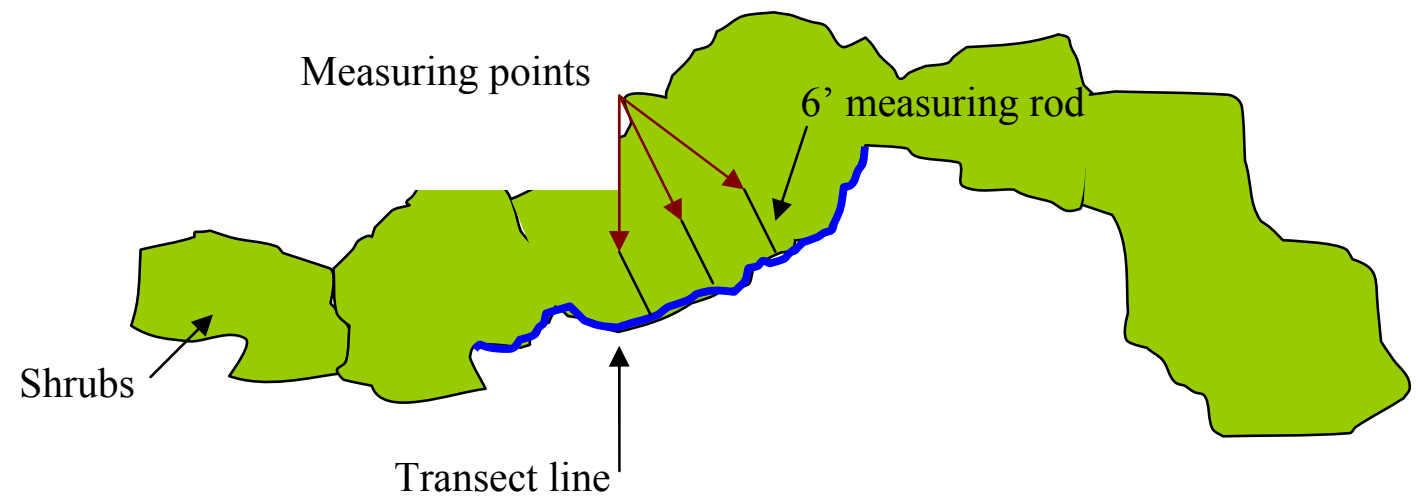

Figure 6. Modified point intercept layout example. 
4D: Complex shrub intercept is used to determine percent shrub cover in multi strata shrub communities. This method is generally associated with point intercept methods whereas overlapping shrubs are identified for each stratum. Percent cover is determined for each of four possible strata as well as total percent shrub cover and overlapping percent cover.

The complex shrub intercept method is identified by adding the suffix "4D" after the appropriate line or point intercept method. For example, "4B-1-4D designates that complex shrub point intercept measurements were taken at two foot intervals. Similarly, 4C-2-4D designates that modified point intercept at five foot intervals was used to determine percent shrub cover for strata in a complex shrub community.

\section{Shrub Height}

5. Shrubs are defined as woody vegetation including trees $<16$ feet in height unless otherwise defined in HEP models. The Regional HEP Team assumes that trees $<16$ feet tall function ecologically more like shrubs than trees.

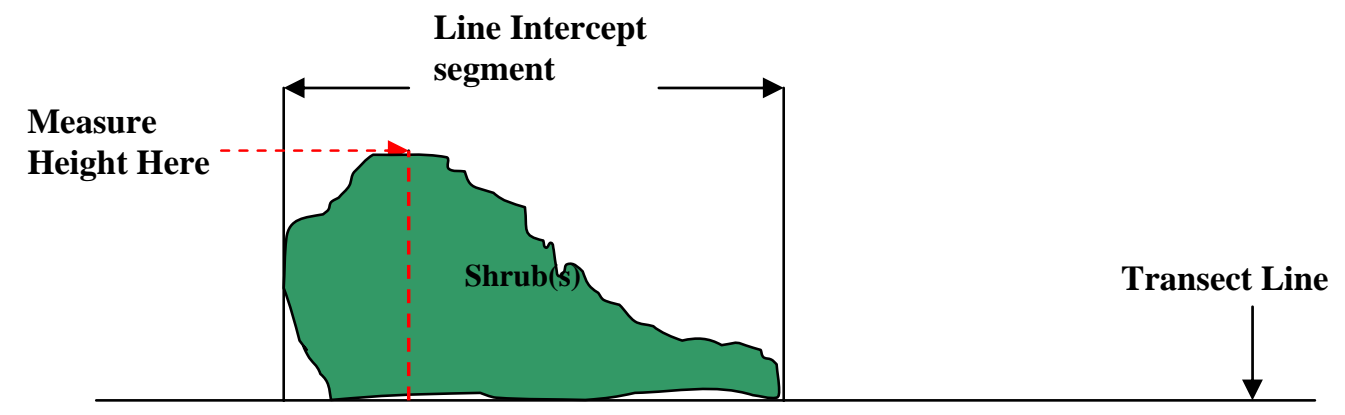

Horizontal View

Figure 7. Line intercept shrub height measurement example.

Shrub height is measured in $10^{\text {ths }}$ of feet at the highest point for each uninterrupted line intercept segment as depicted in Figure 7, or the highest point that crosses each point intercept interval mark on the transect tape (Figure 8).

In structurally complex (overlapping) shrub communities, height is measured for each stratum (maximum of four) as illustrated in Figure 9. It is assumed that shrub height measurements correspond to the method used to determine percent shrub cover. For example, if percent shrub cover is determined using the line intercept 
method (Figure 4), then it is assumed that shrub height will be obtained as illustrated in Figure 7.

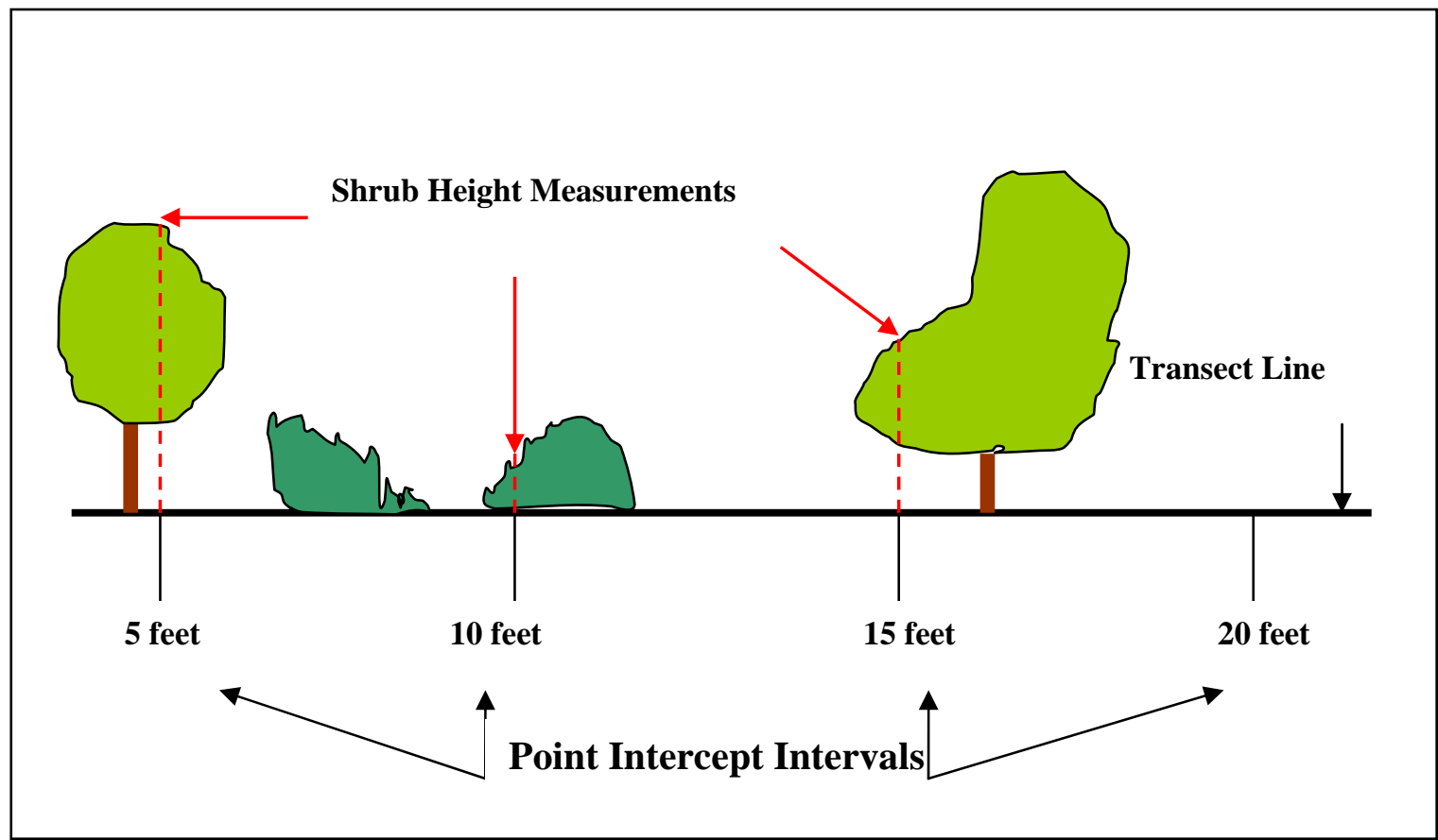

Figure 8. Point intercept shrub height example.

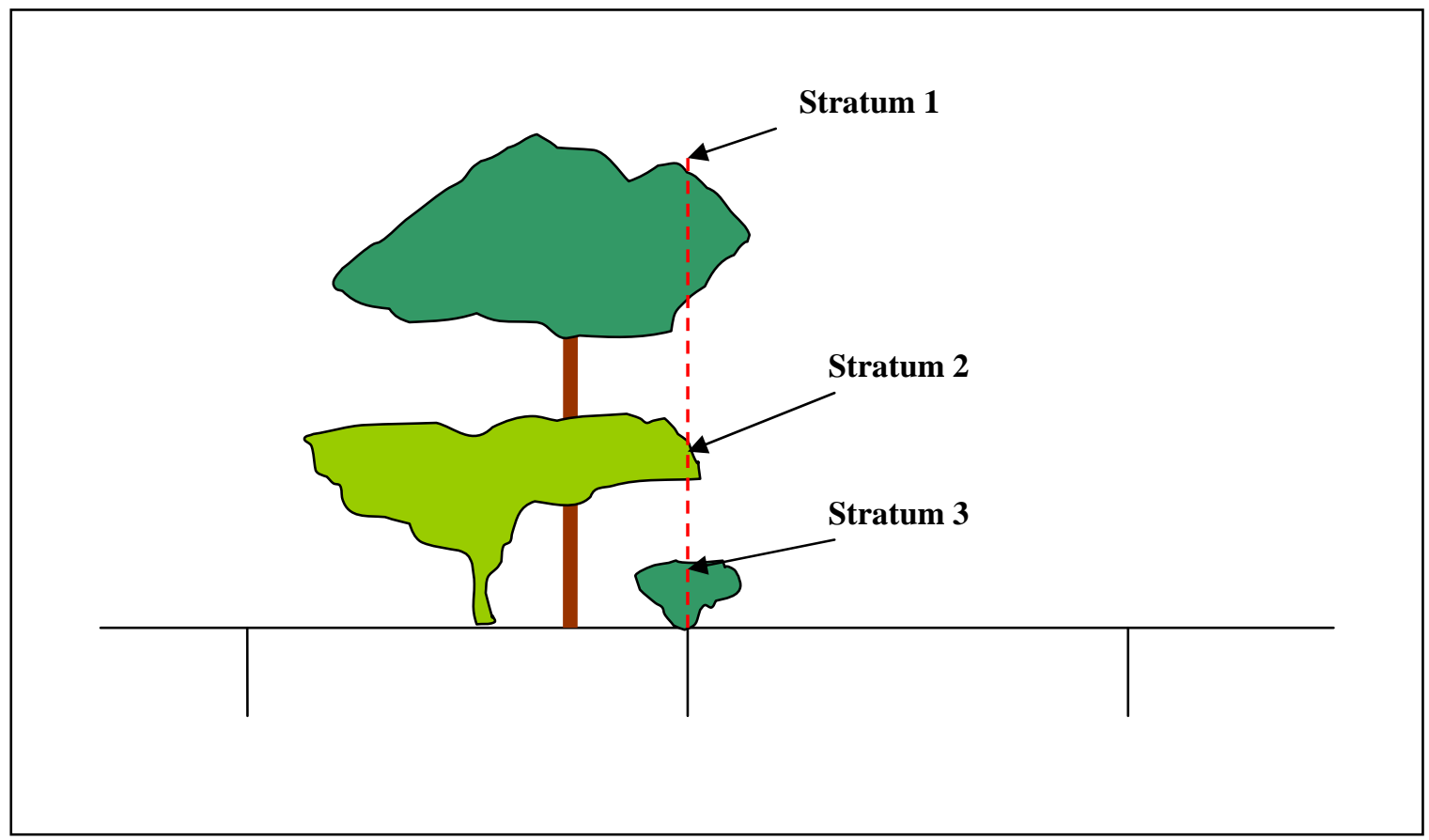

Figure 9. Complex shrub community shrub height measurement example. 
West Foster Creek (Smith) 2007 Follow-up HEP Report

\section{Tree Measurements}

\section{Percent Canopy Cover}

6. Tree canopy cover measurements are recorded at five or ten foot intervals with a densitometer (point intercept). Measurement intervals are determined by visually estimating tree canopy closure prior to initiating the survey. If estimated canopy closure is $<20 \%$ and estimated transect length $\leq 900$ feet, measurements are recorded at five-foot intervals; if estimated canopy closure is $>20 \%$ and estimated transect length is $\geq 600$ feet, ten-foot intervals are used. The size of the sample area strongly influences transect length. In small areas, data from several short (300 foot) transects may be "pooled" in order to determine percent tree canopy cover. As with shrubs, sampled trees are identified by species and the sampling unit is a 100 foot segment of the transect.

6A: 5 ' interval

6B: 10' interval

\section{Height}

7. Tree height is determined generally using a clinometer. In open areas, an electronic height measurement instrument may be used. Measurements are taken at the beginning and end of each transect and at 100 foot intervals. Additional samples may be taken if needed. HEP model variable requirements determine the extent of tree height measurements e.g., multi-canopy, overstory, etc.

Basal Area

8. Tree basal area data is collected at 100-foot intervals using a "factor 10" prism. Each 100-foot interval basal area observation (all tree "hits" at each 100-foot point) is considered an independent sample.

\section{Snag DBH}

9. Snag data is collected on belt transects. RHT members collect snag data in conjunction with tree canopy closure measurements using the same baseline transect. The diameter breast height (DBH) of all snags present within tenth-acre belt transects paralleling the baseline transect is measured. Either the actual DBH is recorded, or snag data is reported by class e.g., 5 snags $<4$ " DBH, 2 snags $>20$ " DBH etc.

Belt transects are 44 feet wide by 100 feet long i.e., 22 feet on each side of the baseline transect. Belt transect layout is depicted in Figure 10. As with shrubs and trees, the sampling unit is each 100-foot segment. 


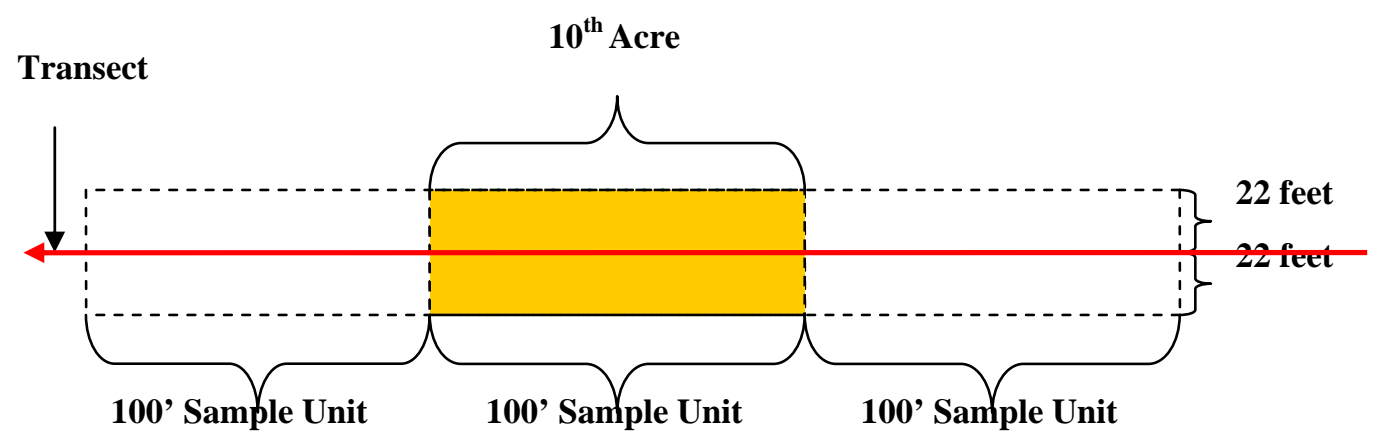

Figure 10. Belt transect layout diagram.

\section{Sample Size Determination}

The process for determining sample size (transect length) varies based on the variable measured. Shrub and tree cover and grid sample sizes are estimated as follows:

The amount of cover within each 100 foot sample unit is divided by sample unit length to obtain percent shrub/tree cover per sample unit (e.g. 10 feet of cover/100 feet $=10 \%$ shrub cover). The standard deviation for each transect is calculated for percent cover data from transect sample units. Sample size (transect length) is then determined through use of the following equation (Avery 1994):

$$
\mathrm{n}=\frac{\mathrm{t}^{2} \mathrm{~s}^{2}}{\mathrm{E}^{2}}
$$

Where: $\mathrm{t}=\mathrm{t}$ value at the 95 percent $(0.05)$ confidence interval for the appropriate degrees of freedom $(\mathrm{df}) ; \mathrm{s}=$ standard deviation; and $\mathrm{E}=$ desired level of precision, or bounds ( \pm 10 percent). Confidence intervals may vary from 80 percent $(0.20)$ to 95 percent $(0.05)$ depending on habitat variable heterogeneity and project management needs. The same method is used to determine sample size for micro plot samples based on total percent cover for herbaceous species. 


\section{References}

Avery, T.E., H. E. Burkhart. 1994. Forest measurements. $4^{\text {th }}$ edition. John Wiley and Sons. New York, NY.

BLM. 1998. Measuring and monitoring plant populations. BLM Technical Reference 1730-1. BLM National Business Center. Denver, CO. 477 p.

Block, W.M., W.L. Kendall, M.L. Morrison, and M. Dale Strickland. 2001. Wildlife study design. Springer Press. New York, NY. 210 p.

Hays, R. L., C. Summers, and W. Seitz. 1981. Estimating habitat variables. Western Energy and land Use Team. Fort Collins, CO: U.S. Fish and Wildlife Service.

Robel, R.J., J. N. Dayton, A.D. Hulbert. 1975. Relationship between visual obstruction measurements and weight of grassland vegetation. Journal of Range Management. 23: 295. 
West Foster Creek (Smith) 2007 Follow-up HEP Report

\section{Appendix C - Transect Location Maps}

(Expanded scale - from north to south; coordinate locations were downloaded directly from GPS units)

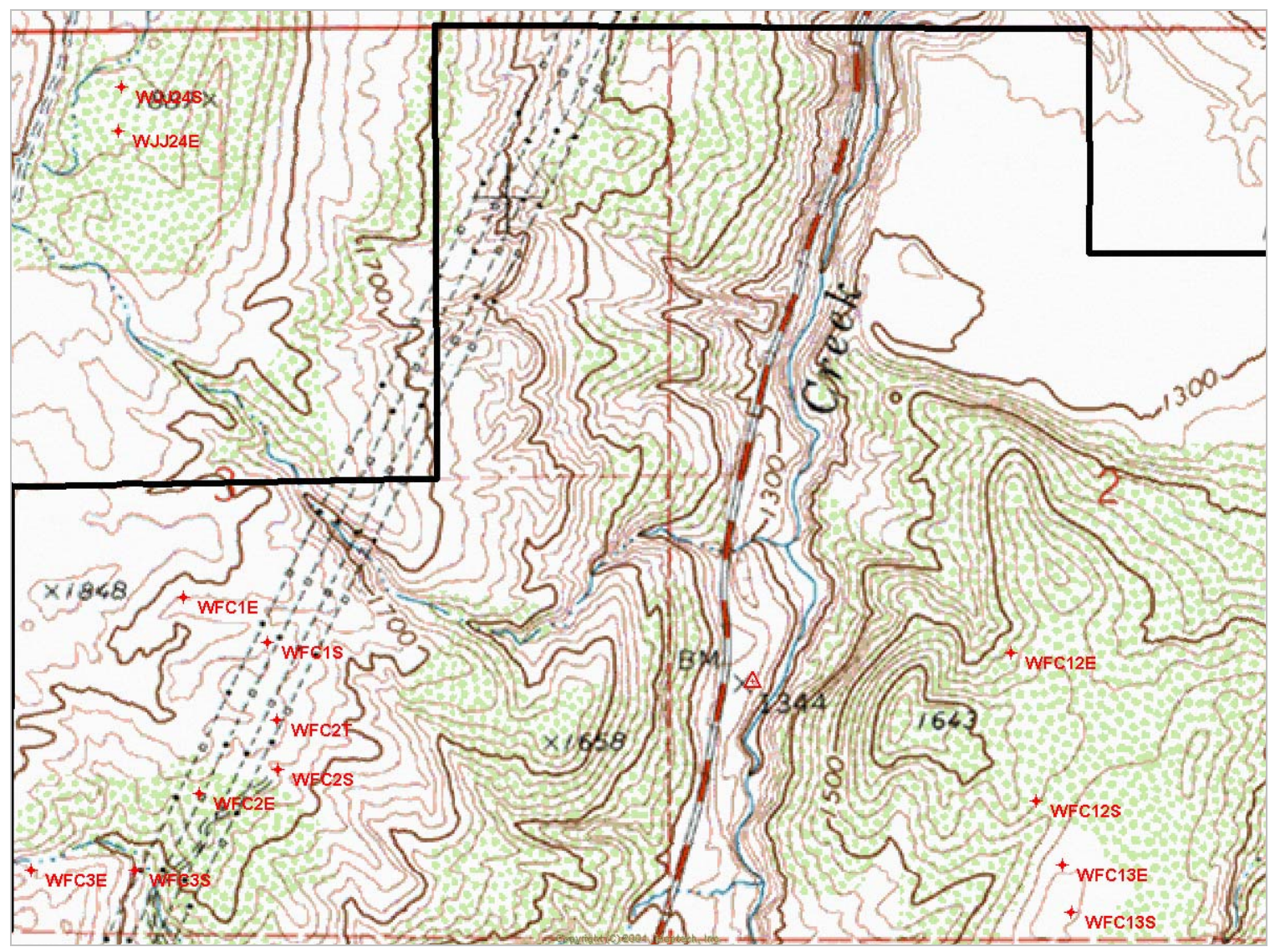


West Foster Creek (Smith) 2007 Follow-up HEP Report

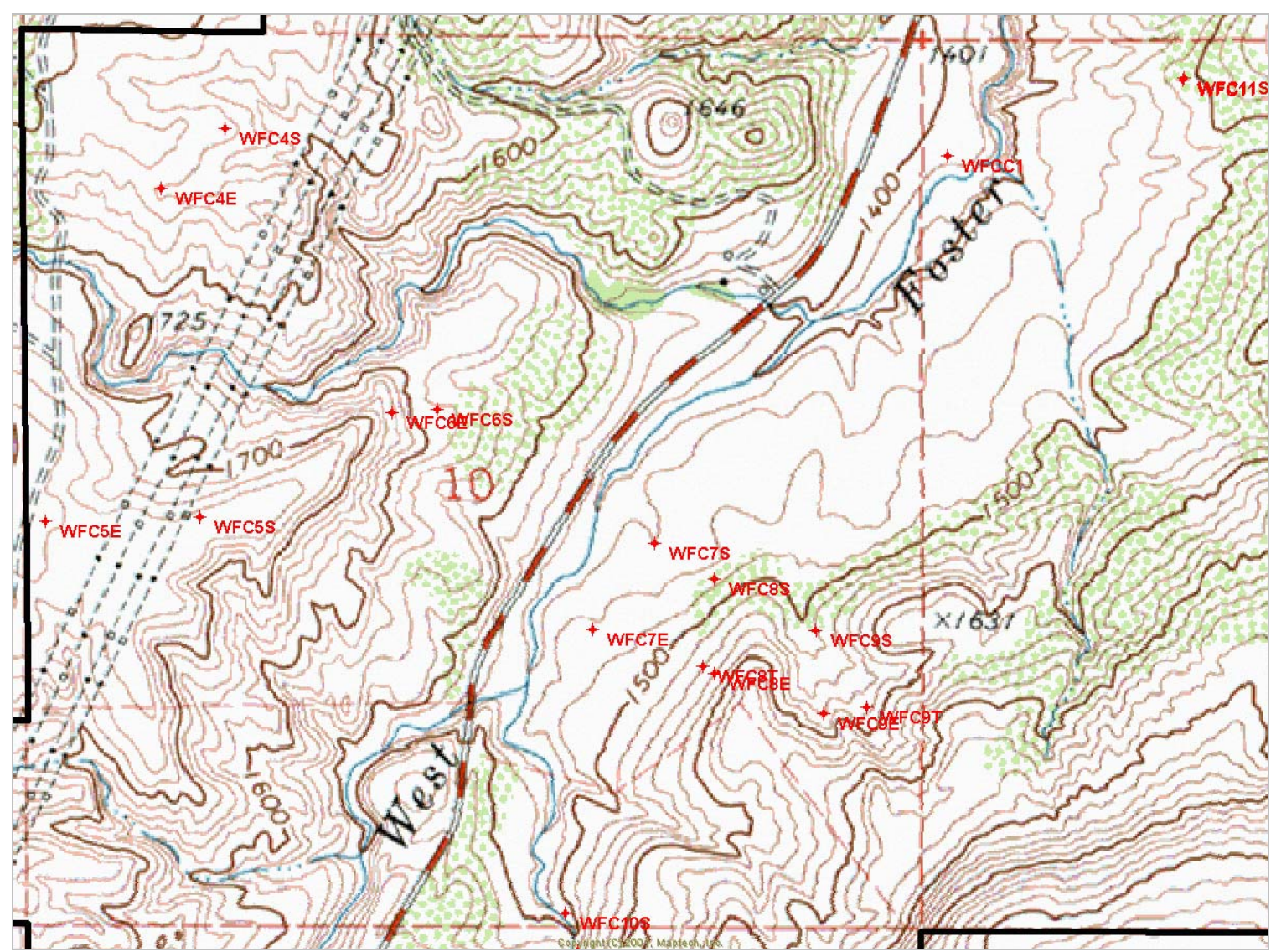


West Foster Creek (Smith) 2007 Follow-up HEP Report

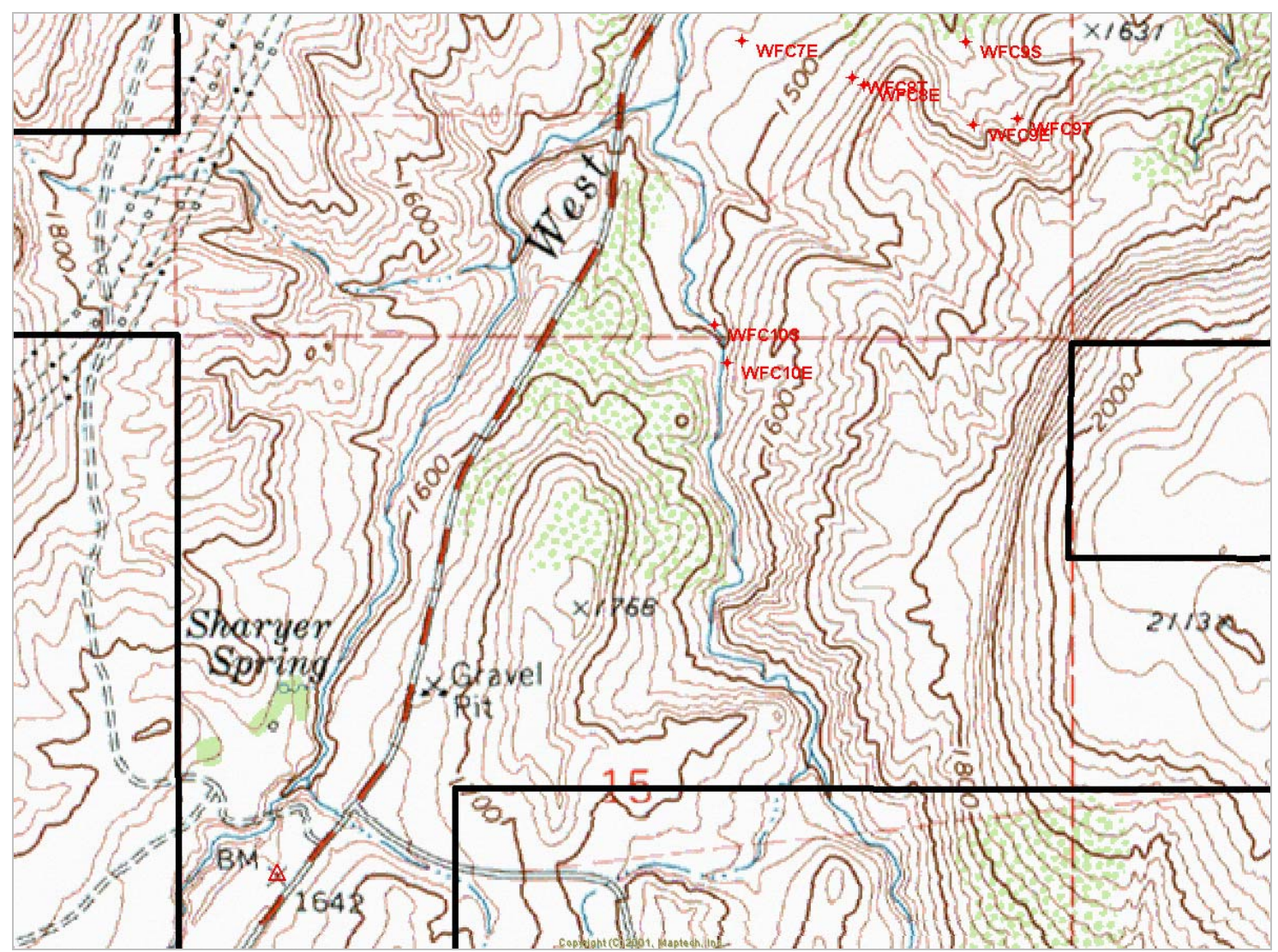


West Foster Creek (Smith) 2007 Follow-up HEP Report

\section{Appendix D - Transect Photographs}

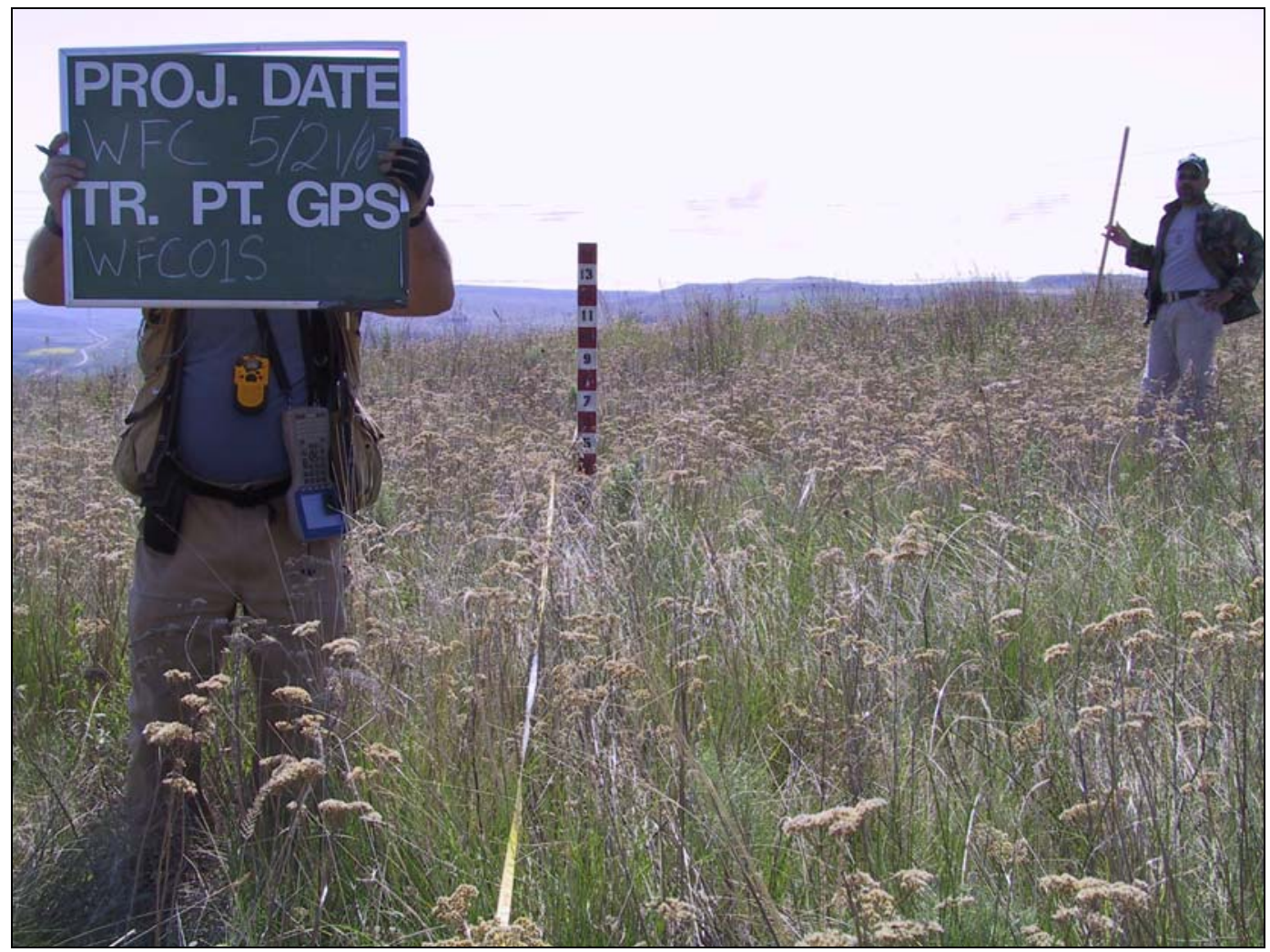

Figure 22. Transect 1 photograph 
West Foster Creek (Smith) 2007 Follow-up HEP Report

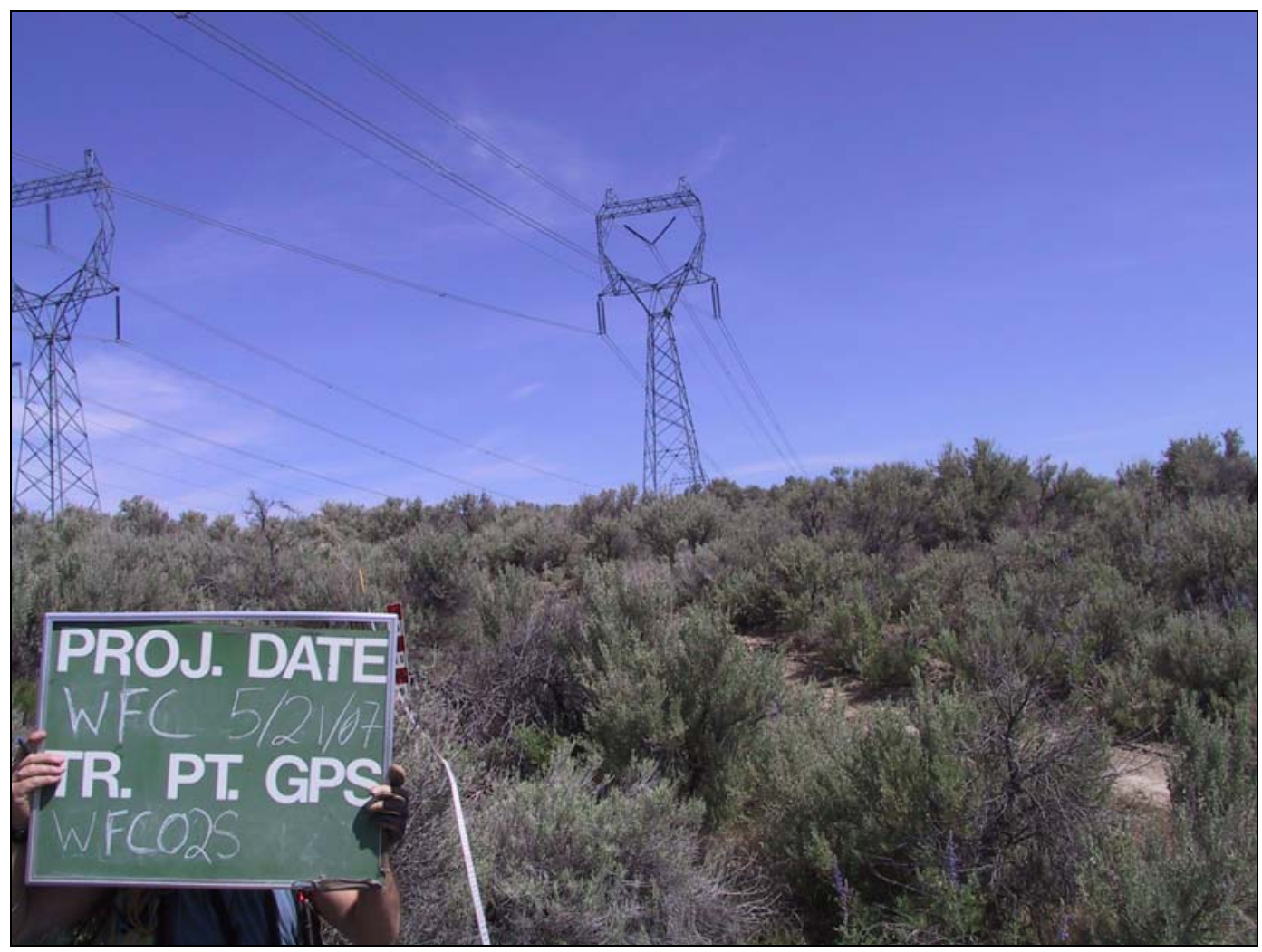

Figure 23. Transect 2 photograph

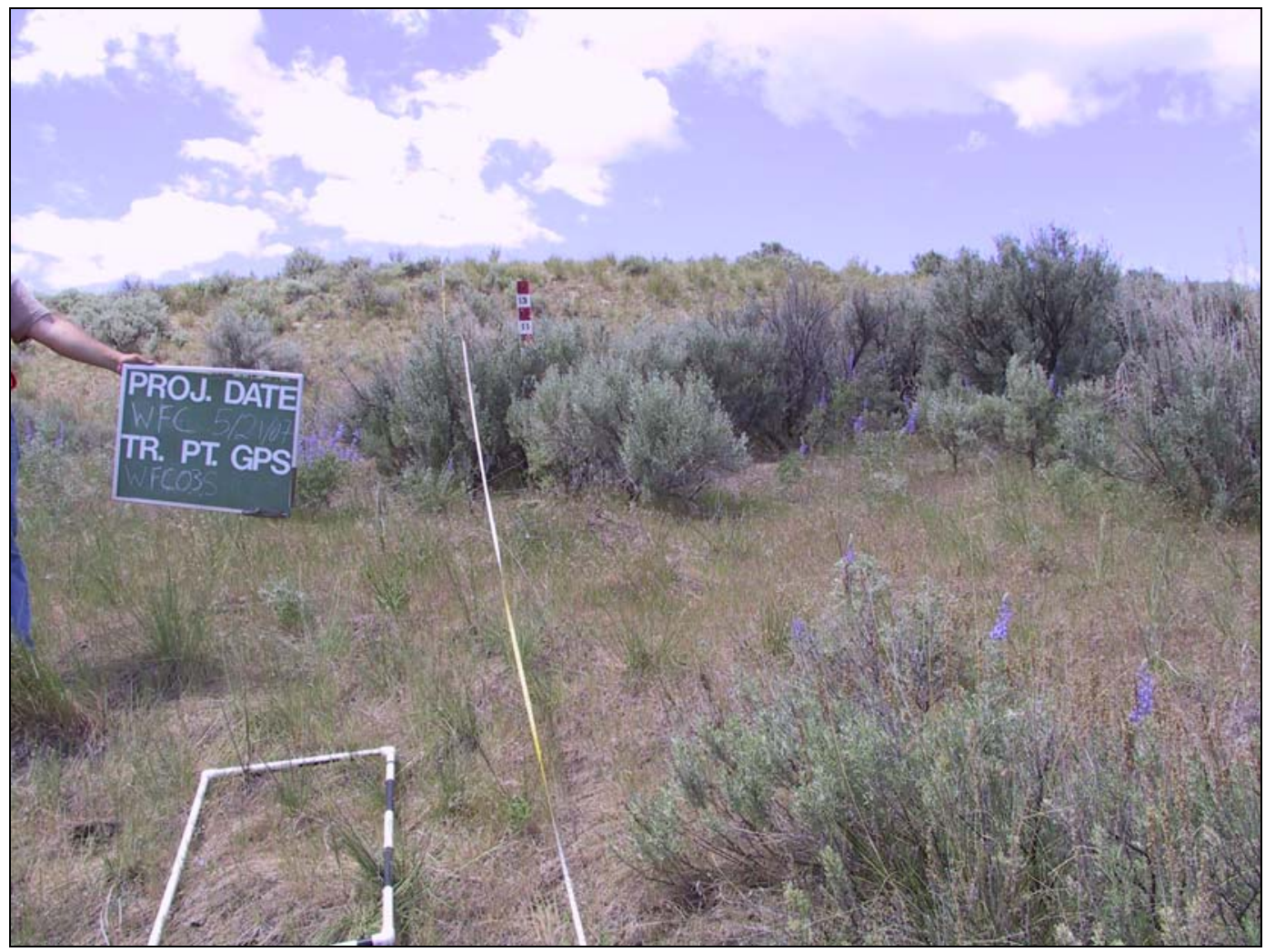

Figure 24. Transect 3 photograph 
West Foster Creek (Smith) 2007 Follow-up HEP Report

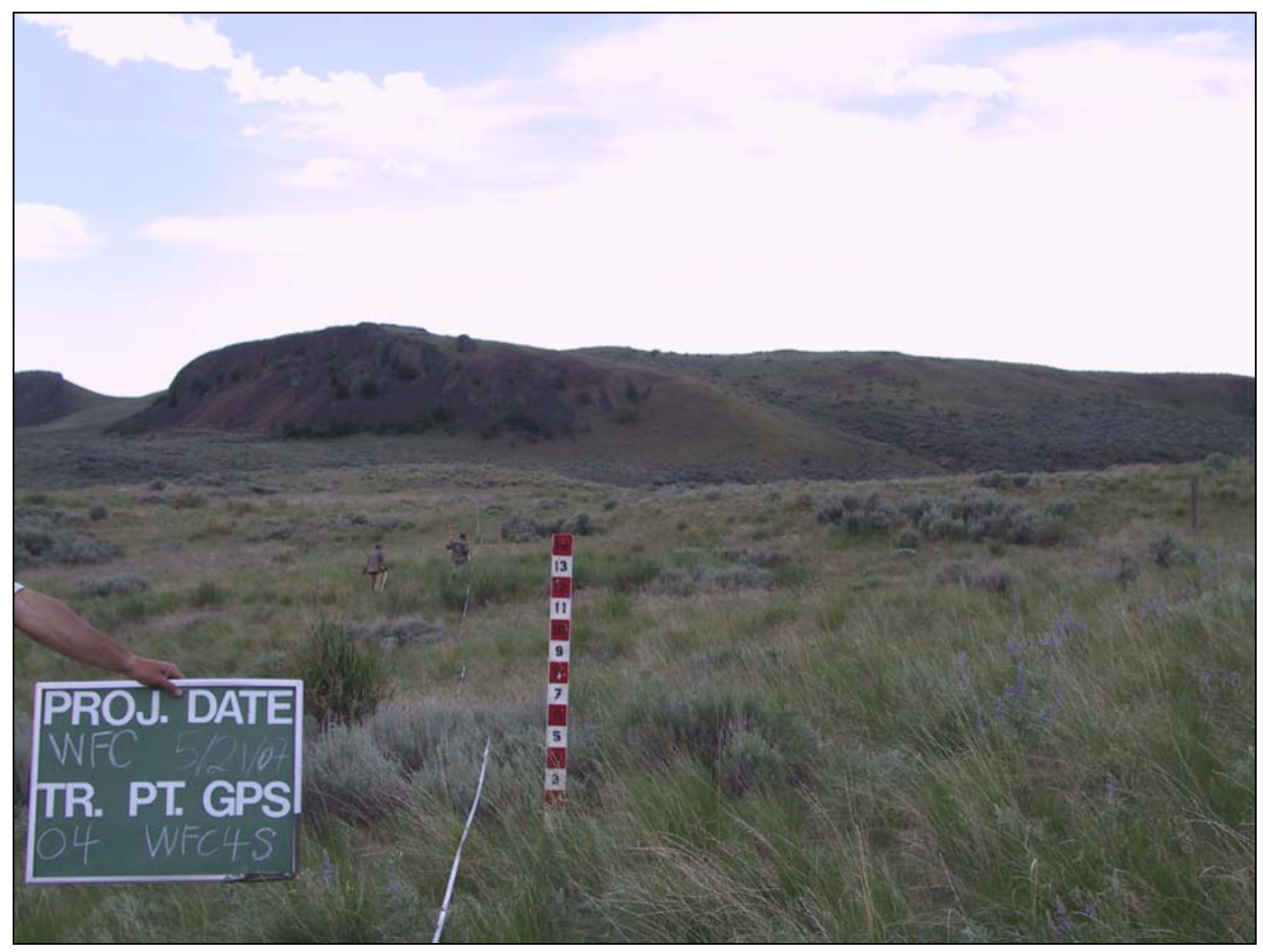

Figure 25. Transect 4 photograph

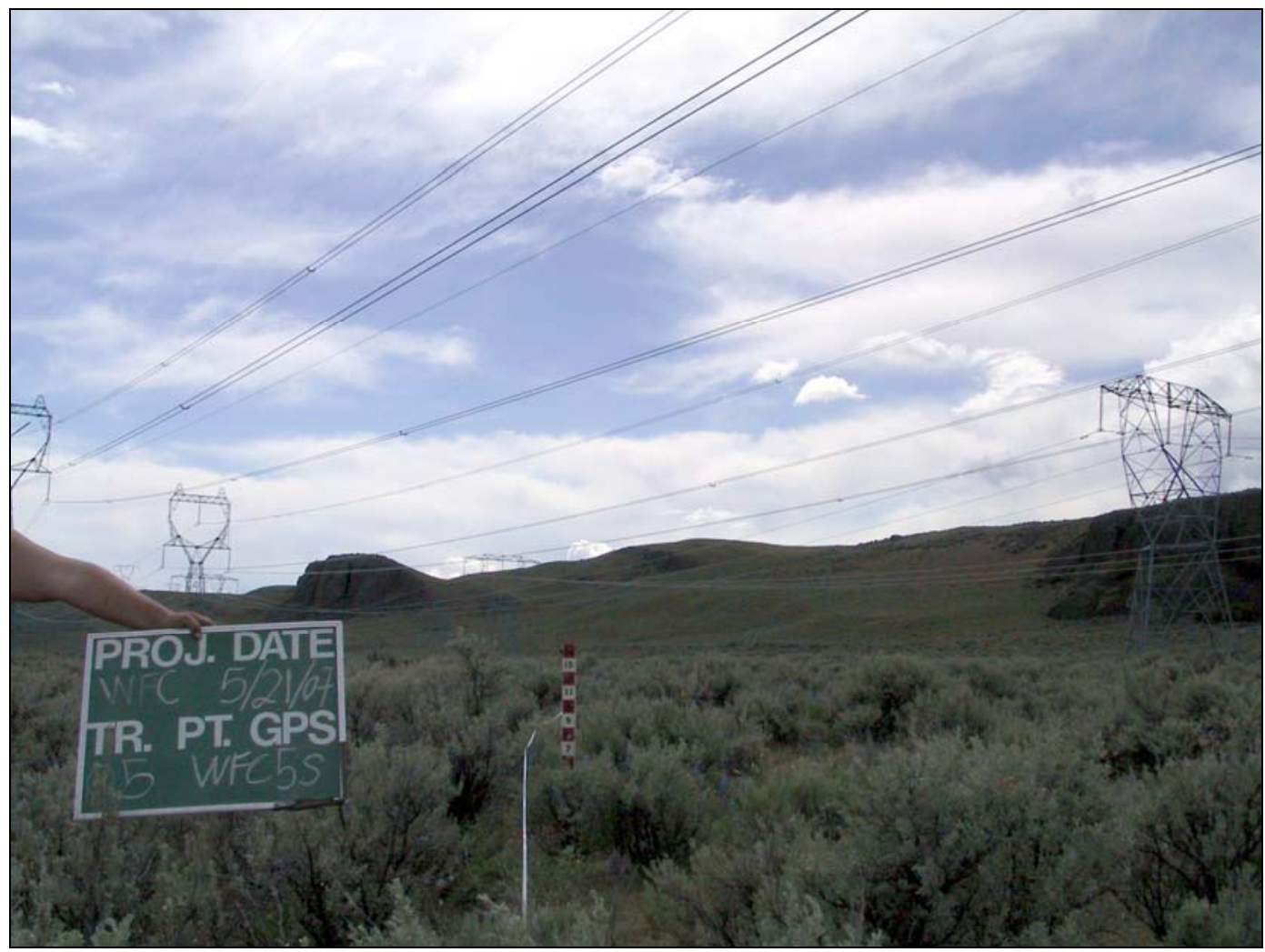

Figure 26. Transect 5 photograph 
West Foster Creek (Smith) 2007 Follow-up HEP Report

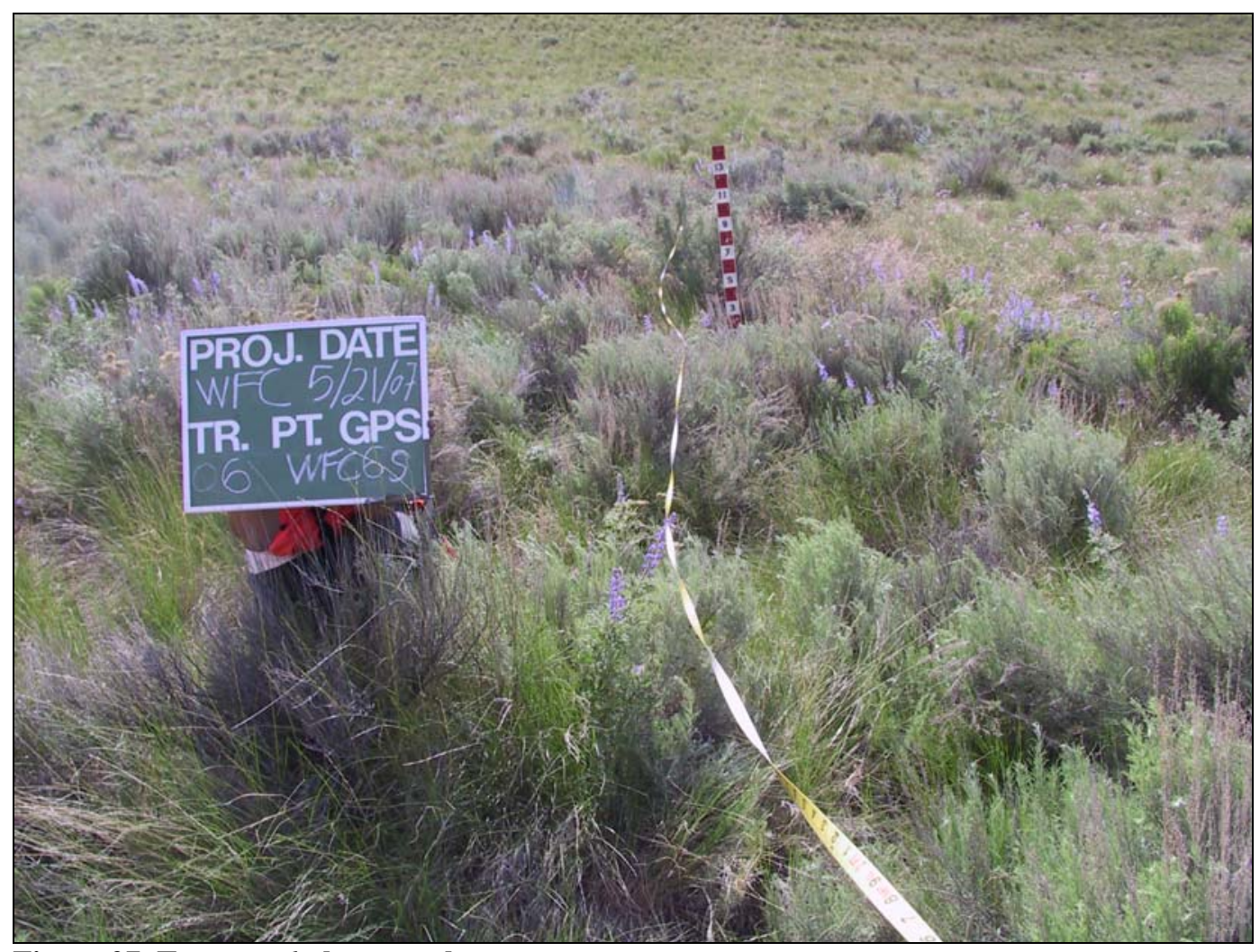

Figure 27. Transect 6 photograph

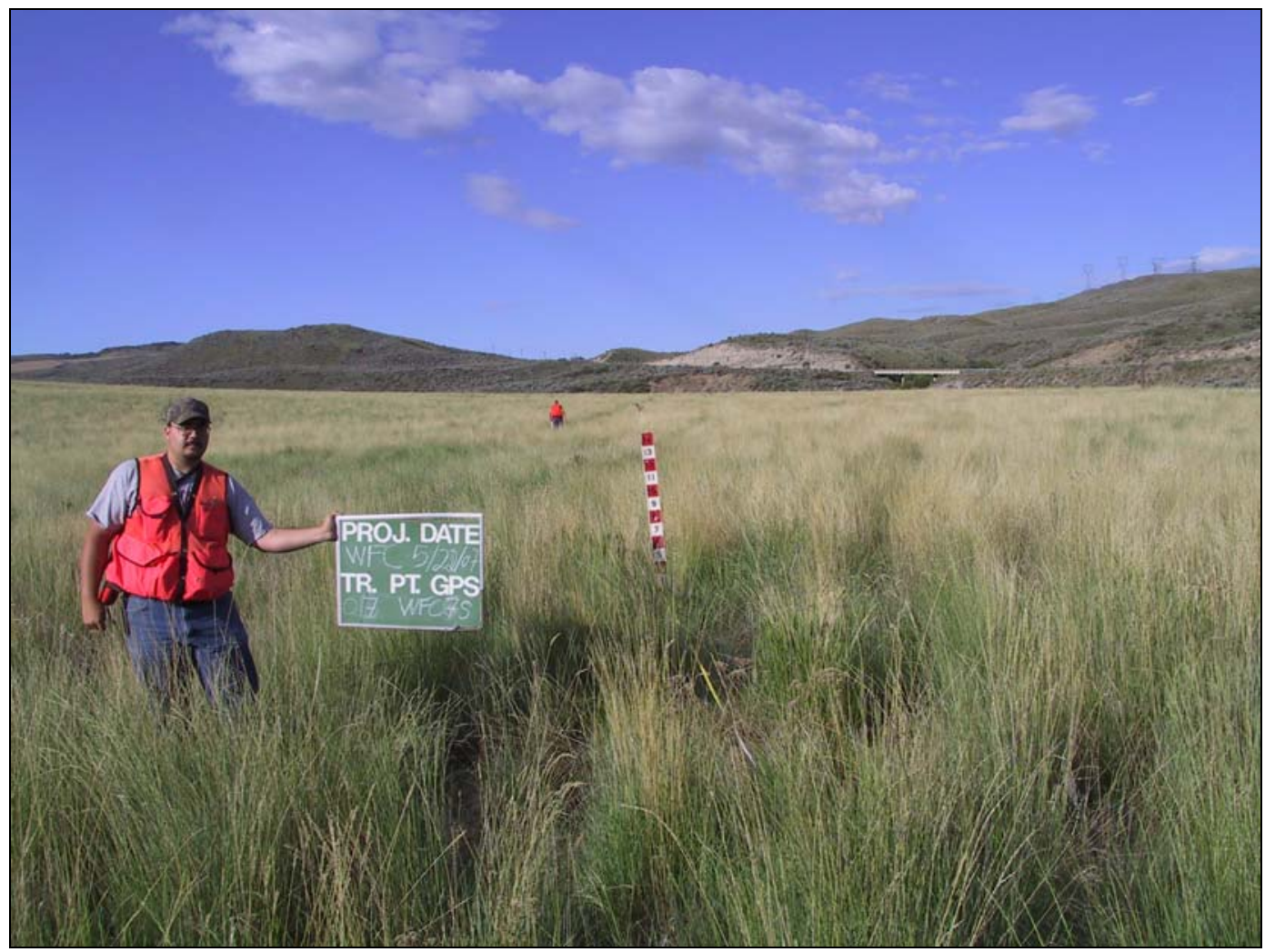

Figure 28. Transect 7 photograph 
West Foster Creek (Smith) 2007 Follow-up HEP Report

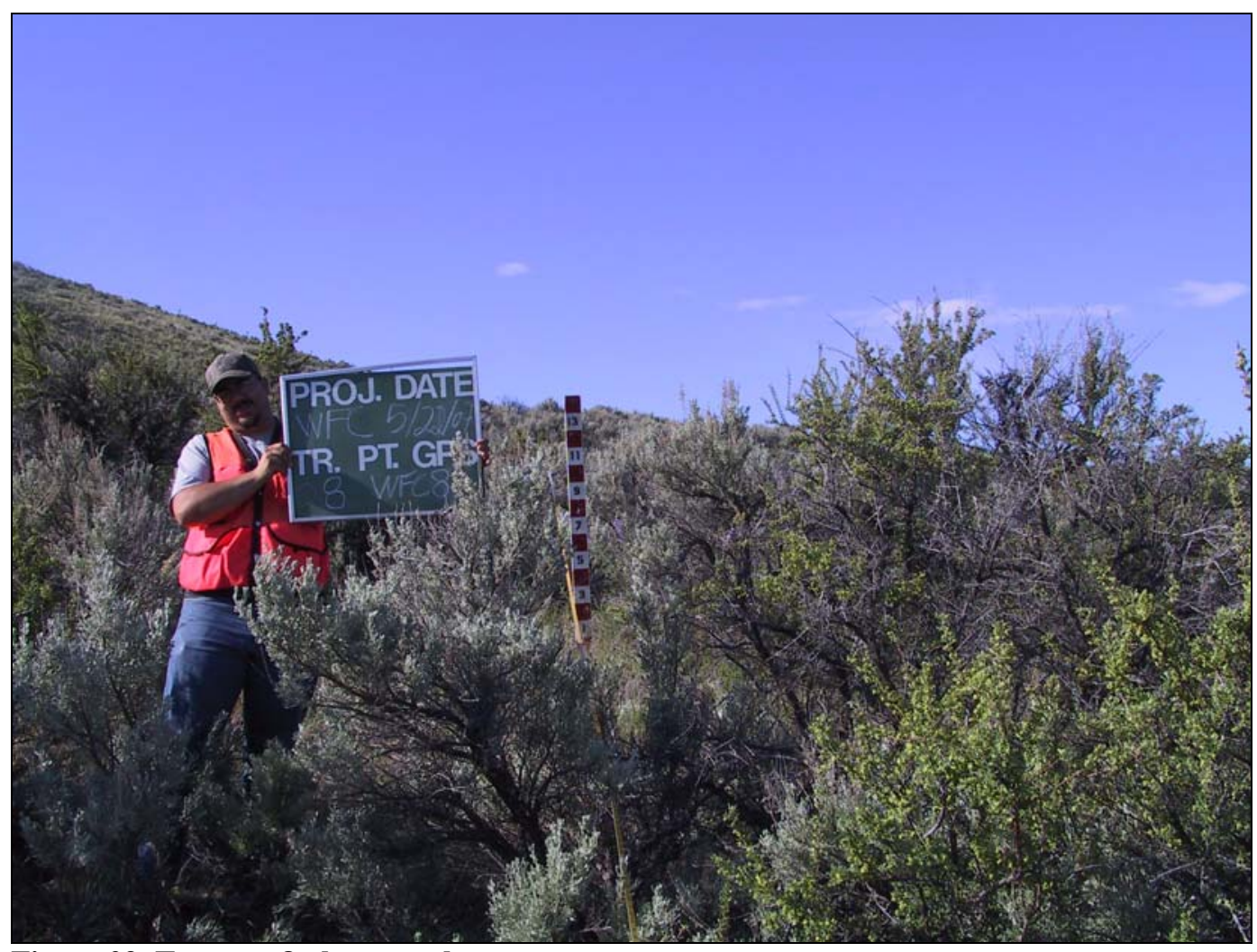

Figure 29. Transect 8 photograph

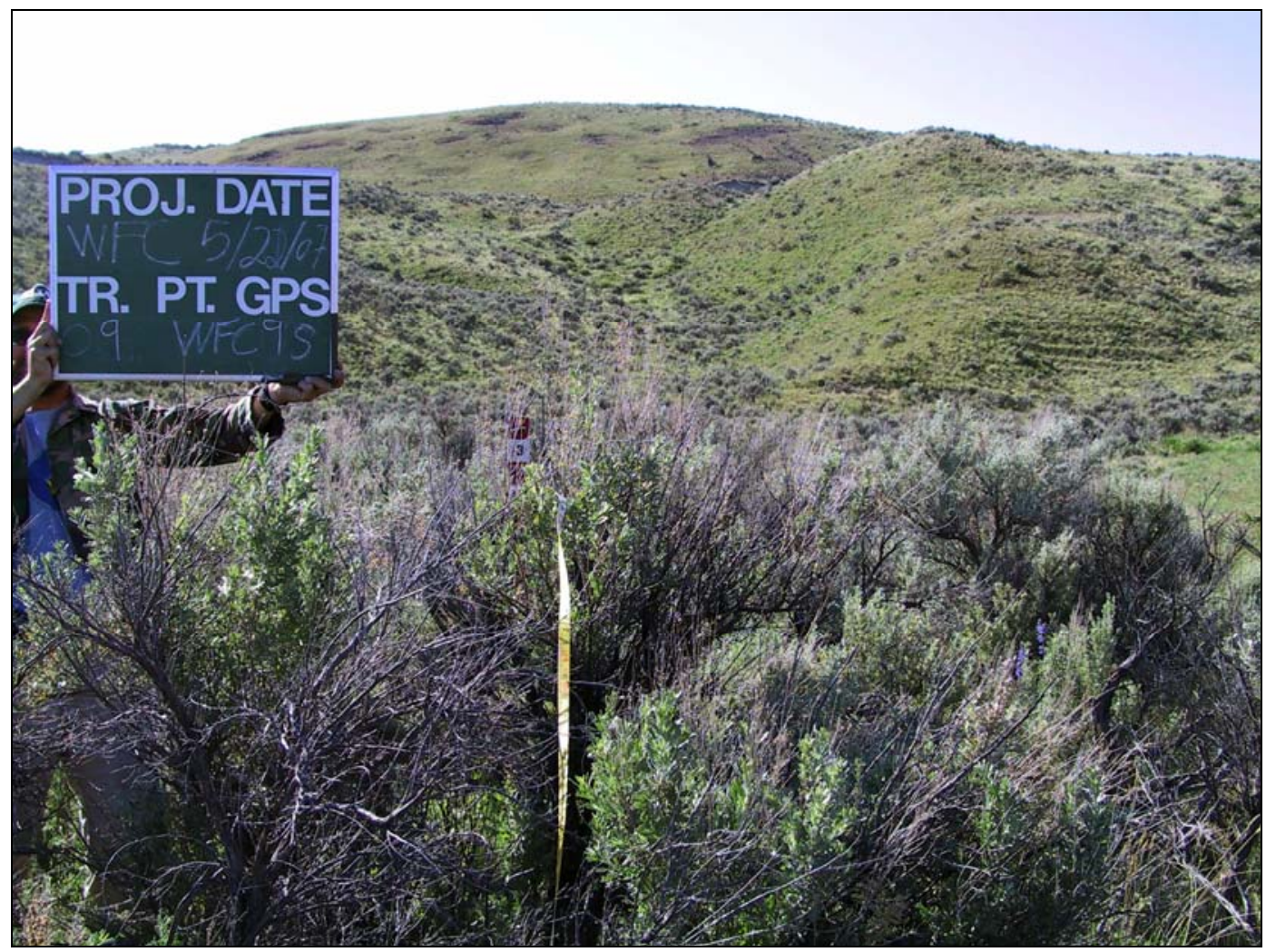

Figure 30. Transect 9 photograph 
West Foster Creek (Smith) 2007 Follow-up HEP Report

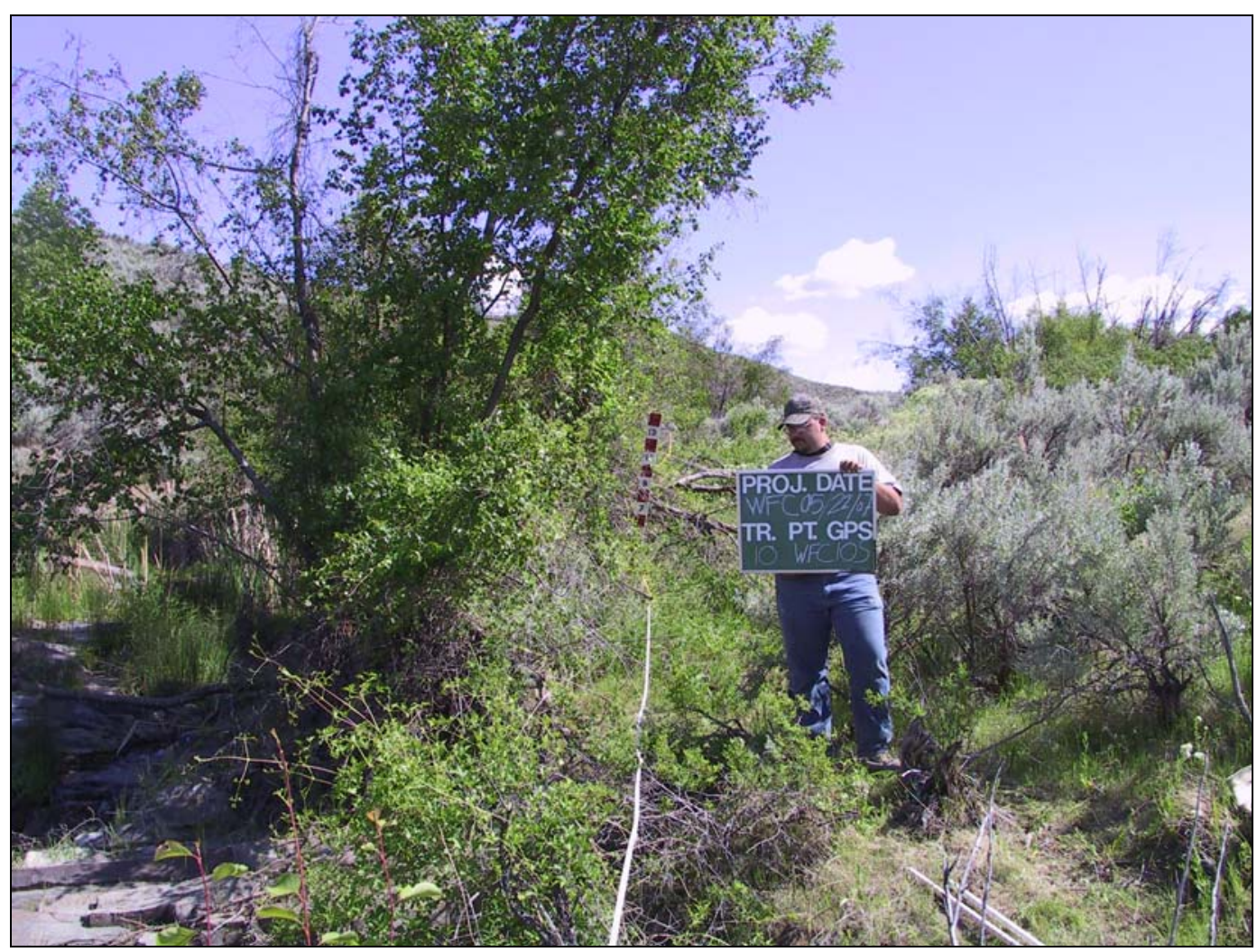

Figure 31. Transect 10 photograph

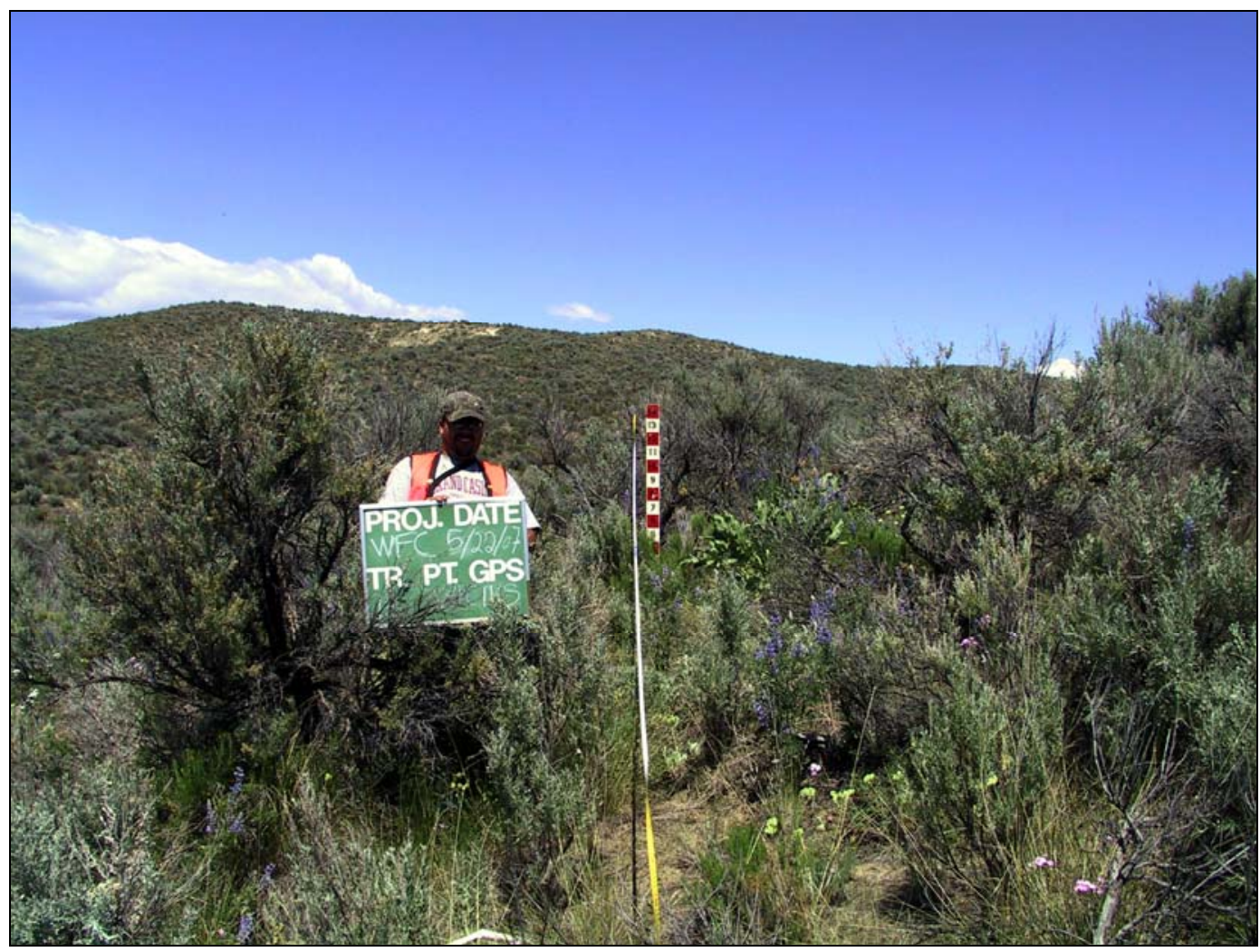

Figure 32. Transect 11 photograph 
West Foster Creek (Smith) 2007 Follow-up HEP Report

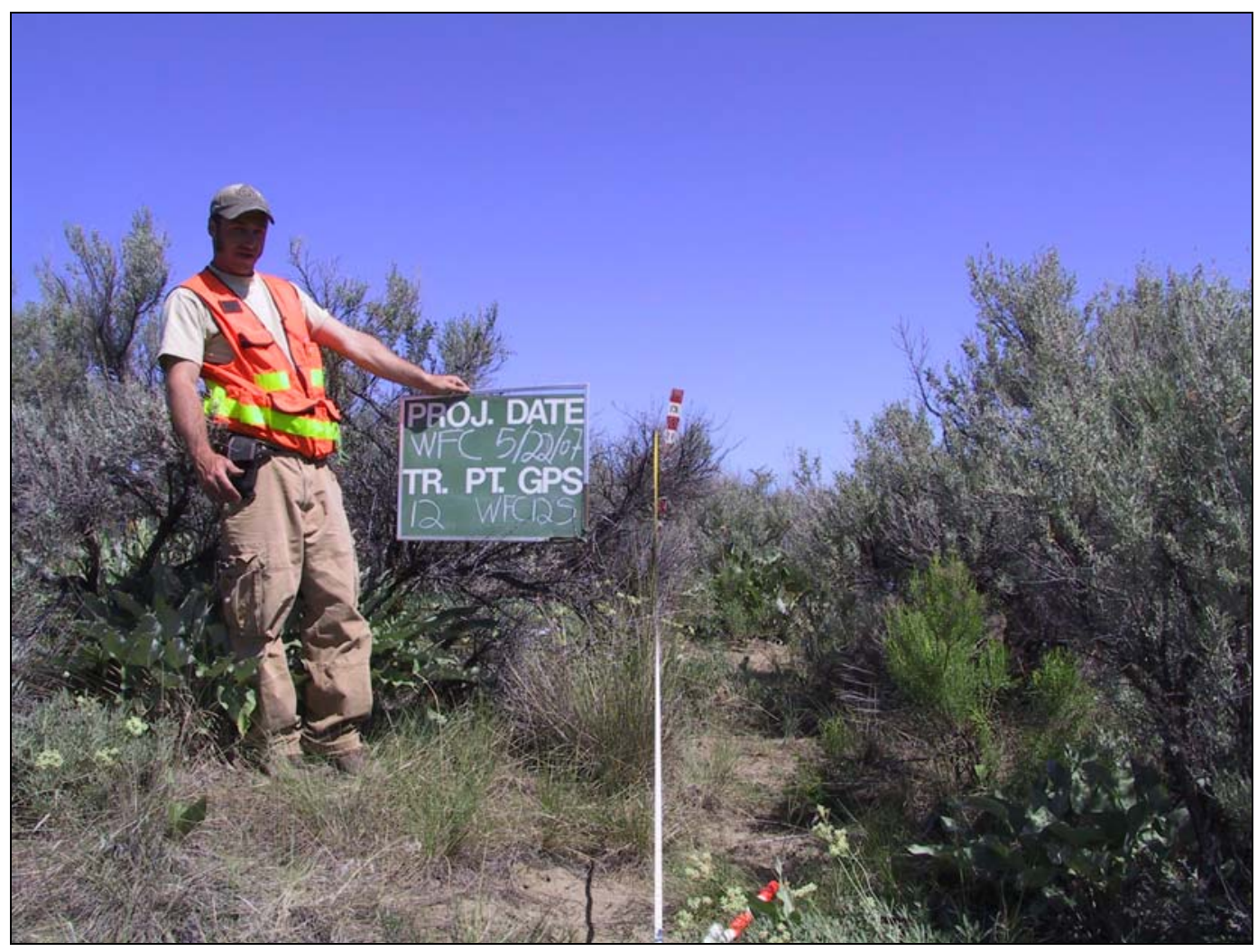

Figure 33. Transect 12 photograph

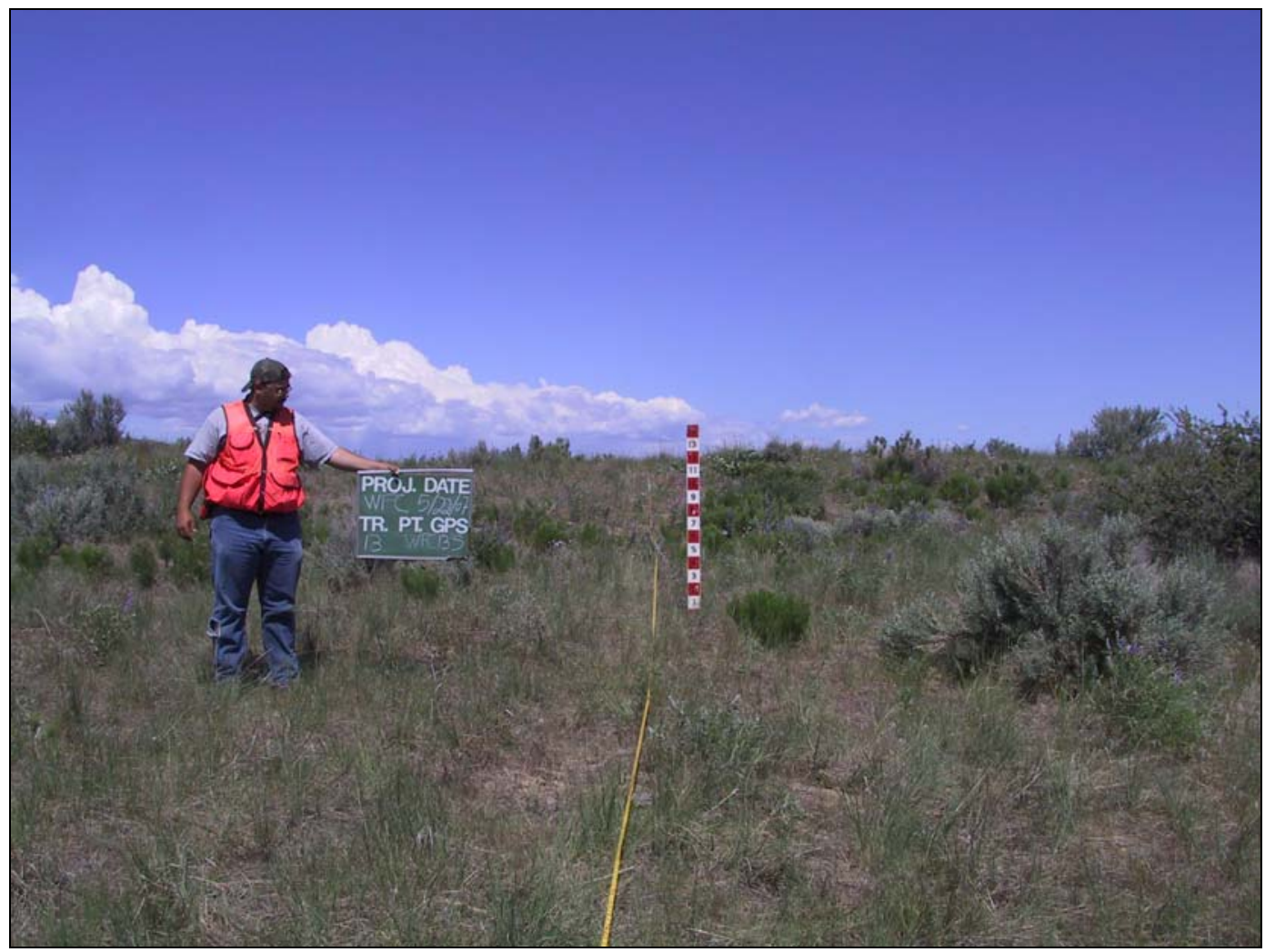

Figure 34. Transect 13 photograph 
West Foster Creek (Smith) 2007 Follow-up HEP Report

\section{THIS PAGE INTENTIALLY LEFT BLANK}

